Wojciech J. Piotrowski', Iwona Bestry ${ }^{2}$, Adam J. Białas ${ }^{3}$, Piotr W. Boros ${ }^{4}$, Piotr Grzanka ${ }^{5}$, Ewa Jassem ${ }^{6}$, Dariusz Jastrzębski ${ }^{7}$, Dariusz Klimczak ${ }^{8}$, Renata Langfort ${ }^{9}$, Katarzyna Lewandowska ${ }^{10}$, Sebastian Majewski ${ }^{1}$, Magdalena M. Martusewicz-Boros ${ }^{11}$, Karina Oniszh ${ }^{2}$, Elżbieta Puścińska ${ }^{12}$, Alicja Siemińska ${ }^{13}$, Małgorzata Sobiecka ${ }^{10}$, Małgorzata Szołkowska ${ }^{9}$, Elżbieta Wiatr ${ }^{11}$, Gracjan Wilczyński ${ }^{14}$, Dariusz Ziora ${ }^{6}$, Jan Kuś ${ }^{10}$

'Department of Pneumology and Allergy, Medical University of Lodz, Poland

${ }^{2}$ Department of Radiology, National Tuberculosis and Lung Diseases Research Institute in Warsaw, Poland

${ }^{3}$ Department of Pathobiology of Respiratory Diseases, Medical University of Lodz, Poland

${ }^{4}$ Lung Pathophysiology Department, National Tuberculosis and Lung Diseases Research Institute in Warsaw, Poland

${ }^{5}$ Department of Radiology, Voivodeship Hospital in Opole, Poland

${ }^{6}$ Department of Allergology and Pneumonology, Medical University of Gdansk, Poland

${ }^{7}$ Department of Lung Diseases and Tuberculosis, Medical University of Silesia, Zabrze, Poland

${ }^{8}$ Patient, Polish Society for IPF Patients' Support, Poland

${ }^{9}$ Department of Pathology, National Tuberculosis and Lung Diseases Research Institute in Warsaw, Poland

${ }^{10}$ First Lung Diseases Department, National Tuberculosis and Lung Diseases Research Institute in Warsaw, Poland

${ }^{11}$ Third Lung Diseases and Oncology Department, National Tuberculosis and Lung Diseases Research Institute in Warsaw, Poland

${ }^{12}$ Second Department of Respiratory Medicine, National Tuberculosis and Lung Diseases Research Institute in Warsaw, Poland

${ }^{13}$ Allergology Department, Medical University of Gdansk, Poland

${ }^{14}$ Patient, not affiliated

\title{
Guidelines of the Polish Respiratory Society for diagnosis and treatment of idiopathic pulmonary fibrosis
}

\section{Reviewers}

1. Anna Dubaniewicz, Department of Pneumonology, Medical University of Gdansk, Poland; Head of ILD Section of Polish Respiratory Society

2. Michael Kreuter, Center for Interstitial and Rare Lung Diseases, Pneumology, Thoraxclinik, Heidelberg University Hospital, Germany; German Center for Lung Research Gießen, Germany; European Respiratory Society Chair of Idiopathic Interstitial Pneumonias Group

3. Helmuth Prosch, Department of Biomedical Imaging and Image-Guided Therapy, Medical University of Vienna, Austria

4. Martina Vašáková, Department of Respiratory Medicine, First Faculty of Medicine of Charles University, Thomayer Hospital, Prague, Czech Republic

5. Paweł Śliwiński, Second Department of Respiratory Medicine, National Tuberculosis and Lung Diseases Research Institute in Warsaw, Poland; President of Polish Respiratory Society

\section{CONTENT}

Abstract 42

An aggregate list of recommendation (Table 1).

INTRODUCTION

Definition, epidemiology, aetiopathogenesis 
The radiographic pattern of usual interstitial pneumonia (UIP) 47

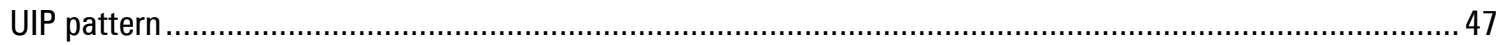

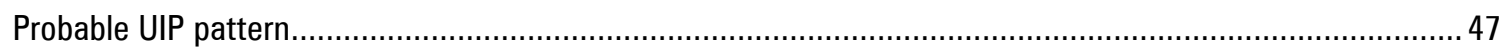

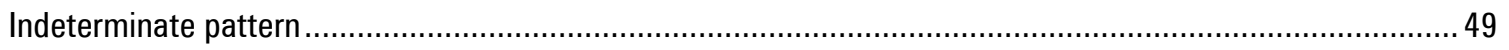

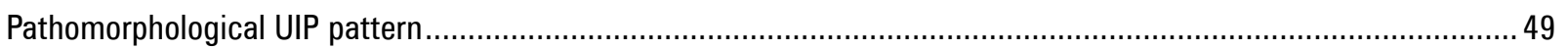

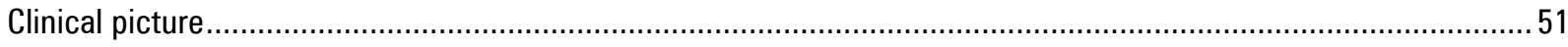

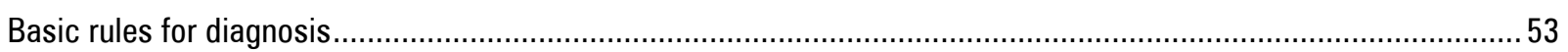

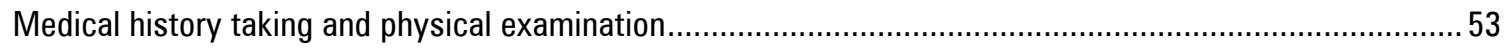

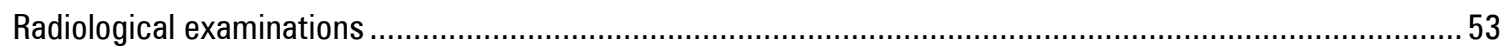

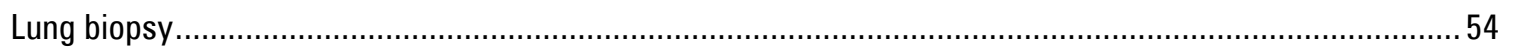

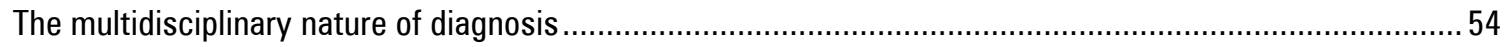

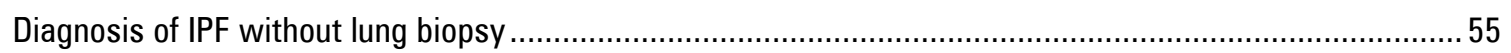

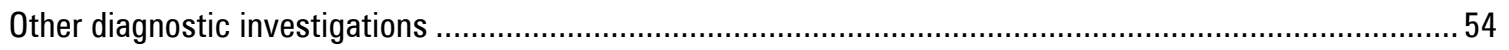

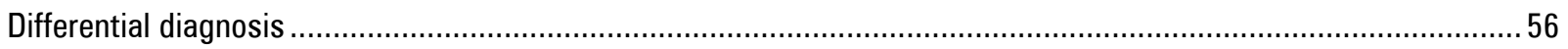

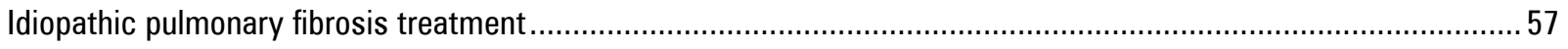

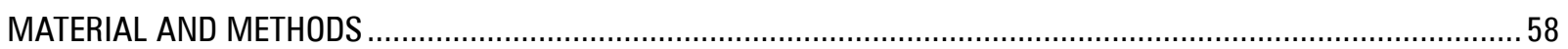

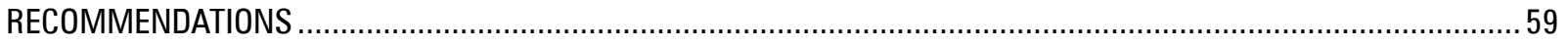

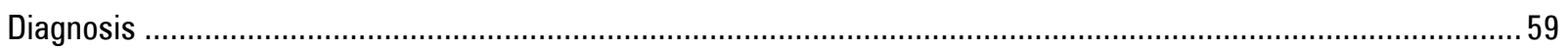

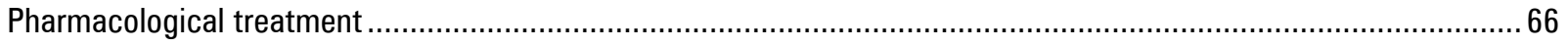

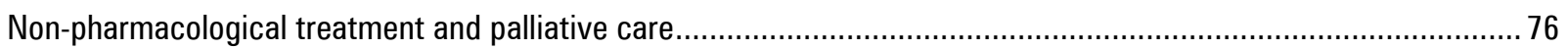

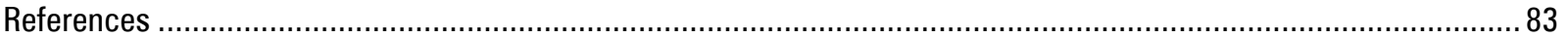

\section{Abstract}

Introduction: This document presents the guidelines of the Polish Respiratory Society (PTChP, Polskie Towarzystwo Chorób Płuc) for diagnosis and treatment of idiopathic pulmonary fibrosis (IPF), developed by a group of Polish experts.

Material and methods: The recommendations were developed in the form of answers to previously formulated questions concerning everyday diagnostic and therapeutic challenges. They were developed based on a current literature review using the Grading of Recommendations Assessment, Development and Evaluation (GRADE) methodology.

Results: We formulated 28 recommendations for diagnosis (8), pharmacological treatment (12) as well as non-pharmacological and palliative therapy (8). The experts suggest that surgical lung biopsy (SLB) not be performed in patients with the probable usual interstitial pneumonia (UIP) pattern, with an appropriate clinical context and unanimous opinion of a multidisciplinary team. The experts recommend using antifibrotic agents in IPF patients and suggest their use irrespective of the degree of functional impairment. As regards non-pharmacological and palliative treatment, strong recommendations were formulated regarding pulmonary rehabilitation, oxygen therapy (in patients with chronic respiratory failure), preventive vaccinations as well as referring IPF patients to transplant centres. Table 1 presents an aggregate list of recommendations.

Conclusions: The Polish Respiratory Society Working Group developed guidelines for IPF diagnosis and treatment.

Key words: diagnosis, idiopathic pulmonary fibrosis, treatment, differentiation, usual interstitial pneumonia

Adv Respir Med. 2020; 88: 42-95 


\section{Table 1. An aggregate list of recommendations}

\begin{tabular}{ccll}
\hline Module & No & Question & Recommendation \\
\hline Diagnosis & 1 & $\begin{array}{l}\text { Can IPF be diagnosed without lung biopsy in a pa- } \\
\text { tient with "probable UIP" HRCT pattern (without } \\
\text { honeycombing, but with peripheral traction bron- } \\
\text { chiectasis or bronchiolectasis)? }\end{array}$ & $\begin{array}{l}\text { We suggest that a "probable UIP" HRCT pattern, if it contains no } \\
\text { changes suggestive of an alternative diagnosis, in an appropriate } \\
\text { clinical context (e.g. male sex, smoking history, age }>60) \text { and } \\
\text { after excluding other causes of such changes, should be a suffi- } \\
\text { cient basis for a multidisciplinary team to diagnose IPF with no } \\
\text { need for diagnostic lung biopsy }\end{array}$ \\
& &
\end{tabular}

2 Can a UIP pattern confirmed by pathomorphological examination of material collected through cryobiopsy be considered equivalent to a diagnosis made based on surgical biopsy?

3 What respiratory function examinations should be performed to assess the risk of lung biopsy complications?

4 Is it necessary to perform serological tests for autoimmune diseases in every patient with suspected IPF without clinical signs of connective tissue disease?

5 Is it necessary to determine serum concentrations of specific immunoglobulins (precipitins) in order to diagnose hypersensitivity pneumonitis (allergic alveolitis) in every patient with suspected IPF?

6 Should BAL be performed in every patient with suspected IPF?

7 What is the role of a multidisciplinary team in diagnosing IPF and who should be part of such a team?

We suggest that material collected for pathomorphological examination through cryobiopsy, sufficient to diagnose UIP, should be considered equivalent to material from surgical lung biopsy

We recommend that qualification for elective lung biopsy include arterial blood gas analysis, spirometry and assessment of transfer factor for carbon monoxide

We recommend that every patient with suspected IPF undergo serological tests for autoimmune diseases

We recommend that a test for the presence of specific immunoglobulins in the serum (precipitins) NOT be performed in all patients with suspected IPF

We suggest that BAL NOT be performed in every patient with suspected IPF.

The examination is not necessary in patients with a radiographic UIP pattern if the clinical context raises no doubt, but it can be helpful in differential diagnosis of ambiguous clinical or radiographic picture

We recommend establishing the diagnosis in all patients diagnosed with signs of fibrosis due to ILD through a multidisciplinary discussion

We recommend that a multidisciplinary team include at least a clinician (pulmonologist) and radiologist as well as pathologist (if lung biopsy has been performed). All team members should be experienced in the diagnosis of ILD

8 How to define disease progression?

We suggest that FVC decline rate be recognized as the basic measure of IPF progression. A loss $\geq 10 \%$ of predicted value within 12 months or less is considered clinically relevant

$\begin{array}{ccl}\begin{array}{c}\text { Pharma- } \\ \text { cological } \\ \text { treatment }\end{array} & 9 & \begin{array}{l}\text { Should IPF patients be treated with pirfenidone? } \\ \text { Should IPF patients be treated with nintedanib? }\end{array} \\ & 11 & \begin{array}{l}\text { Can IPF patients be treated simultaneously with } \\ \text { pirfenidone and nintedanib? }\end{array} \\ 12 & \begin{array}{l}\text { Should patients diagnosed with IPF based on the } \\ \text { clinical context and the "probable UIP" pattern in } \\ \text { lung HRCT be treated with antifibrotic agents? }\end{array} \\ 13 & \begin{array}{l}\text { Should IPF patients with mildly decreased or } \\ \text { normal pulmonary function parameters be treated } \\ \text { with antifibrotic agents? }\end{array}\end{array}$

We recommend the use of pirfenidone in IPF patients

We recommend the use of nintedanib in IPF patients

Currently, we DO NOT recommend simultaneous use of pirfenidone and nintedanib in IPF patients

We suggest that patients with IPF diagnosis established by a multidisciplinary team based on the clinical context and the "probable UIP" pattern in lung HRCT be started on antifibrotic agents

We suggest that antifibrotic treatment be proposed to IPF patients with mildly decreased or normal pulmonary function parameters 


\section{Table 1 cont. An aggregate list of recommendations}

\begin{tabular}{|c|c|c|c|}
\hline Module & No & Question & Recommendation \\
\hline \multirow[t]{7}{*}{$\begin{array}{l}\text { Pharma- } \\
\text { cological } \\
\text { treatment }\end{array}$} & 14 & $\begin{array}{l}\text { Should IPF patients with severe lung function im- } \\
\text { pairment (FVC }<50 \% \text { of predicted, } \mathrm{T}_{\mathrm{L}, \mathrm{C}}<30 \% \text { of } \\
\text { predicted) be treated with antifibrotic agents? }\end{array}$ & $\begin{array}{l}\text { We suggest that antifibrotic treatment following IPF diagnosis be } \\
\text { proposed to all patients without contraindications for this treat- } \\
\text { ment, irrespective of the degree of lung function impairment }\end{array}$ \\
\hline & 15 & $\begin{array}{l}\text { Is disease progression an indication for discontinu- } \\
\text { ation of antifibrotic treatment? }\end{array}$ & $\begin{array}{l}\text { We suggest that disease progression NOT be an indication for } \\
\text { discontinuation of antifibrotic treatment }\end{array}$ \\
\hline & 16 & $\begin{array}{l}\text { In what situations should one consider switching } \\
\text { from one antifibrotic agent to the other? }\end{array}$ & $\begin{array}{l}\text { We suggest switching from one antifibrotic agent to the other in } \\
\text { case of significant lack of tolerance or adverse effects }\end{array}$ \\
\hline & 17 & $\begin{array}{l}\text { Should all IPF patients be treated with anti-acid } \\
\text { agents? }\end{array}$ & $\begin{array}{l}\text { We suggest that anti-acid agents in IPF patients NOT be used in } \\
\text { absence of other indications for such treatment }\end{array}$ \\
\hline & 18 & Should N-acetylcysteine be used in IPF treatment? & $\begin{array}{l}\text { We recommend that N-acetylcysteine NOT be used in the treat- } \\
\text { ment of IPF patients, either as monotherapy or in combination } \\
\text { with other agents. }\end{array}$ \\
\hline & 19 & $\begin{array}{l}\text { Should IPF patients receive immunosuppressive } \\
\text { treatment? }\end{array}$ & $\begin{array}{l}\text { We recommend that NO type of immunosuppressive treatment } \\
\text { be used in IPF patients }\end{array}$ \\
\hline & 20 & $\begin{array}{l}\text { Should agents dedicated to treating pulmonary } \\
\text { hypertension be used in IPF patients? }\end{array}$ & $\begin{array}{l}\text { We suggest that agents dedicated to treating pulmonary hyper- } \\
\text { tension NOT be used in IPF patients }\end{array}$ \\
\hline \multirow{9}{*}{$\begin{array}{l}\text { Non-pharma- } \\
\text { cological } \\
\text { and palliative } \\
\text { treatment }\end{array}$} & 21 & $\begin{array}{l}\text { Should pulmonary rehabilitation be used in IPF } \\
\text { patients? }\end{array}$ & $\begin{array}{l}\text { We recommend the use of pulmonary rehabilitation in IPF pa- } \\
\text { tients }\end{array}$ \\
\hline & 22 & $\begin{array}{l}\text { Should LTOT be used in patients with respiratory } \\
\text { failure in the course of IPF? }\end{array}$ & $\begin{array}{l}\text { We recommend using LTOT in patients with chronic respiratory } \\
\text { failure in the course of IPF }\end{array}$ \\
\hline & 23 & $\begin{array}{l}\text { Should oxygen be used during exercise in IPF } \\
\text { patients? }\end{array}$ & $\begin{array}{l}\text { We suggest using oxygen during exercise in IPF patients with } \\
\text { dyspnoea and exertional desaturation }\end{array}$ \\
\hline & 24 & $\begin{array}{l}\text { Should preventive vaccinations be used in IPF } \\
\text { patients? }\end{array}$ & $\begin{array}{l}\text { We recommend use of pneumococcal and flu vaccinations in IPF } \\
\text { patients }\end{array}$ \\
\hline & 25 & $\begin{array}{l}\text { Should patients with advanced IPF be referred to } \\
\text { palliative care centres? }\end{array}$ & $\begin{array}{l}\text { We suggest that patients with advanced IPF be referred to pallia- } \\
\text { tive care centres }\end{array}$ \\
\hline & 26 & Should morphine be used in palliative treatment? & $\begin{array}{l}\text { We suggest using oral morphine in patients with severe IPF in } \\
\text { palliative treatment of persisting dyspnoe }\end{array}$ \\
\hline & 27 & $\begin{array}{l}\text { Should invasive ventilation be used in IPF patients } \\
\text { with acute respiratory failure? }\end{array}$ & $\begin{array}{l}\text { We suggest that invasive ventilation NOT be used in IPF patients } \\
\text { with acute respiratory failure }\end{array}$ \\
\hline & 28 & $\begin{array}{l}\text { Should IPF patients be referred to lung transplant } \\
\text { centres and if so, when? }\end{array}$ & $\begin{array}{l}\text { We recommend referring to lung transplant centres all IPF pa- } \\
\text { tients without contraindications for the procedure }\end{array}$ \\
\hline & & & $\begin{array}{l}\text { We suggest referring IPF patients to lung transplant centres im- } \\
\text { mediately after the disease is diagnosed }\end{array}$ \\
\hline
\end{tabular}

BAL — bronchoalveoar lavage; FVC — forced vital capacity; HRCT — high-resolution computed tomography; IPF — idiopathic pulmonary fibrosis; ILD — interstitial lung disease; LTOT — long-therm oxygen therapy; $\mathrm{T}_{\mathrm{L}, \mathrm{C}_{0}}$ — transfer factor of the lung for carbon monoxide; UIP — usual interstitial pneumonia

\section{INTRODUCTION}

\section{Definition, epidemiology, aetiopathogenesis}

Idiopathic pulmonary fibrosis (IPF) is a chronic interstitial lung disease (ILD) limited to the lungs, associated with progressive fibrosis and consequentially with disturbances in diffusion of respiratory gases through the alveolar-capillary membrane, most commonly restrictive ventilation impairment, respiratory failure and premature death. The disease affects the elderly, more frequently males, and individuals with a history of tobacco smoking.

The aetiology is unknown and the diagnosis is conditional upon identifying the so-called radiographic or histopathological pattern of usual interstitial pneumonia (UIP) in a patient in whom other causes of ILD have been excluded, such as extrinsic factors damaging the respiratory system or comorbidities that could be associated with lung changes of a similar nature.

Idiopathic pulmonary fibrosis belongs to a group of diseases called idiopathic interstitial pneumonias (IIP) and is the most frequent condition in this group (accounting for $50-60 \%$ of IIP cases) [1]. It is one of the most common interstitial diseases, accounting for $20 \%$ of all diagnoses in patients diagnosed and treated in reference centres [2]. The disease is rare (affecting $<50$ patients per a population of 100,000 ). Its incidence, based on data from New Mexico (US), is estimated at 10.7 per 100, 000/year for men and 7.4 per 100, 000/year for women [3]. British data suggest an incidence of 4.6 per 100 , 
000/year in the general population [4]. Prevalence based on data from an American registry of medical services from 1996-2000 is estimated at 14-47 per 100, 000 [5]. In Poland, no systematic epidemiological studies of IPF have been performed. Szafrański [6] estimated the incidence of interstitial lung disease at 5.0 per 100, 000/year when coded as J84 and at 2.5 per 100, 000/year when coded as J84.1. He compiled this data based on an admission registry of one of non-academic lung disease centres which admitted 554 patients with interstitial diseases in 2000-2009. Of those patients, $55.7 \%$ were individuals with a diagnosis coded as J84. In a publication called the Polish IPF White Book (Polska Biała Księga IPF) [7], the calculations of the estimated number of IPF patients in Poland were based on mean values from different countries: for incidence it was 4.7 and for prevalence 17.1 per 100,000 . This way, the number of patients diagnosed with IPF was estimated at 6585 and the number of annual new cases at 1809 . However, one should remember that the accuracy of disease coding around the world is low, and imprecise diagnostic criteria can render an especially significant bias in coding. Another problem may be introduced by non-specific symptoms, which result in the time from onset to diagnosis of up to several years and misdiagnosis of many IPF patients [8]. Furthermore, the reliability of epidemiological data is undoubtedly affected by the fact that the first systematic criteria for IPF were published only in 2000 [9] and radically redefined in 2011 [10], while most of the cited epidemiological data come from before these publications. The authors of the epidemiological report from the United Kingdom point to an increase in incidence observed in recent years [4]. Szafrański also suggests a possible upward trend [6].

Age, the male sex and tobacco smoking are named as risk factors for IPF. Studies examine the effects of chronic, mostly viral infections (among others, Epstein-Barr virus, other Herpes viruses, hepatitis C), although their role in aetiopathogenesis remains controversial [11-15]. The relationship between IPF and gastroesophageal reflux (GER) is also unclear. The latter promotes microaspirations of gastric content into the respiratory system and can potentially be a factor directly injuring the alveolar epithelium. We still lack an answer to the question whether this phenomenon causes the disease process or rather is a consequence of pulmonary fibrosis, which is associated with changes in the anatomy and pressure distribution within the chest, promoting regurgitation of the gastrointestinal content [16, 17]. Not without significance is the impact of genetic factors [18]. Mutations within the telomerase complex genes and genes encoding surfactant proteins $\mathrm{C}$ and A2 as well as MUC5B gene polymorphism are known to increase the risk of pulmonary fibrosis $[19,20]$. Mutations promoting the development of the disease are more frequent in familial interstitial pneumonia (FIP) [21]. Findings of UIP features can be an element of the rare Hermansky-Pudlak syndrome, an autosomal recessive hereditary disease, in which lung changes are additionally accompanied by such features as oculocutaneous albinism and platelet function disorders caused by lack of delta granules [22].

In light of the current studies, IPF is a consequence of repeated microinjuries of the alveolar epithelium caused by factors such as tobacco smoke components, environmental pollutants, viruses, occupational factors or gastric content microaspirations. The development of fibrosis is conditional upon alveolar epithelial dysfunction (acquired or genetically determined), making the epithelium incapable of physiological regeneration [23]. Cell-level abnormalities are known as "accelerated ageing" or "cellular senescence". Features indicative of this process include, among others, shortened telomeres. In IPF patients, both with the sporadic and familial forms, shorter telomeres have been identified in peripheral blood lymphocytes and alveolar epithelial cells [24-26], and shorter telomere length in IPF patients is correlated with shorter life spans [25, 27]. Another important phenomenon observed in epithelial cells is intracellular accumulation of abnormal proteins (unfolded protein response), associated with impairment of the autophagy process. These phenomena lead to an endoplasmic reticulum [ER] stress response and in consequence to the activation of proapoptotic signals and shortening of the epithelial cells' lives [28]. Fibrosis requires an appropriate environment to develop, one which depends on cell-secreted cytokines. The main role is played here by growth factors i.e. transforming growth factor- $B$, TGF- $B$; fibroblastic growth factor, FGF; platelet-derived growth factor, PDGF; vascular endothelial growth factor, VEGF; connective tissue growth factor, CTGF; and cytokines e.g. interleukin (IL)-1, IL-4, IL-13. This results in the deposition of collagen and other components of extracellular matrix produced directly by stimulated fibroblasts (myofibroblasts). The accumulation of these substances in lungs is a result of epithelial-mesenchymal transition (EMT) during which epithelial cells undergo morphological 


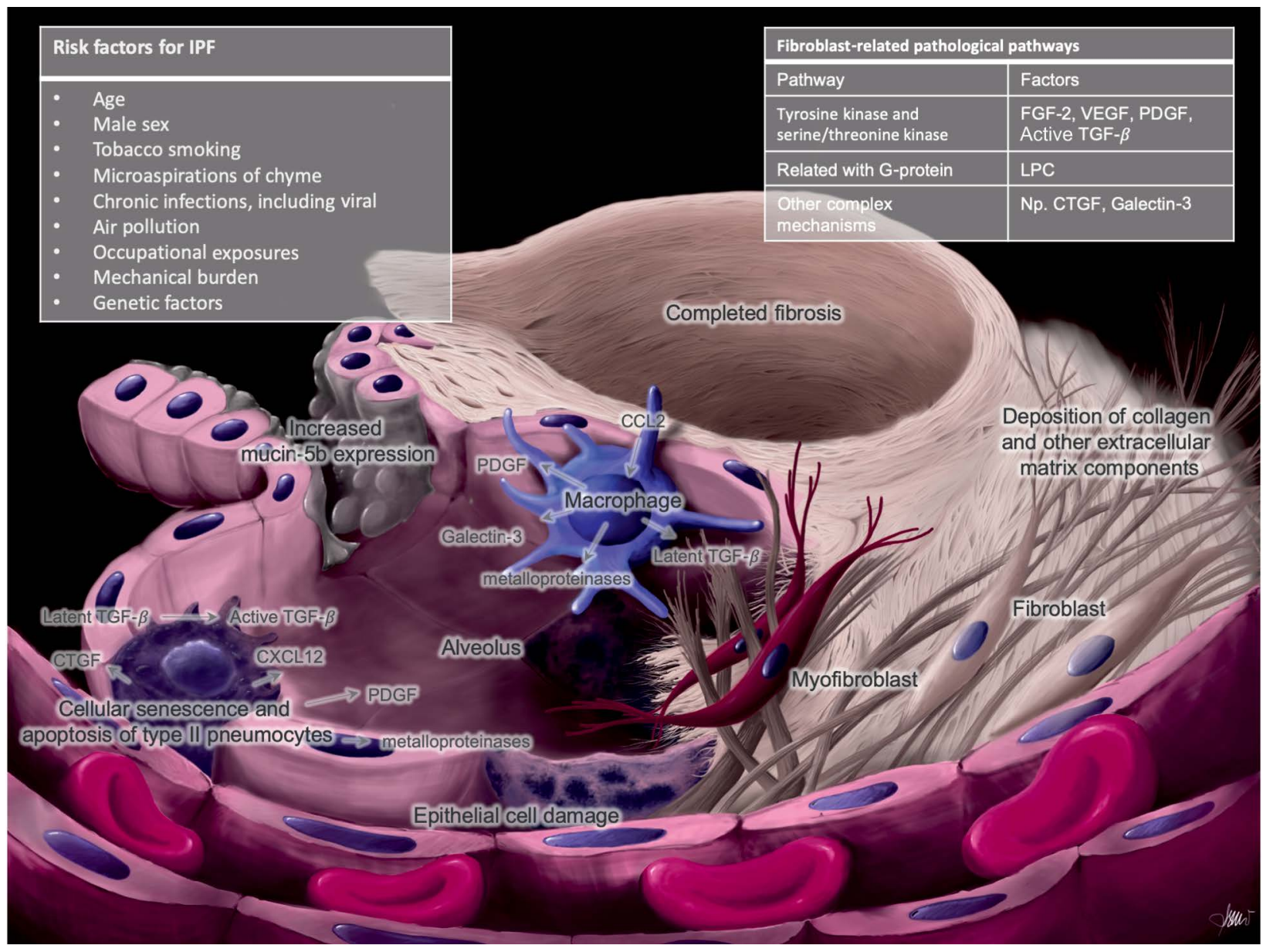

Figure 1. Selected mechanisms leading to pulmonary fibrosis in IPF (author: AJB)

CCL — chemokine (C-C motif) ligand; CXCL C-X-C motif chemokine ligand; CTGF — connective tissue growth factor; FGF — fibroblastic growth factor; LPC — lysophosphatidylcholine; PDGF — platelet-derived growth factor; TGF — transforming growth factor; VEGF — vascular endothelial growth factor

and functional transformation into mesenchymal cells. Another source of fibroblasts in lungs are fibrocytes, cells originating from bone marrow, which acquire mesenchymal features after they are released to the blood stream. When they reach the lungs, they transform into fibroblasts, and then myofibroblasts. Selected mechanisms leading to pulmonary fibrosis in IPF are summarised in Figure 1.

\section{The radiographic pattern of usual interstitial pneumonia (UIP)}

\section{UIP pattern}

The definition of the UIP pattern in high-resolution computed tomography (HRCT) includes reticulation with a predominantly subpleural (occasionally diffuse) and basal distribution. Changes of crucial importance for UIP diagnosis by CT are those of "honeycombing", with or without peripheral bronchiectasis or bronchiolectasis, without findings indicative for alternative diagnoses (Table 2). Honeycomb-type changes manifest as clusters of well-defined, thick-walled, usually subpleural, cyst-like air spaces with a diameter of several millimetres to several centimetres (usually 3-10 mm) [10, 29] (Figure 2).

Bronchiectasis or bronchiolectasis are peripherally located in the areas of reticulation (traction bronchiectasis). A characteristic feature for UIP is heterogeneity of lesions, meaning that areas with architectural distortion are found next to areas of relatively normal parenchymal structure. The UIP pattern is characteristic of IPF but can also be present in other disease entities. After known causes of UIP are excluded, it is possible to diagnose IPF without invasive approach [10, 29].

\section{The probable UIP pattern}

Lack of honeycombing in the HRCT image, with the presence of reticular changes predominantly in the subpleural and basal lung areas, 
Table 2. Criteria for identifying a UIP pattern based on high-resolution computed tomography (Adapted from [29], with modifications)

\begin{tabular}{|c|c|c|c|}
\hline UIP & Probable UIP & Indeterminate & $\begin{array}{l}\text { Findings suggestive of a different } \\
\text { diagnosis }\end{array}$ \\
\hline $\begin{array}{l}\text { Subpleural and basal predomi- } \\
\text { nant }\end{array}$ & $\begin{array}{l}\text { Subpleural and basal pre- } \\
\text { dominant }\end{array}$ & $\begin{array}{l}\text { Subpleural and basal pre- } \\
\text { dominant }\end{array}$ & $\begin{array}{l}\text { Cysts } \\
\text { Marked mosaic attenuation }\end{array}$ \\
\hline $\begin{array}{l}\text { The distribution is often hetero- } \\
\text { geneous, in many cases asym- } \\
\text { metrical } \\
\text { Honeycombing with or without } \\
\text { peripheral traction bronchiecta- } \\
\text { sis or bronchiolectasis } \\
\text { Reticular changes } \\
\text { Possible presence of mild ground } \\
\text { glass opacifications as well as } \\
\text { isolated calcified nodules (ossifi- } \\
\text { cations) in fibrotic areas }\end{array}$ & $\begin{array}{l}\text { The distribution is often } \\
\text { heterogeneous, in many } \\
\text { cases asymmetrical } \\
\text { No honeycombing } \\
\text { Reticular changes with pe- } \\
\text { ripheral traction bronchiec- } \\
\text { tasis or bronchiolectasis } \\
\text { Possible presence of mild } \\
\text { ground glass opacifications }\end{array}$ & $\begin{array}{l}\text { Subtle reticulation, possible } \\
\text { presence of mild ground } \\
\text { glass opacifications and } \\
\text { architectural distortion (the } \\
\text { "early UIP" pattern) } \\
\text { CT features of interstitial } \\
\text { fibrosis or the nature or } \\
\text { distribution of changes not } \\
\text { suggestive of any specific } \\
\text { aetiology (truly indetermi- } \\
\text { nate) }\end{array}$ & $\begin{array}{l}\text { Prevalence of ground glass } \\
\text { Profuse micronodules } \\
\text { Centrilobular nodules } \\
\text { Other nodules } \\
\text { Consolidation } \\
\text { Peribronchovascular, perilymphatic distribution } \\
\text { Changes in the upper or mid-lung fields } \\
\text { Pleural plaques } \\
\text { Dilated oesophagus } \\
\text { Distal clavicular erosions } \\
\text { Extensive lymph node enlargement } \\
\text { Pleural effusion, pleural thickening }\end{array}$ \\
\hline
\end{tabular}

UIP — usual interstitial pneumonia; CT — computed tomography
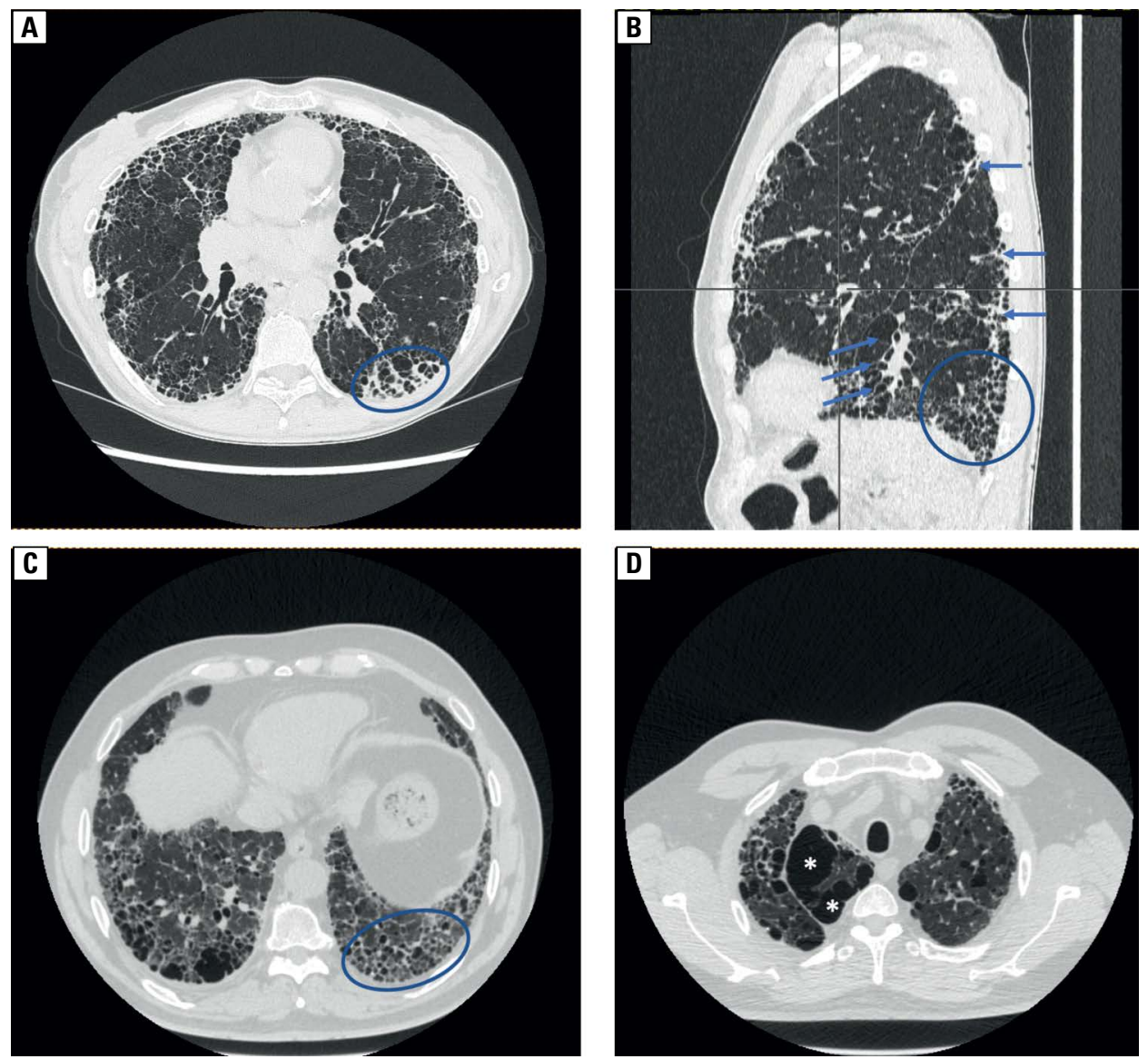

Figure 2. High-resolution computed tomography images depicting: A and B — usual interstitial pneumonia; C and D — usual interstitial pneumonia concomitant to emphysema (from Radiology Department, N. Barlicki University Teaching Hospital $N^{0} 1$ in Lodz). Honeycoming located subpleurally at lung bases (blue ovals), traction bronchiectasis (blue arrows), concomitant emphysema (white asterisks)

with peripheral traction bronchiectasis or bronchiolectasis warrants the diagnosis of probable
UIP. Differentiation of bronchiectasis from honeycombing can be difficult. Traction bronchiectasis 

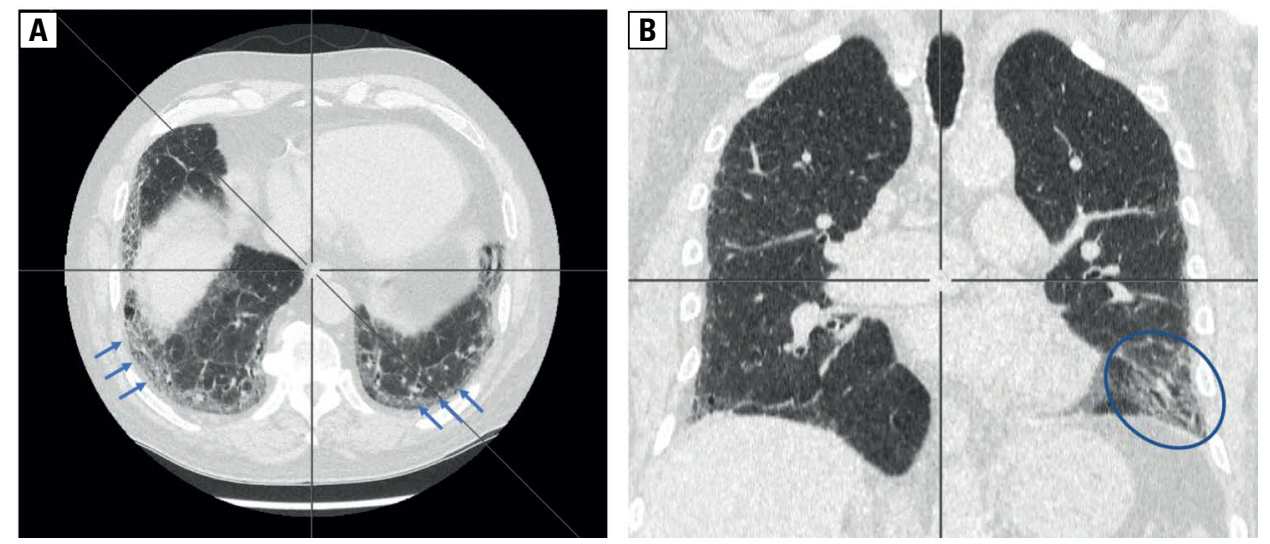

Figure 3. High-resolution computed tomography images illustrating the probable UIP pattern (from the Radiology Department, N. Barlicki University Teaching Hospital N 1 in Lodz). A - axial view; B - coronal view. Subpleural reticulation located at the lung bases (blue arrows), traction peripheral bronchiectases (blue oval)

is irregular, deformed widening of bronchi and bronchioles caused by fibrosis of the surrounding lung parenchyma. Unlike bronchiectasis of different origin, it is located in the area of reticular changes and associated with signs of lobular destruction and architectural distortion of the lung parenchyma. A conglomerate of peripheral traction bronchiolectasis located in the basal lung parts can resemble a honeycombing. Features differentiating traction bronchiectasis from honeycombing include: lack of bronchiectasis or bronchiolectasis directly below the pleura (honeycomb cysts are usually located subpleurally) and distribution of cysts. In bronchiolectasis the cysts are separated from each other whereas in a honeycombing area they are close together and share walls [30, 31]. An example HRCT image illustrating probable UIP is presented in Figure 3.

\section{Indeterminate pattern}

An indeterminate pattern is one in which no honeycombing or traction bronchiectasis or bronchiolectasis is seen but at the same time no features are observed that would allow a specific diagnosis. This category includes patients with slight, limited reticular changes, often with concomitant ground glass opacifications or architectural distortions distributed in subpleural and basal regions of the lung (the "early UIP" pattern). An example of such an HRCT image is presented in Figure 4. If the nature of lung changes distribution does not suggest any specific aetiology, we call it a truly indeterminate pattern. Such patients should undergo supplementary HRCT examinations in the prone position in order to discreetly differentiate early fibrosis from changes caused by the gravitational effect.
An indeterminate pattern does not preclude IPF diagnosis but requires pathomorphological examination to confirm the UIP pattern.

\section{Pathomorphological UIP pattern}

Morphological changes appearing in the course of IPF are identified in microscopic examination, similarly to radiographic examination, as UIP. The international ATS/ERS/JRS/ALAT recommendations (2018) [29] for diagnosis of IPF as well as recommendations contained in the Fleischner Society White Paper [31] point to benefits of making IPF diagnosis based on SLB, which remains the gold standard of microscopic diagnosis of IPF/UIP, in spite of growing experience with other material collection techniques, such as cryobiopsy.

Microscopic changes characteristic of UIP:

- intensive collagenous fibrosis, leading to remodelling of the lung parenchyma, with complete honeycomb-type destruction;

- disseminated fibroblastic foci, usually located at the periphery of remodelling areas;

- areas of fibrosis separated by fragments of less affected lung parenchyma (the characteristic mosaicism reflecting different times of change formation);

- changes located below the pleura, along the interlobular septa, at the periphery of the lobules;

- lack of morphological changes indicative of alternative diagnosis (e.g. granulomas, organising pneumonia, diffuse alveolar damage) or fibrosis located in other areas than those characteristic of UIP (e.g. around the bronchioles). A microscopic image with signs of usual interstitial pneumonia is presented in Figure 5. 

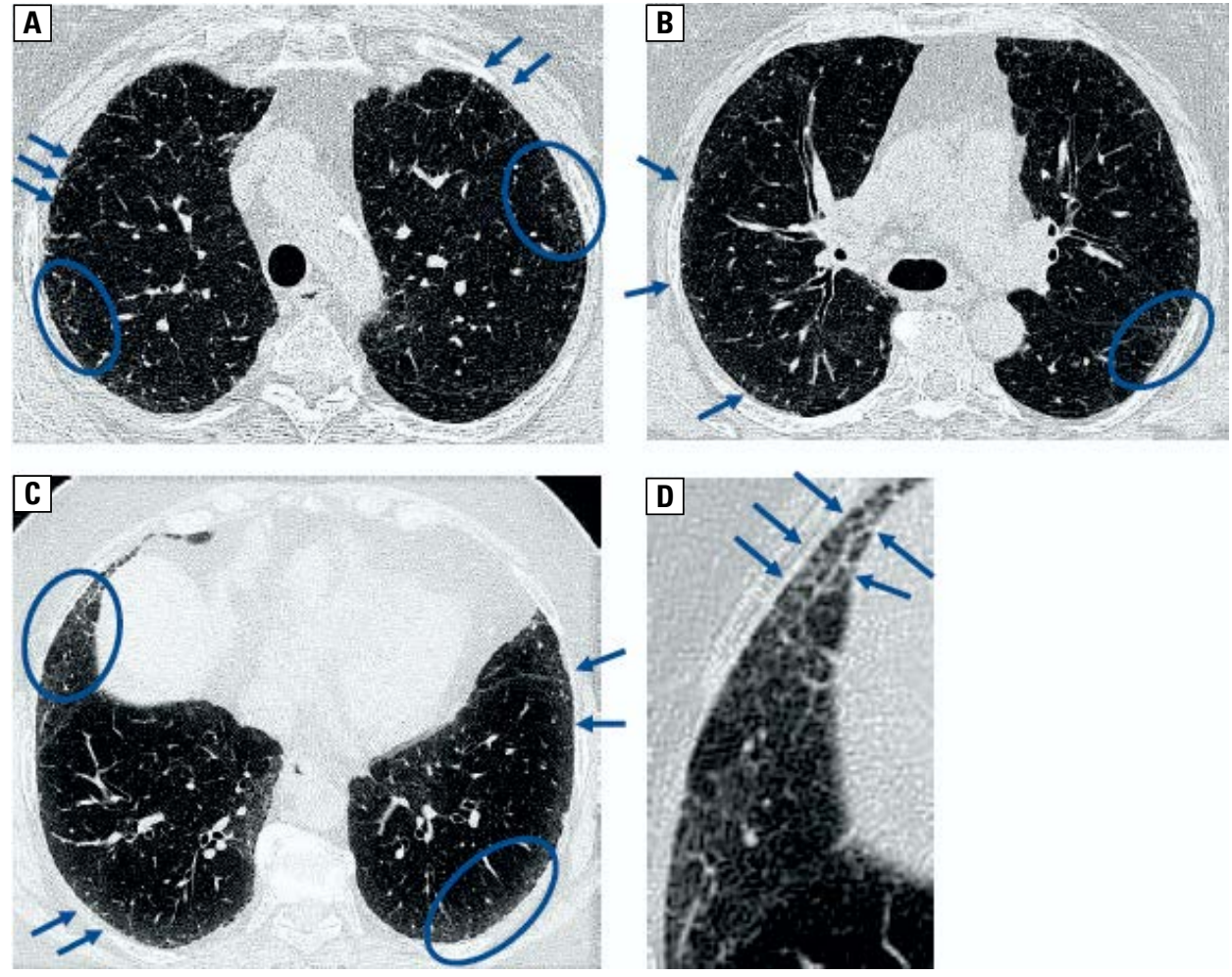

Figure 4. HRCT images illustrating an indeterminate pattern. The radiographic image corresponds to the early UIP pattern (from the Division of Imaging Diagnostics, Voivodeship Hospital in Opole). Axial views: A — at the aortic arch level; B — of the main bronchi; C — supradiaphragmatic; D - a magnified fragment of the middle lobe. Ground glass areas (blue ovals), mild reticular thickening of septal lines (arrows) which are predominant in the subpleural and supradiaphragmatic (basal) areas. Changes are also visible in the middle lobe, near the anterolateral wall, which indicates they are not associated with hydrostatic effect. Pathomorphological examination confirmed UIP
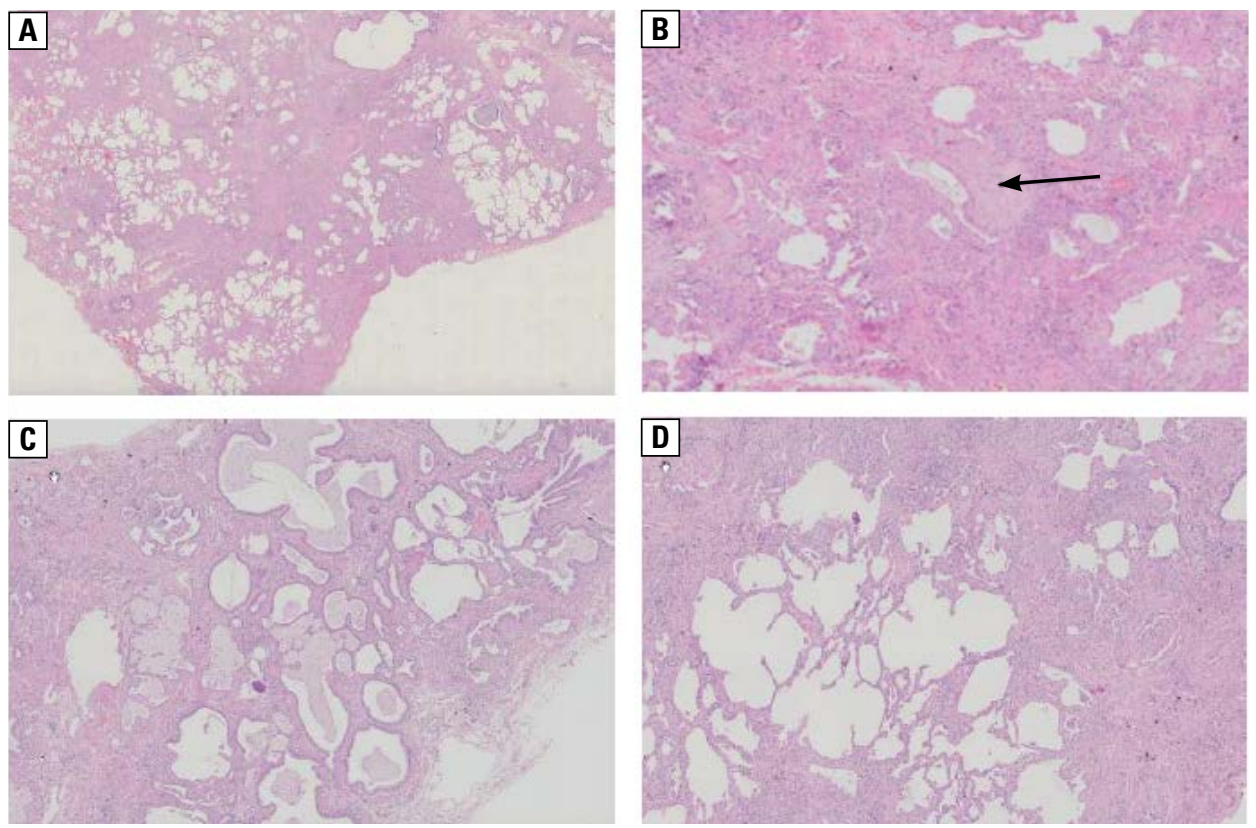

Figure 5. Pathomorphological UIP patterns (Department of Pathology, National Tuberculosis and Lung Diseases Research Institute, Warsaw). A. A fragment of lung parenchyma with visible diffuse fibrosis affecting the subpleural parenchyma, interlobular spaces, with a region of less affected lung parenchyma. Low magnification; B. A fragment of lung parenchyma with diffuse fibrosis, with a focus of fibroblastic fibrosis (fibroblastic focus) visible in the central part (arrow). High magnification; C. Lung parenchyma with areas of cystic remodelling of air spaces with creation of honeycomb-type areas. Medium magnification; D. Fields of completed fibrosis distorting the lung structure are separated by small fragments of aerial parenchyma (mosaicism). Medium magnification 
Table 3. The histopathological criteria for UIP diagnosis (Adapted from [29])

\begin{tabular}{|c|c|c|c|}
\hline Definite UIP & Probable UIP & Indeterminate & $\begin{array}{l}\text { Morphological changes indica- } \\
\text { tive of a different diagnosis }\end{array}$ \\
\hline $\begin{array}{l}\text { Dense fibrosis with architectural } \\
\text { distortion of the lung parenchy- } \\
\text { ma and/or honeycombing }\end{array}$ & $\begin{array}{l}\text { Some features described in } \\
\text { column } 1 \text { are present, but to an } \\
\text { extent that precludes a definite } \\
\text { diagnosis of UIP/IPF }\end{array}$ & $\begin{array}{l}\text { Fibrosis with or without architec- } \\
\text { tural distortion of the parenchy- } \\
\text { ma with morphological features } \\
\text { suggestive of a different diagno- } \\
\text { sis than UIP, or with features } \\
\text { indicative of secondary UIP asso- } \\
\text { ciated with a different cause* }\end{array}$ & $\begin{array}{l}\text { Features typical of other inter- } \\
\text { stitial fibrosis types (e.g. absent } \\
\text { fibroblastic foci, loose connec- } \\
\text { tive tissue fibrosis covering } \\
\text { the entire area of the examined } \\
\text { specimen) }\end{array}$ \\
\hline $\begin{array}{l}\text { - Predominant subpleural and/ } \\
\text { or paraseptal distribution of } \\
\text { fibrosis } \\
\text { - Patchy involvement of lung } \\
\text { parenchyma by fibrosis } \\
\text { - Fibroblastic foci } \\
\text { - Absence of morphological } \\
\text { features suggestive of an } \\
\text { alternate diagnosis }\end{array}$ & $\begin{array}{l}\text { - Absence of morphological } \\
\text { features suggestive of an } \\
\text { alternative diagnosis or } \\
\text { - Presence of honeycombing } \\
\text { only }\end{array}$ & $\begin{array}{l}\text { Certain changes present in co- } \\
\text { lumn } 1 \text { are present but with mor- } \\
\text { phological features suggestive of } \\
\text { an alternative diagnosis** }\end{array}$ & $\begin{array}{l}\text { Morphological changes indi- } \\
\text { cative of a different diagnosis } \\
\text { (e.g. HP, LAM, Langerhans cell } \\
\text { histiocytosis) }\end{array}$ \\
\hline
\end{tabular}

${ }^{*}$ Granulomas, hyaline membranes (except for acute exacerbation of IPF), pronounced peribronchiolar location, diffuse areas of intensive inflammatory infiltration in the stroma without fibrosis, intensive chronic fibrosis of the pleura, organising pneumonia

**Diffuse inflammatory infiltration in areas away from remodelling fields, intensive hyperplasia of lymphoid tissue with the presence of lymph nodules and germinal centres, peribronchiolar location with peribronchiolar metaplasia (bronchiolisation)

HP — hypersensitivity pneumonitis; IPF — idiopathic pulmonary fibrosis; LAM — lymphangioleiomyomatosis; UIP — usual interstitial pneumonia

Microscopic diagnosis requires not only an experienced pathologist, but also adequate fixation and preparation of material for pathomorphological examination. The collected material should be fixed in a $10 \%$ solution of neutral buffered formalin. Lung fragments collected during SLB should be decompressed by injecting the lung parenchyma with a $10 \%$ formalin solution and placed in a vessel containing 10 times more fixing solution in relation to the specimen size.

The histopathological criteria for UIP diagnosis are presented in Table 3.

Microscopic diagnosis of UIP/IPF requires multidisciplinary cooperation. The pathologist must have access to detailed clinical data, information on previous treatment and an up-to-date chest HRCT report. Referral for microscopic examination is completed by a clinician.

\section{Clinical picture}

The most typical and common symptoms of this progressive disease include dyspnoea and non-productive, tiring cough. The symptoms usually appear insidiously, and many patients are unable to pinpoint the date of their appearance. Very often, deteriorating exercise tolerance fails to alarm patients at early stages as they explain the symptoms by the ageing or treat them as a consequence of long-term tobacco smoking.
Other, less common and non-specific, complaints which are usually present in addition to exertional dyspnoea include general fatigue, dizziness, chest discomfort or pain and anxiety [32]. An acute exacerbation is a rare first manifestation of the disease. In such a case, the symptoms appear unexpectedly and intensify in a short time [33].

Most frequently, a patient diagnosed with IPF is male (approximately $70 \%$ of patients), a former or, less frequently, current tobacco smoker (50-70\% of patients), aged above 60 years [32, $34]$. In very rare case the diagnosis is made in patients under the age of 50 . In $2-20 \%$ of patients the disease runs in the family. If this is the case, the first symptoms can develop even before the age of $40[21,35,36]$.

Bilateral, basal crepitations (so called "Velcro-type" cracles) identified during physical examination, especially with concomitant digital clubbing, increases the likelihood of the diagnosis [32, 37]. Crepitations, although not pathognomonic, are present in about $90 \%$ of IPF patients. Digital clubbing is observed in $<30 \%$ of patients [32].

The clinical symptoms accompanying IPF are not characteristic of this condition only. Therefore, the condition is often misdiagnosed as another dyspnoea-associated disease (e.g. chronic obstructive pulmonary disease - due to tobacco smoking history) or heart failure (due to the presence of auscultatory crepitations in the lower 
lung fields). In one study the mean time from the first symptoms to diagnosis was assessed at $3-4$ years. At least $50 \%$ of patients are previously diagnosed with COPD, asthma, other interstitial disease or heart failure. At least $50 \%$ of patients consult 3 or more specialists before receiving the correct diagnosis [8].

IPF is a progressive disease. Progression pattern can be various, from slow loss of lung function parameters slightly above the loss associated with natural ageing, in which cases survival often exceeds 10 years, to violent progression leading to death sometimes in under 1 year. Additionally, the disease course can be complicated with an acute exacerbation. According to a new definition [38], an acute exacerbation of IPF (AE-IPF) is a deterioration of the patient's general condition with developing or worsening of dyspnoea, typically intensifying in a period shorter than 30 days, associated with the appearance of new parenchymal consolidations or areas of ground glass overlapping

Table 4A. The GAP score, used to assess the risk of death

\begin{tabular}{ccc}
\hline Category & Characteristic & $\begin{array}{c}\text { Number } \\
\text { of points }\end{array}$ \\
\hline G - gender & Female & 0 \\
Male & $\leq 60$ & 1 \\
& $61-65$ & 0 \\
P - phy & $>65$ & 1 \\
nal examinations - FVC, & $\mathrm{FVC}>75 \%$ & 2 \\
$\mathrm{~T}_{\mathrm{L}, \mathrm{Co}}$ in reference to pre- & $\mathrm{FVC} \mathrm{50-75 \%}$ & 1 \\
dicted normal values) & $\mathrm{FVC}<50 \%$ & 2 \\
& $\mathrm{~T}_{\mathrm{L}, \mathrm{C} 0}>55 \%$ & 0 \\
& $\mathrm{~T}_{\mathrm{L}, \mathrm{CO}} 30-55 \%$ & 1 \\
& $\mathrm{~T}_{\mathrm{L}, \mathrm{C} 0}<30 \%$ & 2 \\
\hline
\end{tabular}

FVC - foced vital capacity; $T_{L, C O}-$ transfer factor of the lung for carbon monoxide existing sings of fibrosis characteristic of the UIP pattern. In most patients the cause of AE-IPF is never discovered. In others, the symptoms can result from known triggers, such as infection, air pollution, microaspirations or drugs. These events are associated with high mortality (early mortality of around $50 \%$, exceeding $90 \%$ in intubated and mechanically ventilated patients). Those who survive such an episode experience a chronic, irreversible worsening of lung function. The risk of AE-IPF is higher in patients with more advanced disease and lower baseline lung function parameters [38].

The clinical picture of IPF also involves comorbidities. Conditions which are more frequent in IPF patients than in the general population include gastroesophageal reflux disease (GERD) [39-41], lung cancer [42, 43], emphysema [42, 44], pulmonary hypertension [38, 45, 46] and obstructive sleep apnoea [47]. Other common diseases characteristic of this age group include hypertension, ischaemic heart disease, cardiac arrhythmias, stroke, other forms of arterial atherosclerosis, depression, venous thromboembolism and diabetes [48, 49]. Many of these diseases negatively affect survival $[48,49]$ and quality of life [50].

IPF patients have a poor prognosis. Median survival before the introduction of antifibrotic agents was assessed at approximately 3.5 years, while the percentage of patients surviving 5 years after diagnosis was slightly above $30 \%$ [51]. This means that the prognosis can be poorer than in the case of many neoplastic diseases [52].

The prognosis in IPF patients can fundamentally improve as a result of a wider use of antifibrotic agents [53-55].

One of commonly used methods for the assessment of risk of death is the GAP score (gender, age, physiology — Table 4) [56].

After summing all points, an appropriate category should be assigned according to the Table 4B attached.

Table 4B. The table presents how the GAP score should be interpreted, with estimated risk of death in $\mathbf{3}$ consecutive years [57]

\begin{tabular}{ccccc}
\hline Number of points & $\begin{array}{c}\text { Grade } \\
\text { GAP }\end{array}$ & Mortality at 1 year [\%] & Mortality at 2 years [\%] & Mortality at 3 years [\%] \\
\hline $0-3$ & I & 5.6 & 10.9 & 16.3 \\
$4-5$ & II & 16.2 & 29.9 & 42.1 \\
$6-8$ & III & 39.2 & 62.1 & 76.8 \\
\hline
\end{tabular}




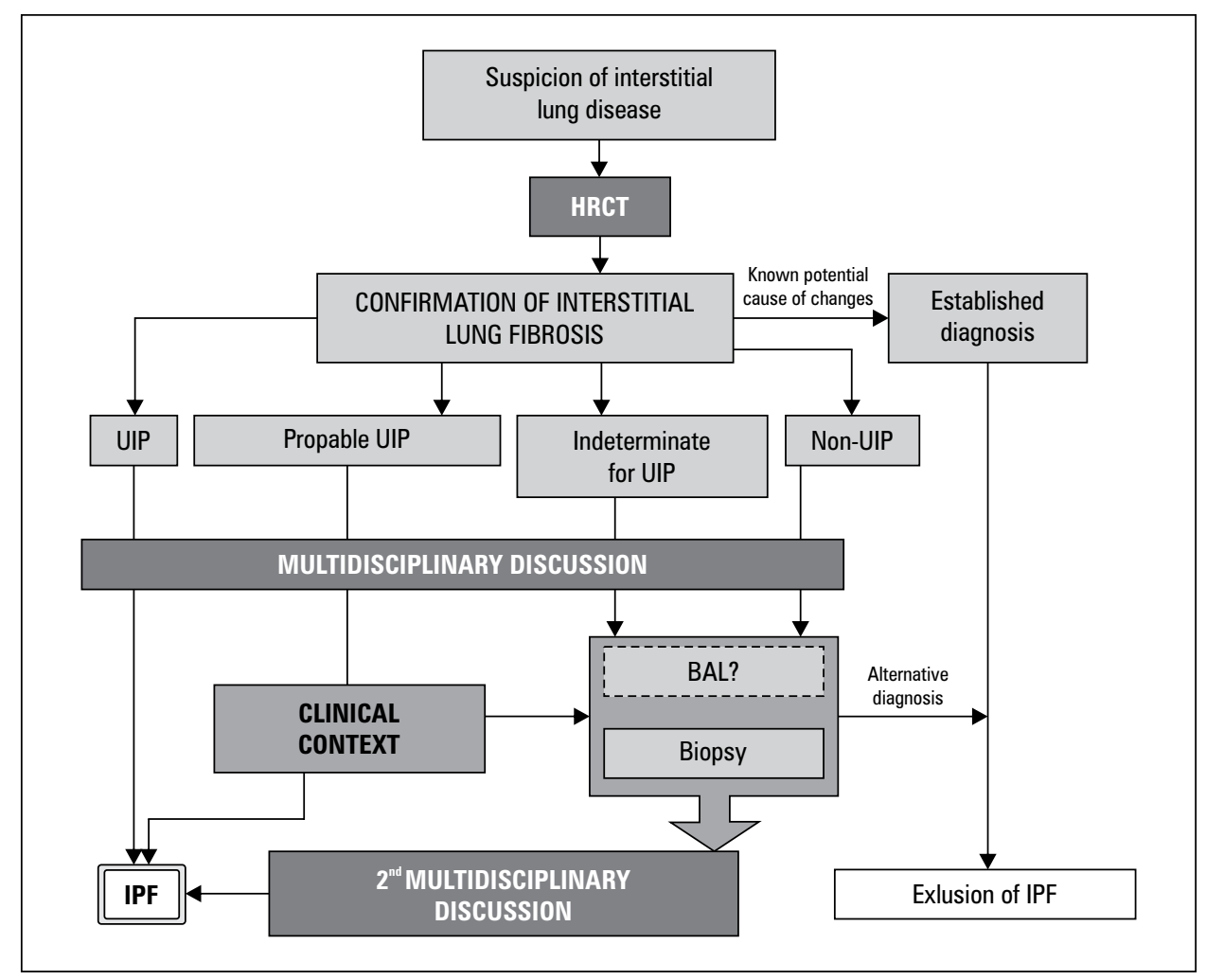

Figure 6. The proposed diagnostic algorithm for IPF (authors: AJB, WJP)

HRCT — high-resolution computed tomography; UIP — usual interstitial pneumonia; BAL — bronchoalveolar lavage; IPF — idiopathic pulmonary fibrosis

\section{Basic rules for diagnosis}

In order to diagnose IPF, one should:

- exclude known causes of ILD;

- confirm the presence of the UIP pattern in HRCT or, if the radiographic image is ambiguous, of the UIP pattern in pathomorphological examination of lung biopsy [29].

Another important factor is the so-called clinical context, i.e. taking into account the fact that IPF is more frequent in men, tobacco smokers and people after the age of 60 .

The proposed diagnostic algorithm for IPF is presented in Figure 6.

\section{Medical history taking and physical examination}

The absolute condition for establishing a diagnosis is exclusion of known causes of interstitial fibrosis. Thorough history taking plays the most important role in this process. It must take into account possible exposure to bioaerosols and toxic substances at workplace, at home, in the immediate neighborhood or in places frequently visited by the patient [29]. The history taking should take into account whether the patient's current or past occupation (this pertains also to distant pass) has been associated with a marked risk of developing lung changes, especially if it has involved exposure to asbestos, silica-containing dusts, metal dusts and other harmful substances. Medical history should include comorbidities and symptoms associated with other organs (e.g. musculoskeletal or other suggestive of autoimmune causes). The question of using pneumotoxic drugs - currently and in the future - is of special importance. The risk of causal relationship can be assessed based on information gathered in medical databases such as Medline or Pneumotox.com.

It is extremely important to collect a detailed family history, aimed at determining the presence of ILDs in members of the immediate and more distant family.

\section{Radiological examinations}

A routine chest radiograph is usually the first stage of imaging diagnostics. It can be used to exclude other causes of abnormalities observed (e.g. heart failure, lung tumour). In some patients it is possible to identify changes suggestive of interstitial pulmonary fibrosis without significant clinical manifestation, which warrants further diagnosis. 
Table 5. The recommended computed tomography protocol in the diagnosis of ILD (Adapted from [29])

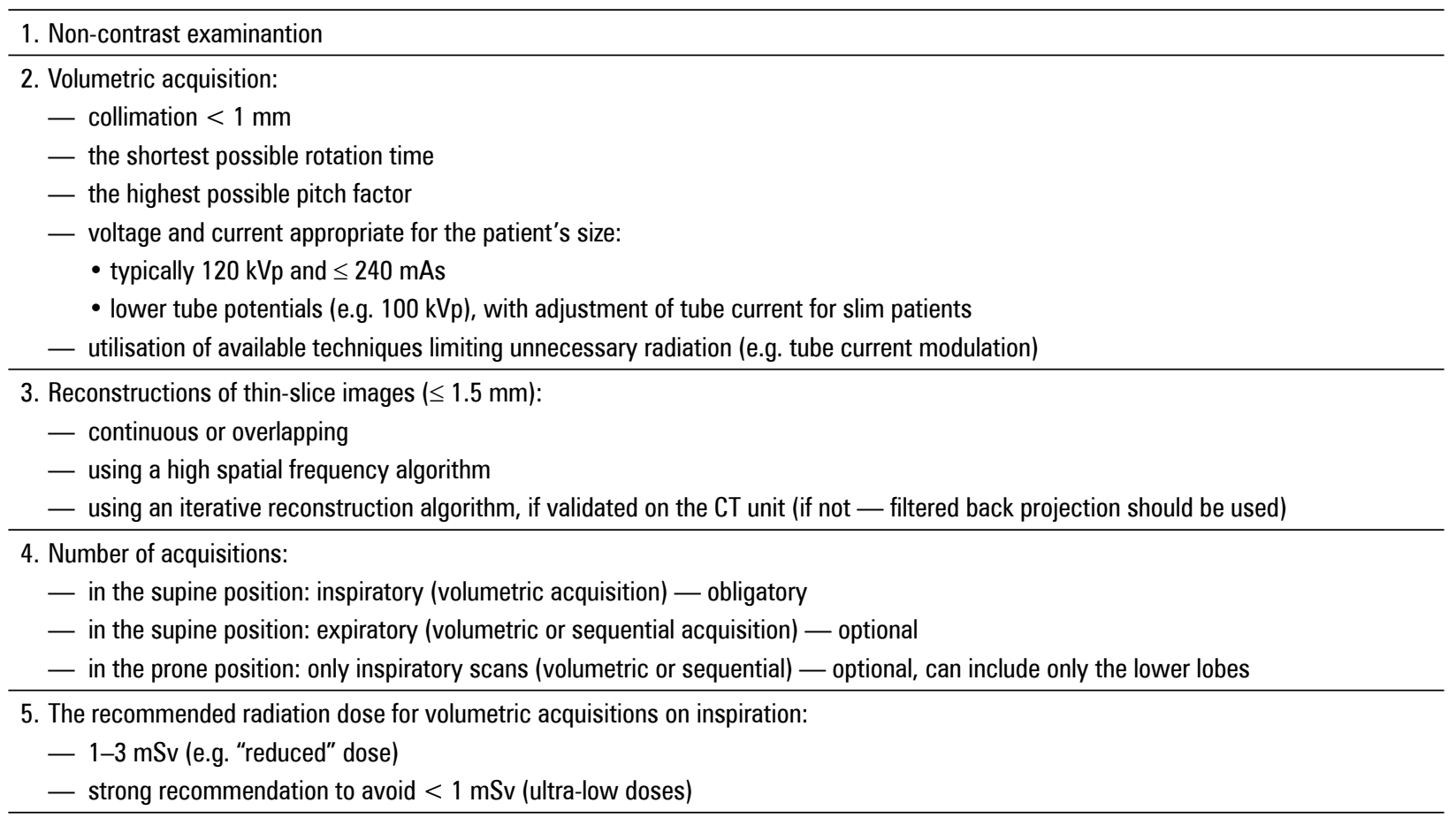

An imaging examination of key importance for IPF diagnosis is HRCT. An experienced radiologist can use its results to diagnose UIP pattern as well as indicate possible changes requiring differential diagnosis [29]. The recommended technique is a multi-detector CT based on volumetric acquisition, which allows multiplanar reconstructions and more thorough radiographic assessment of the nature of lung changes. The standard method is to perform the examination at deep sustained inspiration in the supine position, although in an early fibrosis stage, in order to differentiate from the so-called gravitational effect, an additional examination in the prone position is recommended. Additional scans in the expiration phase can be helpful in differential diagnosis to identify areas of so-called air trapping. Table 5 summarises the technical requirements for HRCT used in the diagnosis of ILDs.

\section{Lung biopsy}

Currently, a common tendency is observed to limit the indications for SLB due to a significant risk of complications in this patient population. There is an ongoing discussion on cases when lung biopsy is indispensable, which is reflected in the disagreement between the Fleischner Society experts [31] and the current version of the international guidelines for IPF diagnosis [29]. The objective of SLB should be arriving at a diagnosis of a disease that can be treated in a specific way based on a pathomorphological diagnosis. A procedure suggestion must be based on an analysis of potential benefits and risks, and should take into account the patient's general condition and comorbidities. Cryobiopsy may be considered a safer alternative for SLB.

\section{The multidisciplinary nature of diagnosis}

The international guidelines for IPF diagnosis stress the role of a multidisciplinary discussion (MDD) in making decisions regarding necessary diagnostic procedures (e.g. lung biopsy) as well as establishing the final diagnosis [29]. The basic composition of the multidisciplinary team should include a clinician (pulmonologist) and radiologist as well as pathologist in cases where lung biopsy has been performed. Specialists involved in the work of such a team should have extensive experience in diagnosing ILD, although a method to measure this experience has not been specifically defined. Many publications recommend extending the team, if possible, to include a rheumatologist, thoracic surgeon (who should take part in assessing indications for SLB and choosing an optimum biopsy site), occupational medicine specialist (potential environmental exposure), cardiologist and other specialists depending on comorbidities, psychologist, ILD nurse as well as palliative care specialist. In spite of unequivocal international guidelines, a survey 
conducted among Polish pulmonologists before antifibrotic agents were commonly available demonstrated that only $55 \%$ of respondents establish IPF diagnosis in cooperation with a radiologist and only $40 \%$ of diagnoses in patients following lung biopsy were discussed directly with a pathologist [58].

The final diagnosis should be clearly formulated. One should also verify whether the diagnosis meets the required formal criteria or rather is a "working" diagnosis (one that does not fulfil the required formal criteria). In the latter case, one should specify whether the diagnosis is "definite" or "provisional/preliminary with high or low likelihood" [31, 59]. Sometimes even if the radiographic and pathomorphological criteria of UIP are met, the diagnosis has a working nature. This can stem, for instance, from inability to exclude in a reliable way the impact of environmental factors or the risk of developing a systemic disease (in a dozen or so per cent of patients with connective tissue diseases (CTDs), lung changes precede the complete presentation of symptoms which allows the diagnosis of CTDs). Every patient with a working diagnosis of IPF should undergo periodic and systematic assessment for a possible change of diagnosis.

Table 6 presents the rules for diagnosing IPF if both HRCT and lung biopsy are available.

\section{Diagnosis of IPF without lung biopsy}

If during the diagnostic process (irrespective of the reason), no diagnostic pathomor- phological material has been obtained, then the diagnosis should be made through a MDD taking into account all clinical factors (such as age, gender, history of tobacco smoking, course of the disease) and the available results of additional tests and examinations (BAL, serological tests and other deemed necessary based on a clinician's suggestion). On this basis one can decide to make either a final or "working" IPF diagnosis [31].

\section{Other diagnostic investigations}

Other diagnostic investigations include tests of autoantibody titres performed in all patients with lung interstitial changes (antinuclear antibodies - ANA, rheumatoid factor - RF) to identify those who require further assessments for connective tissue disease. Bronchoalveolar lavage (BAL) with cellular composition assessment can be used in differential diagnosis of ILDs. In certain cases, determination of serum concentrations of precipitating antibodies makes it possible to confirm environmental exposure, which can be important in establishing the cause of ILD.

In all patients, a full physical examination should be performed as it can be helpful in determining a potential known cause of interstitial changes as well as diagnosing comorbidities. If needed, other specialists should be consulted. Another element of assessment are laboratory tests, such as complete blood count, urea, creatinine and electrolyte concentrations, urinalysis or liver function tests.

Table 6. Idiopathic pulmonary fibrosis diagnosis based upon HRCT and lung biopsy patterns (Adapted from [29, 60], with modifications)

\begin{tabular}{|c|c|c|c|c|c|c|}
\hline & & \multicolumn{4}{|c|}{ Biopsy } & \multirow[t]{2}{*}{ No biopsy } \\
\hline & & UIP & Probable UIP & Indeterminate & $\begin{array}{l}\text { Inconsistent with } \\
\text { the UIP pattern }\end{array}$ & \\
\hline \multirow[t]{4}{*}{ HRCT } & UIP & IPF & IPF & IPF & $\begin{array}{l}\text { A different } \\
\text { diagnosis }\end{array}$ & IPF \\
\hline & Probable UIP & IPF & IPF & IPF likely* & $\begin{array}{l}\text { A different } \\
\text { diagnosis }\end{array}$ & IPF likely* \\
\hline & Indeterminate & IPF & IPF likely* & Indeterminate ${ }^{* *}$ & $\begin{array}{l}\text { A different } \\
\text { diagnosis }\end{array}$ & Indeterminate ${ }^{* *}$ \\
\hline & $\begin{array}{l}\text { Inconsistent with } \\
\text { the UIP pattern }\end{array}$ & IPF likely* & $\begin{array}{l}\text { A different } \\
\text { diagnosis }\end{array}$ & $\begin{array}{l}\text { A different } \\
\text { diagnosis }\end{array}$ & $\begin{array}{l}\text { A different } \\
\text { diagnosis }\end{array}$ & $\begin{array}{l}\text { A different } \\
\text { diagnosis }\end{array}$ \\
\hline
\end{tabular}

*The final diagnosis can be made through a multidisciplinary discussion. The following configurations of demographic and clinical characteristics increase the likelihood of IPF diagnosis: a) moderate to serious traction bronchiectasis/bronchiolectasis (of mild intensity in more than 4 lobes including the lingula or intensive in 2 or more lobes) in males $>50$ years of age or females $>60$ years of age; b) reticular changes affecting $>30 \%$ of the lung area in HRCT in a person $>70$ years of age; c) an increased neutrophil percentage or absence of lymphocytosis in BAL

* If biopsy has provided no signs excluding UIP, no biopsy has been performed or the material's quality is insufficient for diagnosis while medical history and other examinations have excluded the influence of external pneumotoxic factors or diseases associated with interstitial changes in the lungs, the current classification of interstitial diseases states that a diagnosis of unclassifiable interstitial lung fibrosis should be made [1]

IPF — idiopathic pulmonary fibrosis; HRCT — high-resolution computed tomography; UIP — usual interstitial pneumonia 
Table 7. Basic features facilitating differentiation of IPF from selected ILDs leading to fibrosis

\begin{tabular}{|c|c|c|c|c|}
\hline & cHP & CTD-ILD & Pneumoconioses & $\begin{array}{l}\text { Interstitial changes } \\
\text { associated with the use } \\
\text { of pneumotoxic drugs }\end{array}$ \\
\hline $\begin{array}{l}\text { Medical } \\
\text { history }\end{array}$ & $\begin{array}{l}\text { In some patients it is possible to } \\
\text { identify potential exposure. }\end{array}$ & $\begin{array}{l}\text { Most patients present } \\
\text { with extrapulmonary } \\
\text { symptoms }\end{array}$ & $\begin{array}{l}\text { A history of exposure to } \\
\text { dusts }\end{array}$ & $\begin{array}{l}\text { Interstitial fibrosis can result } \\
\text { from long-term exposure to } \\
\text { a drug, often lasting many } \\
\text { years }\end{array}$ \\
\hline HRCT & $\begin{array}{l}\text { The UIP pattern may be observed in } \\
\text { a chronic, fibrotic form of HP. } \\
\text { Extensive areas of ground glass } \\
\text { appearance, mosaic attenuation, air } \\
\text { trapping, centrilobular nodules. } \\
\text { Predominantly upper-zone distribu- } \\
\text { tion (although predominantly lower } \\
\text {-zone distribution is also possible), } \\
\text { predilection for affecting areas surro- } \\
\text { unding bronchovascular bundles. } \\
\text { Common coexistence of changes } \\
\text { typical for the acute form }\end{array}$ & $\begin{array}{l}\text { The UIP pattern is ob- } \\
\text { served most commonly } \\
\text { in RA. } \\
\text { The most typical feature } \\
\text { of lung changes in the } \\
\text { course of CTD is the } \\
\text { NSIP pattern. } \\
\text { More extensive ground } \\
\text { glass areas can suggest } \\
\text { CTD-ILD. } \\
\text { Coexistence of exudative } \\
\text { pleuritis can be suggesti- } \\
\text { ve of CTD-ILD }\end{array}$ & $\begin{array}{l}\text { The UIP pattern can be } \\
\text { present in asbestosis. } \\
\text { Local thickenings of the } \\
\text { pleura called pleural } \\
\text { plaques may suggest as- } \\
\text { bestosis. Pleural effusion } \\
\text { or pleural mesothelioma } \\
\text { can coexist with the pic- } \\
\text { ture of asbestosis }\end{array}$ & $\begin{array}{l}\text { The typical UIP pattern is } \\
\text { a rare manifestation of drug- } \\
\text {-induced lung changes. } \\
\text { More frequently observed } \\
\text { patterns include HP, NSIP } \\
\text { or OP }\end{array}$ \\
\hline BAL & $\begin{array}{l}\text { Severe lymphocytosis, more often in } \\
\text { patients with active exposure. Patients } \\
\text { with a fibrotic form, when the exposu- } \\
\text { re occurred in a distant past, can have } \\
\text { a normal differential cell counts }\end{array}$ & Possible lymphocytosis & $\begin{array}{l}\text { Possible lymphocytosis, } \\
\text { presence of asbestos } \\
\text { bodies }\end{array}$ & $\begin{array}{l}\text { Possible lymphocytosis and } \\
\text { eosinophilia }\end{array}$ \\
\hline $\begin{array}{l}\text { Laboratory } \\
\text { tests }\end{array}$ & $\begin{array}{l}\text { Precipitins can be positive, but they } \\
\text { document exposure rather than pro- } \\
\text { ve the disease diagnosis }\end{array}$ & $\begin{array}{l}\text { Increased titres of ANA, } \\
\text { RF, aCCP and other } \\
\text { autoantibodies are } \\
\text { suggestive of a CTD-ILD } \\
\text { diagnosis. } \\
\text { The diagnosis should be } \\
\text { confirmed by a rheuma- } \\
\text { tologist }\end{array}$ & $\begin{array}{l}\text { No specific studies } \\
\text { confirming } \\
\text { diagnosis }\end{array}$ & $\begin{array}{l}\text { No specific studies } \\
\text { confirming } \\
\text { diagnosis }\end{array}$ \\
\hline $\begin{array}{l}\text { Clinical } \\
\text { picture }\end{array}$ & $\begin{array}{l}\text { Although, in most cases chronic } \\
\text { fibrosing HP develops in more advan- } \\
\text { ced age, disease onset at a young } \\
\text { age, sometimes in childhood, is also } \\
\text { possible }\end{array}$ & $\begin{array}{l}\text { An interstitial disease } \\
\text { can precede the full } \\
\text { picture of a CTD. Usually } \\
\text { symptoms characteristic } \\
\text { of a specific disease } \\
\text { entity are present }\end{array}$ & $\begin{array}{l}\text { Usually progressive } \\
\text { dyspnoea and cough in } \\
\text { an individual with long- } \\
\text { term occupational expo- } \\
\text { sure. Clinical symptoms } \\
\text { and radiographic chan- } \\
\text { ges are present during or } \\
\text { after the exposure }\end{array}$ & $\begin{array}{l}\text { Exposure to a harmful drug } \\
\text { is associated with the treat- } \\
\text { ment of comorbidities }\end{array}$ \\
\hline Lung biopsy & $\begin{array}{l}\text { Peribronchial distribution of changes, } \\
\text { loosely formed granulomas, lympho- } \\
\text { cytic infiltrations, empty spaces left } \\
\text { by washing away cholesterol crystals }\end{array}$ & $\begin{array}{l}\text { Presence of abundant } \\
\text { lymphocytic infiltrations } \\
\text { with visible germinal } \\
\text { centres }\end{array}$ & Asbestos bodies & HP, OP, NSIP \\
\hline
\end{tabular}

ILD — interstitial lund diseases; cHP — chronic hypersensitivity pneumonitis; CTD-ILD — connective tissue disease-associated interstitial lung disease; HRCT — high-resolution computed tomography, UIP — usual interstitial pneumonia, RA — rheumatoid arthritis; NSIP — non-specific interstitial pneumonia; OP — organizing pneumonia; ANA — antinuclear antibodies; RF — rheumatoid factor; aCCP — anti-cyclic citrullinated peptide autoantibodies

\section{Differential diagnosis}

Differentiation should include above all those disease entities which can be associated with a radiographic or histopathological pattern of UIP. First and foremost, differentiation should pertain to chronic hypersensitivity pneumonitis (cHP) [61], ILD in the course of CTD (CTD-ILD) (especially in the course of rheumatoid arthritis, RA) [62], pneumoconioses (especially asbestosis) [63] or drug-induced changes [22]. Table 7 presents the basic features of other diseases facilitating such differentiation.

The features useful in the differential diagnosis listed in Table 7 should be understood as typical for individual disease entities, but their absence does not preclude a given diagnosis. In addition to the above disease entities, one should take into account very rare causes of the radiographic UIP pattern, such as sarcoidosis [64] and other rare ILDs [65]. 
Table 8. Selected forms of pharmacotherapy not recommended in IPF treatment based on the results of randomised trials

\begin{tabular}{|c|c|c|c|}
\hline Name of the drug & $\begin{array}{l}\text { Recommendation in the international } \\
\text { guidelines }\end{array}$ & Acronym & References \\
\hline Interferon gamma-1b & Strongly against [10] & INSPIRE & [71] \\
\hline Colchicine & Strongly against [10] & & [72] \\
\hline Cyclosporine & Strongly against [10] & & [73] \\
\hline TNF-alpha antagonist (etanercept) & Strongly against [10] & & {$[74]$} \\
\hline Oral anticoagulants (warfarin) & Strongly against [75] & ACE-IPF & [68] \\
\hline Triple therapy (prednisone + azathioprine + NAC) & Strongly against [75] & PANTHER-IPF & [67] \\
\hline Selective endothelin-1 receptor antagonist (ambrisentan) & Strongly against [75] & ARTEMIS-IPF & [70] \\
\hline Dual endothelin receptor antagonist (bosentan, macitentan) & Conditionally against [75] & $\begin{array}{l}\text { BUILD-3 } \\
\text { MUSIC }\end{array}$ & {$[76,77]$} \\
\hline Phosphodiesterase-5 inhibitor (sildenafil) & Conditionally against [75] & STEP-IPF & [78] \\
\hline Single-target tyrosine kinase inhibitor (imatinib) & Strongly against [75] & IMATINIB-IPF & [79] \\
\hline LOXL-2 inhibitor (simtuzumab) & Not considered & RAINIER & [80] \\
\hline
\end{tabular}

Differentiation of the UIP pattern from a fibrotic form of non-specific interstitial pneumonia (NSIP) can be another issue. Problems can arise from overlapping of radiographic features. For instance, IPF patients can present with limited ground glass areas (one of the radiographic features of NSIP). On the other hand, traction bronchiectasis is also often observed in NSIP patients. The presence of honeycombing areas in NSIP is also possible, although rare, and changes in both patterns are predominantly located in the lower lung zones. In addition, coexistence of both histopathological patterns may be observed in one lung biopsy [66].

\section{Idiopathic pulmonary fibrosis treatment}

Idiopathic pulmonary fibrosis treatment approaches have drastically changed in the last 20 years. Furthermore, new reports are continuously emerging on the molecular pathomechanisms and options of pharmacological interventions. In the guidelines for the diagnosis and treatment of IPF of 2000, the only recommended pharmacotherapy methods were glucocorticosteroids and immunosuppressants [9]. As new evidence arose indicating a secondary role of inflammation and a primary role of fibrosis in the pathogenesis of IPF, a search for new IPF treatment options began. Numerous randomised clinical trials have been conducted, proving lack of efficacy or even harmful effects of many treatment regimens used. For instance, we currently have access to unequivocal data documenting harmful effects of glucocorticosteroids and immunosuppressants [67]. Despite this fact, the aforementioned survey demonstrated that in 2016 $23 \%$ of IPF patients in Poland received glucocorticosteroids [58]. Negative results were obtained also in the ACE-IPF study, which demonstrated detrimental effects of warfarin use [68] in spite of encouraging results from earlier studies [69].

Negative results were also achieved in studies of an endothelin-1-receptor antagonist (ARTEMIS-IPF) [70]. Endothelin-1 is a cytokine involved in the pathogenesis of both IPF and pulmonary hypertension. Table 8 summarizes drugs which according to the current state of knowledge should not be used in the treatment of IPF patients.

The breakthrough in IPF treatment was possible thanks to studies demonstrating the efficacy of pirfenidone [81, 82] and nintedanib [83]. These drugs, currently called antifibrotic agents, slow down the rate of fibrosis progression.

AE-IPF significantly worsen the prognosis. Most centres use high-dose glucocorticosteroids, often in combination with an immunosuppressant. This treatment is recognised as the standard of care, although evidence supporting its efficacy is very limited [38]. For this reason, this document omits the problem of the pharmacological treatment of IPF exacerbations.

Non-pharmacological treatment is an important element of therapy. This mostly pertains to the treatment of chronic respiratory failure. In this document we discuss problems associated with the use of oxygen in individuals with respiratory failure and with the use of ventilation 
support in AE-IPF and in patients with end-stage respiratory failure. Pulmonary rehabilitation is another important and underestimated element of non-pharmacological treatment. Given the progressive nature of the disease, sooner or later every IPF patient requires palliative care.

\section{MATERIAL AND METHODS}

The Polish recommendations for diagnostic and therapeutic management were developed by a team of Polish experts in ILDs. The initiative of developing national guidelines arose in a group of specialists in ILDs. It was sparked by nonunanimous opinions on IPF diagnosis, qualification for treatment, management using antifibrotics, supportive and palliative treatment as well as methods for monitoring of the disease course. The initiative gained support by the General Board of the Polish Respiratory Society (PTChP, Polskie Towarzystwo Chorób Płuc) and the Head of the Interstitial Lung Diseases Section of the society.

The guidelines were created following two important publications: the Fleischner Society expert opinion published in February 2018 [31], which contained suggested changes to the international guidelines for IPF diagnosis of 2011 [10], and the final version of the updated international guidelines published in September 2018 [29]. This publication was based on a systematic review of global literature, taking into account local factors resulting from the uniqueness of the Polish healthcare system and the rules of the IPF treatment programme currently in place. The literature review was completed on $30^{\text {th }}$ June 2019.

Objectives of the guidelines:

- improving the quality and reliability of IPF diagnoses;

- increasing antifibrotic treatment accessibility by popularising the diagnostic and treatment qualification criteria in Poland;

- creating conditions for optimal utilisation of Poland's existing IPF treatment programme;

- identification of shortcomings and health needs in terms of IPF patient care.

The patient population to which the guidelines pertain are patients with suspected or diagnosed IPF. The audience for whom the guidelines have been developed are doctors dealing with the subject matter of ILDs, especially pulmonologists, radiologists, pathologists, thoracic surgeons, pulmonary rehabilitation specialists, healthcare organisation specialists, representatives of the
Polish National Health Fund (Narodowy Fundusz Zdrowia) or other institutions shaping the healthcare politics in Poland.

Working team members: The working team comprises doctors specialising in ILDs, representative of various expert centres: pulmonologists (AJB, PWB, EJ, DJ, JK, KL, SM, MMM-B, WJP, EP, AS, MS, EW, DZ), radiologists (IB, PG, KO), pathologists (RL, MSz), as well as patients (DK, GW). The literature review regarding specific issues was prepared independently by authors assigned to a given task and by the author assigned to act as a librarian (AJB). WJP and AJB supervised the methodological consistency of the guidelines.

The methodology was adapted from the document "Ramy metodyczne opracowywania zaleceń diagnostyczno-terapeutycznych" (Methodological framework for developing diagnostic and therapeutic recommendations) published by the Agency for Health Technology Assessment and Pricing (Agencja Oceny Technologii Medycznych i Taryfikacji) [84]. The guidelines were developed according to the GRADE methodology (Grading of Recommendations Assessment, Development, and Evaluation) in a form similar to one used in the American Thoracic Society's position [85]. Contentious issues were resolved using the Delphi method. At every development stage, the criteria described in the document "Narzędzie oceny wytycznych AGREE II" (A tool to assess the AGREE II guidelines) were also taken into account [86].

The recommendations were divided into three parts: 1. Diagnosis; 2. Pharmacological treatment; 3 . Non-pharmacological and palliative treatment. The experts presented clinical problem suggestions in the form of a list of questions. The suggested questions were sent to all Editorial Board members, and the formulated clinical questions, after initial revisions and proofreading, were assessed in terms of their relevance. The score proposed by the authors of the Swiss Lung Disease Society consensus was used [87]. The importance of individual questions was evaluated in a 9-point score and grouped into the following categories: very important questions (8-9 points), important questions (6-7 points), unimportant questions (below 6 points). Questions considered by a majority as very important and important were subjected to further process.

Subsequently, a working team was established with an aim to develop individual guidelines: MMM-B, WJP - diagnosis; KL, SM, MS - pharmacological treatment; EP, AJB, AS, WJP - non-pharmacological treatment and palliative care. 
The review of available literature was performed in the Medline and Cochrane databases. Existing systematic reviews were used as well as de novo reviews were made if a given systematic review was not available. The quality of evidence was determined as high, moderate, poor or very poor. The strength of recommendation was assessed as strong or conditional [29].

The authors of respective sections developed the initial version of a response to a given question, accompanied by a short commentary. Subsequent versions were developed following discussions via electronic means and face-to-face meetings. A preliminary version was sent out to all guideline authors for internal review.

The final version was sent for external review. After introducing final revisions, the work was sent to print. The English-language version was assumed as the original one.

The recommendations will undergo planned revision every five years or earlier if new evidence emerges affecting in a significant way the state of knowledge on the diagnosis and/or treatment of IPF and an expert panel decides that it changes significantly the meaning of the previously published recommendations, thus necessitating an earlier than planned update.

\section{RECOMMENDATIONS}

\section{DIAGNOSIS}

\section{Question 1. Can IPF be diagnosed without lung biopsy in a patient with "probable UIP" HRCT pattern (without honeycombing, but with peripheral traction bronchiectasis or bronchiolectasis)?}

\section{Introduction}

Analyses of patient populations meeting the "probable UIP" criteria in high-resolution computed tomography (HRCT) indicate that lack of honeycombing should not exclude IPF diagnosis if all remaining radiographic features of the UIP pattern are present (especially predominantly subpleural and basal distribution of changes as well as the presence of bronchiectasis) [30, 88-98]. The extent of reticular changes is of great importance. This is because if they exceed $1 / 3$ of the total lung volume (in a person above 60 ), the probability of IPF diagnosis exceeds $80 \%$, with a 96\% specificity [99]. The "probable UIP" pattern in HRCT co-exists with changes typical of definite or probable UIP in pathomorphological examination of SLB material in $82-94 \%$ of patients [88-90]. A recently published meta-analysis demonstrated that IPF diagnosis can be made in as many as $94 \%$ (87-99\%) of patients with a radiographic pattern corresponding to "probable UIP" [100]. The probability of IPF diagnosis increases in an appropriate clinical context, comprising the following: age above 60 years, a positive history of tobacco smoking (currently or in the past) and lack of other identifiable causes that could lead to interstitial fibrosis (especially lack of significant environmental exposure, chronic use of potentially pneumotoxic drugs or signs of CTD) [31, 97, 99, $101,102]$. In the group of patients with "probable UIP" (who had not undergone lung biopsy), an annual FVC decline was observed as well as a response to antifibrotic treatment (with nintedanib) reducing the rate of this decline, comparable with outcomes observed in the "definite UIP" group (based on radiographic or pathomorphological presentation) [103].

\section{Recommendation 1.}

We suggest that a "probable UIP" HRCT pattern, if it contains no changes suggestive of an alternative diagnosis, in an appropriate clinical context (e.g. male sex, smoking history, age above 60) and after excluding other causes of such changes, should be a sufficient basis for a multidisciplinary team to diagnose IPF with no need for diagnostic lung biopsy.

Quality of evidence: very poor

Strength of recommendation: conditional

Votes: strongly for (IPF diagnosis in the case of probable UIP with no need for diagnostic lung biopsy) -6 ; conditionally for -14 ; strongly against -1 ; conditionally against -0 ; abstained -0

\section{Commentary}

This recommendation is in line with the Fleischner Society's position presented as a consensus of an international group of experts in ILDs (including eight pulmonologists, six radiologists and three pathologists), which was developed based on a systematic literature review [31]. Ad- 
ditionally, this position is not inconsistent with the international ATS/ERS/JRS/ALAT recommendations (2018), which suggests to consider invasive diagnosis (BAL or even SLB) in patients with the "probable UIP" HRCT pattern. However, the guidelines also allow the possibility of establishing IPF diagnosis without any invasive procedures, taking into account the clinical context (presented in the above discussion) through a multidisciplinary discussion (MDD) [29, 104]. A group of experts, including the co-authors of both documents, stress the fact that the recommendation to perform lung biopsy in case of "probable UIP" is conditional (with a poor strength of evidence) and in a situation when the only missing element of the radiographic UIP pattern is lack of honeycombing while the other criteria are met and the clinical picture is highly suggestive of IPF, such a final diagnosis is highly likely. Surgical lung biopsy is an invasive, costly procedure associated with possible complications, while it does not guarantee diagnosis [105-109].

\section{Question 2. Can a UIP pattern confirmed by pathomorphological examination of material collected through cryobiopsy be considered equivalent to a diagnosis made based on surgical biopsy?}

\section{Introduction}

Surgical lung biopsy remains the gold standard in invasive diagnosis of ILD, including UIP/ IPF [29, 31]. In most situations, video-assisted thoracoscopic surgery (VATS) is preferred over open lung biopsy (OLB). Video-assisted thoracoscopic surgery, like OLB, allows a controlled and precise choice of the biopsy site as well as achieving adequately sized (even several centimetres) diagnostic material for examinations, which is especially important for appropriate pathomorphological assessment [110, 111]. The optimal management involves collecting material in the form of numerous specimens, from different lobes, with a margin extending 1-2 cm away from the pleura [112-114]. Surgical lung biopsy is a procedure associated with risk that encompasses standard periprocedural complications (pneumothorax, bleedings), infections as well as, in the case of UIP/IPF patients, a higher risk of AE-IPF and also death [115, 116]. SLB-associated mortality depends on the advancement of disease, the need for mechanical ventilation, comorbidities, immunosuppressive treatment and the centre's experience [117-119]. In spe- cialist centres of the United States and England, the mean intrahospital mortality due to this diagnostic procedure only was $1.7 \%$, with mortality within 30 days after biopsy of $2.4 \%$ and within 90 days of $3.9 \%[120,121]$. Transbronchial lung cryobiopsy (TBLC) is a new diagnostic technique [92, 122-126]. Its diagnostic effectiveness and complication rates are varied and depend on the experience of the person performing the procedure [123, 125, 127-139]. The mean mortality due to this diagnostic procedure only has been estimated at $0.2 \%$, with less frequent sudden exacerbations than in the case of SLB $(1.2 \% \mathrm{vs}$ $6.1 \%)$. However, there are frequent complications of pneumothorax ( $0 \%$ vs $26 \%$ with TBLC; in the case of SLB, the rates of pneumothorax or persistent air leak are lower) and bleeding (on average, $5.3 \%$ vs $0.8 \%$ with SLB) [111, 123 , $128,133,135-145]$.

\section{Recommendation 2.}

We suggest that material collected for pathomorphological examination through cryobiopsy, sufficient to diagnose UIP, should be considered equivalent to material from surgical lung biopsy.

Quality of evidence: very poor

Strength of recommendation: conditional

Votes: strongly for (accepting a UIP-confirming result based on material from cryobiopsy) -8 ; conditionally for -11 ; strongly against -0 ; conditionally against -1 ; abstained -1

\section{Commentary}

The international ATS/ERS/JRS/ALAT recommendations (2018) on IPF diagnosis do not take into account a situation where the patient is unable or unwilling to undergo SLB [29]. Observational studies based on IPF patient registries indicate that material for lung pathomorphological examination is ever-more often collected using the TBLC method [146]. At present, the procedure is not commonly available or practiced, although there are ongoing attempts at its standardisation [147-149]. Material collected with this method is usually smaller than in surgical biopsy, with no possibility of choosing the precise biopsy site it usually comes from the more centrally located areas [122]. The percentage of TBLC-based diagnoses is up to $80-85 \%$ vs more than $95 \%$ in the case of diagnoses based on SLB [122-124].

The classical transbronchial lung biopsy (TBLB), given its low clinical effectiveness, 
is not a recommended method for confirming the UIP pattern in pathomorphological examination. However, sometimes (in over one third of IPF patients) it is possible to use TBLB material to demonstrate changes corresponding to elements of the UIP pattern (such as fibroblastic foci) $[91,127,128,138,140,150$, 151]. Although TBLB can be useful in certain situations, e.g. differential diagnosis (if changes inconsistent with UIP are present, in order to confirm an alternative diagnosis) [117], prospective studies that would reliably determine the place of this method in UIP/IPF diagnosis are still lacking $[29,130]$.

\section{Question 3. What respiratory function examinations should be performed to assess the risk of lung biopsy complications?}

\section{Introduction}

In light of the current clinical practice and international guidelines for IPF diagnosis, in cases where non-invasive methods do not make it possible to establish diagnosis with a satisfactory level of confidence, it is recommended to perform pathomorphological examination of lung biopsy material [29]. At present, the recommended diagnostic procedure is SLB [29]. The invasiveness of this method is associated with a risk of complications (including disease exacerbations and even death) [152]. The identified risk factors for complications include: the male sex, non-elective or open procedure, requirement of mechanical ventilation following the procedure, preliminary diagnosis of IPF or connective tissue disease-associated ILD (CTD -ILD), immunosuppressive treatment or $\mathrm{T}_{\mathrm{L}, \mathrm{CO}}$ $<50 \%$ of predicted [105, 121, 153]. Another method providing tissue material of acceptable sizes is TBLC. This method is associated with a lower risk of death but also characterised by lower diagnostic effectiveness [123]. The nature of its complications is also different (with more frequent bleedings and pneumothorax). The recognised risk factors for cryobiopsy complications include, among others, forced vital capacity (FVC) $<50 \%$ of predicted and carbon monoxide lung transfer $\left(\mathrm{T}_{\mathrm{L}, \mathrm{CO}}\right)<35 \%$ of predicted, serious hypoxaemia $\left(\mathrm{PaO}_{2}<50-\right.$ $60 \mathrm{~mm} \mathrm{Hg}$ when breathing atmospheric air at rest), suspected pulmonary hypertension with $>40 \mathrm{~mm} \mathrm{Hg}$ in echocardiographic examination. These factors are sometimes considered relative contraindications for the procedure $[147,148]$.

\section{Recommendation 3.}

We recommend that qualification for elective lung biopsy include arterial blood gas analysis, spirometry and assessment of transfer factor for carbon monoxide.

Quality of evidence: very poor

Strength of recommendation: strong

Votes: strongly for (performing examinations to assess the degree of respiratory dysfunction before elective biopsy) -11 ; conditionally for -6 ; strongly against -0 ; conditionally against -0 ; abstained -4

\section{Commentary}

In the case of biopsy, loss of lung parenchyma is small, and this element is not important for risk analysis. The suggested threshold values of lung function parameters to be used in qualification for diagnostic lung biopsy in patients with suspected IPF are arbitrary and have been chosen based on retrospective analyses and observational studies. In such $a$-priori studies, patients with very low values of functional parameters (FVC, $\mathrm{T}_{\mathrm{L}, \mathrm{CO}}$ ) and with respiratory failure, were excluded - that is why it is impossible to perform an assessment of the procedure safety with consideration of a wide range of FVC and $\mathrm{T}_{\mathrm{L}, \mathrm{CO}}$ values. On the other hand, there is a safety analysis performed in 699 patients with ILDs. The analysis revealed that complications were not more frequent in patients with FVC $<50 \%$ of predicted and $\mathrm{T}_{\mathrm{L}, \mathrm{CO}}<35 \%$ of predicted compared with individuals with higher values of these parameters [154]. Pneumothorax was more frequent in patients with a higher radiographic fibrosis index and pathomorphological UIP diagnosis, irrespective of FVC $<50 \%$ of predicted or $\mathrm{T}_{\mathrm{L}, \mathrm{CO}}<35 \%$ of predicted [154]. In light of the above, no definite recommendation can be given regarding threshold values defining an absolute contraindication for the procedure.

A separate problem associated with biopsy is an increased risk of AE-IPF. It is believed that when mechanical ventilation is used during any surgical procedure, intraoperative exposure to high oxygen concentrations (hyperoxia) and high pressures (barotrauma) or respiratory volumes (volutrauma) can increase recruitment of circulating proinflammatory cells and mediators, thus intensifying the fibrotic process [155]. The recognised factors predisposing for an exacerbation in the periprocedural period include reduced FVC and $\mathrm{T}_{\mathrm{L}, \mathrm{CO}}$ values, although it is impossible to name any specific factors that would constitute contraindications for biopsy [156]. 


\section{Question 4. Is it necessary to perform serological tests for autoimmune diseases in every patient with suspected IPF without clinical signs of connective tissue disease?}

\section{Introduction}

Increased titres of ANA and RF are present in many IPF patients with no signs of CTD [157-161]. Many studies point to lack of significant differences in the clinical course and prognosis of IPF patients with high antibody titres compared with IPF patients without antibodies [158, 161, 162], although the most recent meta-analysis of 9 studies (a total of 4602 IPF patients) indicates a higher risk of developing autoimmune disorders by patients with high titres of ANA and myeloperoxidase-specific anti-neutrophil cytoplasmic antibodies (MPO-ANCA) [163, 164]. Interstitial lung disease can be the first symptom of CTD in more than ten per cent of patients [165]. The UIP pattern is the most common pulmonary presentation of rheumatoid arthritis (RA) [166], but it can also occur in patients with systemic scleroderma $[167,168]$ and, much less frequently, in the course of other CTDs [169]. Similarly to IPF, lung changes among RA patients are more frequent in males and older patients and exhibit a relationship with tobacco smoking [166, 170-174]. Differentiation can be especially difficult in such cases if no extrapulmonary RA symptoms are present.

\section{Recommendation 4.}

We recommend that every patient with suspected IPF undergo serological tests for autoimmune diseases.

Quality of evidence: very poor

Strength of recommendation: strong

Votes: strongly for (performing serological tests for autoimmune diseases in all patients with suspected IPF) - 14; conditionally for -6 ; strongly against -0 ; conditionally against -0 ; abstained -1

\section{Commentary}

The current international guideline for IPF diagnosis recommends performing serological tests in all patients with suspected IPF. This is a motherhood statement, i.e. a recommendation adopted a priori and not subjected to voting [29]. However, the guidelines fail to specify the exact tests that should be performed. It has been agreed that the basic serological tests include tests for antinuclear antibodies (ANA), rheumatoid factor (RF) and antibodies against cyclic citrullinated peptide (aCCP). Experts recommend that the panel be extended to include tests for other specific antibodies (e.g. a dermatomyositis-specific profile) depending on the clinical situation and diagnostic capabilities of a given facility [10, 29]. Patients with positive titres of ANA, RF, aCCP or other autoantibodies should be consulted by a rheumatologist and if connective tissue disease is preliminarily excluded, they should undergo periodic assessment for the development of an autoimmune disease. In patients with increased autoantibody titres (ANA $>1: 320, \mathrm{RF}>60 \mathrm{U} / \mathrm{L}$ ) but without other signs of autoimmune diseases and meeting other diagnostic criteria, a working IPF diagnosis should be established through a MDD and scrupulously monitored.

\section{Question 5. Is it necessary to determine serum concentrations of specific immunoglobulins (precipitins) in order to diagnose hypersensitivity pneumonitis (allergic alveolitis) in every patient with suspected IPF?}

\section{Introduction}

Radiographic changes in lung HRCT in patients with chronic hypersensitivity pneumonitis (cHP) can correspond to the radiographic UIP pattern. It was demonstrated that in as many as $40 \%$ of patients with an initial IPF diagnosis, the diagnosis was changed to cHP after more thorough examinations [175]. This makes it the most important disease entity that needs to be excluded in differential diagnosis of patients with suspected IPF. The identification of the antigen cause and source is of crucial importance for prognosis [176]. In everyday practice, the element of key importance is a scrupulously collected, systematic medical history of possible exposures in the occupational and domestic environments as well as in the immediate neighborhood and frequently visited places [177, 178]. Unfortunately, it is estimated that in $50 \%$ of cHP cases the causative antigen remains unidentified [178-180]. A suggestion was made to name this form a cryptogenic hypersensitivity pneumonitis [178].

One of recently published studies revealed positive results of a precipitin test for farmer's lung in $78 \%$ of patients with an acute form, but only in $48 \%$ of patients with a chronic form [181]. Specific antibodies were detected only in $52 \%$ of pigeon breeders with a chronic form of lung disease [182]. In a group of 86 bird breeders with 
lung disease, the presence of specific immunoglobulins was identified in $92 \%$ of patients (only in 2 radiographic signs of UIP were observed), while in the control group comprising healthy pigeon breeders specific antibodies were detected in as many as $87 \%$ of subjects [183]. By contrast, in the case of many patients with signs of cHP with positive results for specific antibodies, these antigens are not detected in the patients' domestic environments [184]. The value of positive precipitins in differentiation of cHP from other ILDs associated with pulmonary fibrosis was considered low (sensitivity: $72 \%$, specificity: $68 \%$ ) vs diagnosis made based on a MDD [185].

\section{Recommendation 5.}

We recommend that a test for the presence of specific immunoglobulins in the serum (precipitins) NOT be performed in all patients with suspected IPF.

\section{Quality of evidence: very poor}

\section{Strength of recommendation: strong}

Votes: strongly for (performing a test for the presence of precipitins in the serum in all patients with suspected IPF) -0 ; conditionally for -0 ; strongly against -11 ; conditionally against -9 ; abstained - 1

\section{Commentary}

There is no need for assessing precipitins in all patients with a radiographic pattern corresponding to UIP. It is especially unjustifiable to perform a wide panel of all available tests (for instance, performing a test for farmer's lung in someone who has never had any contact with rural environment is aimless). In HP a potential role is played by antigens present in the domestic environment: avian antigens contained in bedding [180], nontuberculous mycobacteria [180] and fungal antigens [186]. For this reason, in justified cases, the domestic environment examination as well as choice of antibodies to test should above all take into account these antigen groups. However, detailed history taking is the most important element. It is justified to test for selected antibodies in the following situations: historical data pointing to possible exposure to antigens; presence of radiographic signs in HRCT suspicious of HP, such as ground glass, mosaic attenuation, air trapping; changes distributed predominantly in the upper and middle fields; young age of the patient; high lymphocyte percentage in BAL fluid [175, 177, 178, 187].

\section{Question 6. Should bronchoalveolar lavage (BAL) be performed in every patient with suspected IPF?}

\section{Introduction}

The cellular composition of BAL fluid in IPF patients does not have any characteristic features that would distinguish this disease entity from other ILDs [188]. Most patients are identified with an increased total cell count [189], increased neutrophil percentage $>5 \%$ [188, 190], increased eosinophil percentage $>2 \%$ [188], while the lymphocyte percentage is normal or slightly increased [188, 190]. Many authors point to a high lymphocyte percentage in BAL fluid (BALF) as a feature differentiating IPF from cHP [190, 191]. In a group of patients with ILDs it was observed that no IPF patient had a BALF lymphocyte percentage higher than $25 \%$ [190]. Another study demonstrated that a BALF lymphocyte percentage $>30 \%$ was the cause of changing the diagnosis from IPF to non-specific interstitial pneumonia (NSIP) or chronic cHP [191]. However, the BALF lymphocyte percentage in patients with chronic (fibrotic) HP can be normal, especially when exposure that caused the (now completed) disease occurred in the past. Other authors state that the BALF lymphocyte percentage in IPF patients can be increased and does not differentiate IPF patients from those with cHP. For instance, in one study $18 \%$ of patients with the final diagnosis of IPF (biopsy-confirmed) the BALF lymphocyte percentage was above $40 \%$ [188]. In studies by Vasakova et al., the BALF lymphocyte percentage did not differentiate IPF patients from those with cHP - in both disease entities the median was $22-23 \%$ [192]. The lack of differences in the lymphocyte percentage between patients with IPF and cHP is also referred to by the authors of the current international IPF guidelines who support it with meta-analysis results [29].

\section{Recommendation 6.}

We suggest that bronchoalveolar lavage (BAL) NOT be performed in every patient with suspected IPF.

The examination is not necessary in patients with a radiographic UIP pattern if the clinical context raises no doubt, but it can be helpful in differential diagnosis of ambiguous clinical or radiographic picture. 
Quality of evidence: very poor

Strength of recommendation: conditional

Votes: strongly for (performing BAL in all patients with suspected IPF) -0 ; conditionally for -2 ; strongly against -6 ; conditionally against -13 ; abstained -0

\section{Commentary}

If known causes of ILDs have been excluded and the radiographic image indicates UIP, the analysis of BALF cellular composition usually contributes little to the diagnosis. Even though an increased lymphocyte percentage decreases the likelihood of IPF diagnosis, it does not preclude it $[188,192]$. On the other hand, in cHP patients the likelihood of increased lymphocyte percentages in BALF decreases with fibrosis progression [190]. An increased lymphocyte percentage may, however, suggest an alternative diagnosis [in the context of IPF diagnosis this is usually cHP, NSIP (idiopathic or associated with CTD), much less frequently sarcoidosis, drug-induced changes or pneumoconioses]. If cHP is suspected, it is important to identify a potential antigen since its elimination from the environment can significantly alter the prognosis [176]. That is why patients with an increased lymphocyte percentage should undergo thorough assessment for environmental exposure.

The threshold value for lymphocytosis in BALF, which when exceeded should suggest a different diagnosis than IPF, is $25 \%$ according to the ATS/ERS guidelines dedicated to assessing the cellular composition of the BALF [193]. The current guidelines for IPF diagnosis of 2018 do not specify any cut-off value [29]. Exceeding the BALF eosinophil percentage above $25 \%$ can suggest acute or chronic eosinophilic pneumonia [193].

\section{Question 7. What is the role of a multidisciplinary team in diagnosing IPF and who should be part of such a team?}

\section{Introduction}

The current ATS/ERS/JRS/ALAT guidelines (2018) on IPF diagnosis attribute a very important role to a multidisciplinary discussion (MDD), which is suggested in case of every patient diagnosed for ILD of elusive aetiology, with a clinical suspicion of IPF [29]. The agreement between a single discipline decision (SDD) and one made through a MDD is assessed at $70 \%(47-87 \%)$ [194-198]. A MDD can prevent the initiation of inappropriate treatment, delay of the correct therapy or redundant but potentially dangerous diagnostic procedures [29, 199, 200].

A multidisciplinary team involved in IPF diagnosis should always include a clinician (pulmonologist) and radiologist as well as pathologist (in case of lung biopsy has been performed) all should be experienced in ILD diagnosis, and if needed, also a rheumatologist (possibility of CTD), occupational medicine specialist (potential environmental exposure), specialist in respiratory physiology, cardiologist (both helpful, for instance, in assessing the risk associated with invasive diagnosis) or another specialist whose assessment can be helpful in making diagnostic or therapeutic decisions [29, 87, 201-203]. A MDD in IPF diagnosis is of greatest importance when there is no unequivocal radiographic diagnosis of UIP (in HRCT) [29, 31, 204].

\section{Recommendation 7A.}

We recommended establishing the diagnosis in all patients diagnosed with signs of fibrosis due to ILD through a multidisciplinary discussion.

Quality of evidence: very poor

Strength of recommendation: strong

Votes: strongly for (arriving at ILD diagnosis through a multidisciplinary discussion) -13 ; conditionally for -7 ; strongly against -0 ; conditionally against -0 ; abstained -1

\section{Recommendation 7B.}

We recommend that a multidisciplinary team include at least a clinician (pulmonologist) and radiologist as well as pathologist (if lung biopsy has been performed). All team members should be experienced in the diagnosis of ILD.

Quality of evidence: very poor

Strength of recommendation: strong

Votes: strongly for (the recommended makeup of a multidisciplinary team) -11 ; conditionally for -8 ; strongly against -0 ; conditionally against -0 ; abstained -2

\section{Commentary}

The involvement of a MDD is considered the gold standard in the diagnostic process for IPF, especially in differentiation from other ILDs associated with fibrosis [1, 29, 31, 87, 201]. An appropriate assessment of the HRCT image forms the basis of IPF diagnosis. However, the 
consistency of change assessment in reference to the UIP pattern is moderate even among experienced radiologists (especially at an early stage of the disease). That is why patients diagnosed due to suspected IPF should be referred to reference centres capable of providing diagnosis by an experienced team of doctors and organising a MDD, which facilitates establishing an adequate management approach [200, 205-208]. Sometimes a discussion of this type, offering a broader perspective on the disease contexts, leads to changing a previously made diagnosis [195, 197]. In cases where the radiographic image does not meet all the UIP criteria but corresponds to the "probable UIP" pattern, with an appropriate clinical context and lack of other lung changes, a MDD can be helpful in arriving at a diagnosis with no need for invasive diagnostic methods [31, 104]. In other cases, IPF can be diagnosed based on a combination of specific HRCT patterns in relation to the pathomorphological picture and clinical context. In such situations, the involvement of a multidisciplinary team is also recommended [29]. If biopsy cannot be performed or the patient does not consent to it (in spite of existing indications), the diagnosis should be made through a MDD taking into account any clinical factors and available results of additional tests and examinations (BAL, serological tests and other deemed necessary). On this basis, depending on the likelihood of correct diagnosis, a decision can be taken to establish a final IPF diagnosis (if it is definite) or a temporary, "working" one (if not all formal requirements have been met) [59]. A MDD should occur both before making a decision to use invasive diagnosis and after receiving pathomorphological examination results for a lung fragment (if biopsy has been performed) in order to agree the most likely diagnosis and further management. The seemingly best way to conduct a MDD is direct confrontation of opinions, but a discussion through electronic means (telemedicine) is also acceptable $[31,59]$.

\section{Question 8. How to define disease progression?}

\section{Introduction}

Idiopathic pulmonary fibrosis is a disease characterised by progressive interstitial fibrosis [10]. Progression rate clearly affects the prognosis. The course of disease is difficult to predict and can range from slow worsening of lung function parameters in a span of many years to a dramatically fast progression, leading to death within several months of diagnosis [209-211]. In addition, the course can be complicated with an acute exacerbation, which is associated with an approximately 50\% mortality rate [38]. There are many ways to monitor progression, from assessment of symptom severity and quality of life through questionnaires [209], to evaluation of fibrosis progression in imaging examinations (assessment of variations in the nature and extent of changes visible in HRCT at different intervals) [179, 212, $213]$, to objective measurements of exercise capacity (e.g. changes of distance in the six minute walking test, 6MWT) [209], changes in the transfer factor of the lung for carbon monoxide $\left(\mathrm{T}_{\mathrm{L}, \mathrm{CO}}\right)$ and changes in vital capacity (usually forced vital capacity, FVC) [214, 215] within 6-12 months intervals. An absolute decline in FVC within 6 or 12 months expressed in \% of predicted is the most commonly used measure of progression. The reasons include the ease of measurement, repeatability of results and a documented relationship with prognosis [179, 214-219]. An absolute FVC decline during the study is the primary endpoint in all major clinical trials of antifibrotics [82, 83, $217,218,220,221]$. A decline in FVC $\geq 10 \%$ is a component of a composite endpoint (FVC decline or death) defining lack of treatment response [82, $222,223]$, and a lower rate of patients with a FVC decline $\geq 10 \%$ in the actively treated group compared with the placebo group proves the efficacy of a treatment [222-224].

\section{Recommendation 8.}

We suggest that forced vital capacity (FVC) decline rate be recognised as the basic measure of IPF progression. A loss $\geq 10 \%$ of predicted value within 12 months or less is considered clinically relevant.

\section{Quality of evidence: poor}

Strength of recommendation: conditional

Votes: strongly for (recognising the FVC decline rate as the basic measure of IPF progression) -8 ; conditionally for -9 ; strongly against -0 ; conditionally against -0 ; abstained -4

\section{Commentary}

There is no single ideal indicator that would define clinically relevant IPF progression. An absolute decline in FVC $\geq 10 \%$ from the baseline is the most commonly used, arbitrary measure of clinically relevant progression (which should not be confused with a clinically perceptible change) and is associated with a significantly higher risk of acute exacerbations and death. A comparison 
of two methods for calculating FVC decline (absolute decline, for instance from $80 \%$ to $70 \%$ of predicted vs relative decline by $10 \%$, for instance from $4.0 \mathrm{~L}$ to $3.6 \mathrm{~L}$, which with a predicted normal of 5.0 translates into a decline from $80 \%$ to $72 \%$ of predicted) indicates greater sensitivity of the relative index [225]. This means that thus defined number of patients with progression in a studied patient population will be higher, but there is also a risk of overestimating the percentage of patients with clinically relevant progression. Both methods are characterised by a comparable predictive value of progression-free survival, progression being defined as requirement of transplant or death [225]. Many authors point to the fact that a decline in the range from $\geq 5 \%$ to below $10 \%$ is also associated with a poorer distant prognosis [226, 227]. Another frequently used measure of progression is a decrease in $\mathrm{T}_{\mathrm{L}, \mathrm{CO}}$ $\geq 15 \%$ or shortening of distance in the $6 \mathrm{MWT}$ by $\geq 50 \mathrm{~m}$ [224, 228]. A possible alternative to individual functional indices is the composite physiologic index (CPI), which takes into account the FVC, $\mathrm{FEV}_{1}$ and $\mathrm{T}_{\mathrm{L}, \mathrm{CO}}$ values [222, 224, 229]. However, given the common use of spirometers, the ease of measurement, good repeatability as well as a well-documented relationship with prognosis, an absolute decline in FVC $\geq 10 \%$ within 12 months or less should be considered the basic measure of clinically relevant progression [230]. When assessing progression based on pulmonary function tests, it is important to use the same reference values. Currently, it is recommended to use the Global Lung Function Initiative (GLI) reference values [231, 232].

\section{PHARMACOLOGICAL TREATMENT}

\section{Question 9. Should IPF patients be treated with pirfenidone?}

\section{Introduction}

Pirfenidone is the first agent of antifibrotic agents to have been approved for IPF treatment. It's main mode of action is inhibition of fibroblast activity and type I collagen production by affecting TGF- $\beta$. The antifibrotic effects of this agent were initially demonstrated in non-randomised studies in the 1990s [233] and later confirmed in randomised, double-blind, placebo-controlled trials. The first studies performed in Japan demonstrated deceleration of FVC decline in treated patients compared with the placebo group. A decreased rate of AE-IPF was also observed in the treatment group, which however was not confirmed in further studies [234, 235]. The agent was approved based on the results of three international multi-centre, randomised studies, CAPACITY 1 and 2 and ASCEND, involving close to 1300 patients. The results of the CAPACITY 2 and ASCEND studies as well as a pooled analysis of all three trials confirmed the efficacy of the drug in patients with mild-to-moderate IPF. Patients with a severe form of the disease (FVC $<50 \%$ of predicted) were excluded from these trials. Deceleration of FVC decline rate of approximately $50 \%$ was demonstrated vs the placebo group, while a pooled analysis of patients in all three clinical trials demonstrated a reduction in the risk of death in the treatment group by almost $50 \%$ [81, 82]. Furthermore, post-hoc analyses of these trials in pirfenidone-treated patients revealed a reduced number of hospitalisations due to respiratory causes and a lower number of post-discharge deaths [236]. Pirfenidone also reduced worsening of dyspnoea, especially in patients with stages GAP II and GAP III, as well as severity of cough, one of the most bothersome symptoms experienced by IPF patients [223]. The proven benefits and safety of pirfenidone-based antifibrotic treatment allowed its approval for the treatment of IPF patients in 2011 in Europe and in 2014 in the US. The drug has received a conditional recommendation in the international IPF treatment guidelines, supporting its use in the treatment of IPF patients [75].

\section{Recommendation 9.}

We recommend the use of pirfenidone in IPF patients.

\section{Quality of evidence: moderate}

Strength of recommendation: strong

Votes: strongly for (the use of pirfenidone in IPF patients) - 13; conditionally for -6 ; strongly against -0 ; conditionally against -0 ; abstained -2

\section{Commentary}

The results of randomised, placebo-controlled studies as well as a pooled analysis of data gathered in these studies indicate that pirfenidone effectively slows down fibrosis progression in IPF patients [81, 82]. Pirfenidone is a safe drug, but one that can cause adverse effects. The most frequent ones include gastrointestinal symptoms (nausea, vomiting, lack of appetite, bodyweight loss) in approximately $20-40 \%$ of patients and 
skin changes, especially rash associated with exposure to sunlight (in approximately 10\%). An important but much less common treatment complication is elevated liver enzyme activity (approx. 3.5\% of treated patients). In most cases, these effects are observed within the first six months of treatment. Their severity can be reduced through appropriate patient education as well as using preventive means and symptomatic treatment. If necessary, it is possible to reduce the pirfenidone dose or transiently interrupt the treatment, with no negative effects on its efficacy [237]. PASSPORT, a study designed to assess long-term safety of pirfenidone, failed to reveal any new adverse effects of the drug in addition to those already observed in randomised trials [238]. Contraindications include individuals diagnosed with hypersensitivity to the active substance or to any of the excipients; patients with a history of angioedema following pirfenidone administration; cases where simultaneous use of fluvoxamine is necessary; serious hepatic dysfunction or end-stage liver disease; and serious renal dysfunction with endogenous creatinine clearance $<30 \mathrm{~mL} / \mathrm{min}$ or requiring dialysis therapy. The initiation of pirfenidone treatment should always be preceded by a discussion with the patient, explaining the benefits of the treatment but also the risk of adverse effects. A decision to start the treatment should be made jointly by the doctor and the patient.

\section{Question 10. Should IPF patients be treated with nintedanib?}

\section{Introduction}

Nintedanib is a non-selective tyrosine kinase receptor inhibitor. It acts by simultaneously inhibiting three growth factor receptor families involved in fibrogenesis and angiogenesis. These factors include platelet derived growth factor (PDGF), fibroblast growth factor (FGF) and vascular endothelial growth factor (VEGF) [239]. A clinical trial programme assessing the efficacy and safety of nintedanib in IPF treatment includes a phase 2 trial, TOMORROW [240], and two replicated phase 3 clinical trials - INPULSIS-1 and 2 [83], which collectively enrolled nearly 1,500 patients who were treated for 12 months. The INPULSIS studies confirmed the efficacy of the drug in reducing the rate of FVC decline in patients, irrespective of their baseline clinical characteristics or degree of lung dysfunction (FVC $>v s<70 \%$ of predicted). The FVC loss observed during follow-up in the nintedanib-treated group was lower by approximately 50\% than in the placebo group [241]. A pooled analysis of data, complemented with a meta-analysis of the above three randomised trials of nintedanib in the treatment of IPF patients, additionally demonstrated that nintedanib treatment was associated with a reduction in the risk of an acute exacerbation of the disease (AE-IPF) by $47 \%$ compared to placebo, a trend towards reduced all-cause mortality and mortality due to respiratory causes as well as a significant reduction in mortality during treatment [221]. At the same time, an acceptable safety profile of the treatment was observed. Long-term observational studies confirm the efficacy and safety of nintedanib treatment in IPF patients [242]. The proven benefits and safety of nintedanib-based antifibrotic treatment allowed its approval for the treatment of IPF patients in 2014 in the US and in 2015 in Europe. The drug has received a conditional recommendation in the international IPF treatment guidelines, supporting its use in the treatment of IPF patients [75].

\section{Recommendation 10.}

We recommend the use of nintedanib in IPF patients.

Quality of evidence: moderate

Strength of recommendation: strong

Votes: strongly for (the use of nintedanib in IPF patients) - 13; conditionally for -6 ; strongly against -0 ; conditionally against -0 ; abstained -2

\section{Commentary}

A programme of randomised, placebo-controlled clinical studies [83, 221, 240] as well as long-term observational studies [242] confirms the beneficial effects of nintedanib on slowing down IPF progression and an acceptable safety profile of the treatment. The beneficial effect of the drug is comparable across all analysed subgroups of studied subjects [241]. Nintedanib reduces the risk of AE-IPF, at the same time demonstrating a trend towards reduction of the risk of death [221]. This data supports the use of nintedanib in antifibrotic treatment of IPF patients. The main adverse effects reported by patients during nintedanib treatment include diarrhoea, nausea, abdominal pain and vomiting [83, 240, 242]. Diarrhoea observed during treatment responds well to symptomatic treatment (loperamide), a temporary interruption of treatment or dose reduction. Liver function should be assessed before starting nintedanib and monitored during the treatment. The drug 
should not be used in patients with liver injury (Child-Pugh classes B and C) and severe kidney failure. Since the drug's mode of action involves the VEGF receptor, caution is recommended when treating patients with a history of cardiovascular diseases or increased risk of bleedings. Patients with a history of myocardial infarction or unstable angina pectoris in the last six months, and those receiving intensive antiplatelet treatment ( $>325 \mathrm{mg}$ /day of acetylsalicylic acid or $>75 \mathrm{mg} /$ /day of clopidogrel) or full anticoagulation therapy were not enrolled into randomised clinical studies of nintedanib. Nevertheless, no contraindication for nintedanib treatment in this patient population has been formulated, and a decision to start this treatment should be based on an analysis of the benefit-risk balance [243]. The initiation of nintedanib treatment should always be preceded by a discussion with the patient, explaining the benefits of the treatment but also the risk of adverse effects. A decision to start the treatment should be made jointly by the doctor and the patient.

\section{Question 11. Can IPF patients be treated simultaneously with pirfenidone and nintedanib?}

\section{Introduction}

The necessity of exerting pharmacological action on different profibrotic signalling pathways as a result of the multifactorial and complex pathogenesis of IPF suggest that better outcomes could be achieved with combination therapy. In recent years, several studies have been published assessing the safety, tolerability and pharmacokinetics of combination therapy with pirfenidone and nintedanib in IPF patients [244-247]. In a randomised, double-blind phase 2 study conducted in a small group of $50 \mathrm{IPF}$ patients, Ogura et al. $[30,57]$ demonstrated that combination therapy with pirfenidone and nintedanib had acceptable safety and tolerability profiles, which was confirmed in other studies [245-247]. A Japanese study, however, revealed reduced values of the peak serum plasma concentration and area under the curve (AUC) of nintedanib when it was used simultaneously with pirfenidone [244]. However, further studies of the pharmacokinetics and safety of combination therapy with pirfenidone and nintedanib failed to reveal any pharmacokinetic interactions between these agents [245-247]. No randomised studies assessing the efficacy of combination therapy with pirfenidone and nintedanib compared with monotherapy with either of the agents have been performed to date. Vancheri et al. only observed a trend towards a lower FVC decline in a group receiving simultaneous treatment with nintedanib and pirfenidone, compared with a group treated with nintedanib alone [245].

\section{Recommendation 11.}

Currently, we DO NOT recommend simultaneous use of pirfenidone and nintedanib in IPF patients.

Quality of evidence: very poor

Strength of recommendation: strong

Votes: strongly for (simultaneous use of pirfenidone and nintedanib in IPF patients) -0 ; conditionally for -2 ; strongly against -8 ; conditionally against -7 ; abstained -4

\section{Commentary}

There is scarce data on simultaneous treatment with pirfenidone and nintedanib in IPF patients. Different modes of action and targets of pirfenidone and nintedanib suggest the possibility of further deceleration of FVC decline with their simultaneous use in the treatment of IPF. By contrast, in the case of combination therapy, there is a threat of unexpected or previously not observed toxicity as well as an increased risk of adverse effects, which partially overlap in the case of pirfenidone and nintedanib, especially as regards gastrointestinal disorders and increased liver enzyme activity [81-83, 240]. The currently available studies of the safety and tolerability of combination treatment with these drugs covering a period of only 12 to 24 weeks have failed to reveal any new, unexpected adverse effects, and most patients completed the planned combination therapy [245, 246]. Given small study populations, a short duration of combination therapy assessment and lack of randomised studies of the efficacy of simultaneous treatment with nintedanib and pirfenidone as well as the high costs of simultaneous treatment with the two drugs, combination therapy only should be used within randomised clinical trials.

\section{Question 12. Should patients diagnosed with IPF based on the clinical context and the "probable UIP" pattern in lung HRCT be treated with antifibrotic agents?}

\section{Introduction}

Data on the efficacy and safety of antifibrotic treatment in IPF patients with the probable UIP pattern in lung HRCT are significantly limited. 
This is because this term was introduced into clinical practice in 2018 [29, 31], after randomised phase 3 clinical trials of antifibrotics had been conducted. The terminology of radiographic patterns was based at that time on the international guidelines for IPF diagnosis of 2011 [10], which did not differentiate the probable UIP pattern. Nevertheless, patients with a pattern of reticular changes characterised by basal and peripheral distribution (formerly, "possible UIP”) associated with peripheral traction bronchiectasis or bronchiolectasis suggestive of a fibrotic process but without the typical honeycombing in lung HRCT, which corresponds, in line with the current nomenclature, to the "probable UIP" pattern [29, 31], were enrolled into randomised phase 3 studies using nintedanib in IPF patients (approx. $30 \%$ of subjects) [83]. A subgroup analysis taking into account clinical characteristics and results of pulmonary function examinations demonstrated consistent effects of nintedanib in this patient group (without honeycombing in imaging) and the group of patients with "definite UIP" (presence of honeycombing) in lung HRCT [248]. There is currently no data assessing the effects of pirfenidone in IPF patients with the "probable UIP" pattern in lung HRCT. However, observational retrospective studies of IPF patients treated with pirfenidone indicate lack of differences in the effect on decelerated FVC decline between IPF patients with the "typical UIP" and "possible UIP" lung HRCT patterns [249] according to the nomenclature of radiographic patterns used in the previous international guidelines for IPF diagnosis of 2011 [10].

\section{Recommendation 12.}

We suggest that patients with IPF diagnosis established by a multidisciplinary team based on the clinical context and the probable UIP pattern in lung HRCT be started on antifibrotic agents.

\section{Quality of evidence: very poor}

\section{Strength of recommendation: conditional}

Votes: strongly for (starting treatment with antifibrotic agents in patients with the probable UIP pattern) -2 ; conditionally for -15 ; strongly against -0 ; conditionally against -1 ; abstained -3

\section{Commentary}

Retrospective analyses of randomised and observational studies demonstrated that reticular changes distributed peripherally and subpleu- rally associated with traction bronchiectasis or bronchiolectasis but without honeycombing in lung HRCT, identified as "possible UIP" [10] or "probable UIP" [29, 31], in patients with an appropriate clinical context are very likely to represent the histopathological pattern of UIP in biopsy material. When assessing the probability of the histopathological UIP pattern in these patients, it is helpful to take into account the clinical probability of IPF, which is higher in individuals above 60 years of age, current or former tobacco smokers and persons with no history indicative of other potential causes of lung fibrosis [29]. In the above context and in light of the evolving diagnostic recommendations on IPF, it seems justified to start antifibrotic treatment in patients with a diagnosis based solely on clinical assessment and the "probable UIP" pattern in lung HRCT. Out of the two drugs, nintedanib has better quality evidence for the efficacy of antifibrotic treatment in this patient population [248].

\section{Question 13. Should IPF patients with mildly decreased or normal pulmonary function parameters be treated with antifibrotic agents?}

\section{Introduction}

This problem has important implications for the efficacy and tolerability of the treatment. In most countries it is recommended to start treatment on diagnosis, irrespective of symptoms or the degree of lung dysfunction. This is associated with inevitable disease progression whose rate is unpredictable. However, the randomised clinical trials enrolled patients with specific demographic and functional profiles, which makes extending their results to the general population more challenging.

The CAPACITY and ASCEND studies involved patients whose FVC was at least $50 \%$ of predicted and not above $90 \%$. In a post-hoc analysis of these studies, the subjects were assigned into subgroups depending on the degree of disease advancement: FVC $<80 \%$ of predicted (GAP II and III) or $\geq 80 \%$ (GAP I). An analysis of the placebo group revealed that disease progression was seen in patients with both higher and lower functional parameters. In the group receiving active treatment, patients of both subgroups experienced comparable benefits of using pirfenidone in terms of FVC decline rate and distance in the walking test [223, 250]. Japanese studies demonstrated that the greatest benefit of pirfenidone treatment was seen among patients 
with better preserved lung function (FVC $\geq 70 \%$ of predicted). Patients with less advanced stage of IPF more frequently maintained stable lung function, with less common worsening during pirfenidone treatment than patients with lower baseline lung function parameters [251-253]. The INPULSIS studies did not use the exclusion criterion of the upper limit of FVC\% of predicted. In these studies, an efficacy assessment was planned in pre-defined subgroups, for instance in individuals with FVC $\geq 70 \%$ and $<70 \%$. Equal treatment outcomes were demonstrated in patients with both lower and higher FVC values. In addition, post-hoc analyses demonstrated that nintedanib was equally efficacious in patients with FVC $>90 \%$ and $<90 \%$ [241, 254]. The INPULSIS-ON study, in which patients continued taking nintedanib for up to 192 weeks, also failed to reveal any differences in the therapeutic effect depending on the degree of FVC decline.

\section{Recommendation 13.}

We suggest that antifibrotic treatment be proposed to IPF patients with mildly decreased or normal pulmonary function parameters.

Quality of evidence: very poor

Strength of recommendation: conditional

Votes: strongly for (antifibrotic treatment of IPF patients with mildly decreased or normal respiratory functional parameters) -2 ; conditionally for -16 ; strongly against -0 ; conditionally against -0 ; abstained -3

\section{Commentary}

In each case before treatment is started, the benefits of the therapy and risk of adverse effects should be discussed with the patient. Antifibrotic agents slow down IPF progression while decreasing the rate of FVC decline. Thus, it seems logical to start the treatment when the lung capacity is still well preserved. However, treatment can be problematic to patients who do not experience any disease symptoms. An especially concerning aspect is the risk of adverse effects which can lower the quality of life. It is important to inform the patient about the nature of the disease, with its unpredictable course and the possibility that the rate of vital capacity decline increases at any moment. The patient should also be advised that even persons with low disease activity lose more FVC a year than healthy individuals [255]. In some situations, especially in patients who have been diagnosed incidentally, without any clinical symptoms and with normal functional test results, a decision can be made jointly with the patient to use the "watch and wait approach". In such a case, however, lung function should be monitored regularly (every 3-6 months) and treatment should be started immediately after worsening is observed [87, 203, 256, 257]. Means of coping with adverse effects of the treatment should be discussed with the patient in particular detail. Given the possibility that a patient with normal results of lung function test may receive an antifibrotic for many years, it is necessary to inform them how they can reduce possible adverse effects.

\section{Question 14. Should IPF patients with severe lung function impairment (FVC $<50 \%$ of predicted, $T_{L, C O}<30 \%$ of predicted) be treated with antifibrotic agents?}

\section{Introduction}

Randomised phase 3 clinical trials of pirfenidone (CAPACITY 004 and 006 and ASCEND) [81, 82] and nintedanib (INPULSIS 1 and 2) [83] did not enroll patients with advanced IPF and serious lung dysfunction (FVC $<50 \%$ of predicted, $\mathrm{T}_{\mathrm{L}, \mathrm{CO}}$ $<30 \%$ of predicted). Data on the efficacy and safety of antifibrotic agents in IPF patients with severe lung function impairment (FVC $<50 \%$ of predicted, $\mathrm{T}_{\mathrm{L}, \mathrm{CO}}<30 \%$ of predicted) are indeed limited. Nevertheless, an increasing body of evidence from observational studies using antifibrotic agents in this patient population indicates they have similar efficacy and adverse reaction profiles as those observed in pre-marketing randomised clinical trials [253, 258-263]. This data supports antifibrotic treatment in IPF patients outside the range of pulmonary function parameters that was used in the inclusion criteria of randomised studies assessing the use of pirfenidone and nintedanib in IPF.

\section{Recommendation 14.}

We suggest that antifibrotic treatment following IPF diagnosis be proposed to all patients without contraindications for this treatment, irrespective of the degree of lung function impairment.

Quality of evidence: very poor

Strength of recommendation: conditional

Votes: strongly for (antifibrotic treatment of IPF patients irrespective of the degree of 
lung dysfunction) - 3; conditionally for -13 ; strongly against -0 ; conditionally against -3 ; abstained -2

\section{Commentary}

A sudden decline in lung function or AE-IPF can occur at any stage of the natural history of the disease. Data from randomised clinical trials and observational studies involving the population of IPF patients indicate that antifibrotic agents are efficient in slowing down progressive lung function decline, irrespective of the baseline degree of respiratory dysfunction [81-83, 241, 250, 253, 258-263]. The decision-making process regarding the initiation of pharmacotherapy should take into account the patient's treatment preferences. Patients should be informed about the anticipated disease course as well as the benefits and potential risks associated with starting antifibrotic treatment. Discussing the treatment limitations and achievable goals is especially important. It is key for the patient to understand that pharmacological treatment will not improve lung function but only slow down disease progression and that the patient will likely fail to experience much improvement in terms of disease symptoms and quality of life. The choice of an antifibrotic agent for IPF treatment should take into account the patient's individual preferences, comorbidities and concomitant treatment. Patients with serious comorbidities associated with a poor prognosis and short life expectancy will most likely not benefit from antifibrotic treatment.

\section{Question 15. Is disease progression an indication for discontinuation of antifibrotic treatment?}

\section{Introduction}

IPF is a chronic progressive disease and the currently used antifibrotic treatment offer no curative potential but only deceleration of disease progression [81-83, 240]. Based on clinical trials, it was assumed that an absolute FVC decline by $\geq 10 \%$ indicates insufficient treatment response. On this basis different local regulations and guidelines recommend discontinuation of pirfenidone or nintedanib in case of disease progression, i.e. an FVC decline by $\geq 10 \%$, within 12 months of treatment [82]. The published pooled data from the CAPACITY and ASCEND trials provided evidence that continuation of pirfenidone treatment is beneficial to IPF patients who have experienced significant disease progression during treatment (defined as an FVC decline by $\geq 10 \%$ within 6 months of treatment), in the form of a reduced risk of further FVC decline or death [264]. Similar pooled data from the INPULSIS I and II studies, suggestive of treatment benefits despite reduced FVC, are available for nintedanib [265]. A recently published study assessed the frequency of multiple disease progression events within 12 months. The progression events were defined as a relative reduction in FVC by $\geq 10 \%$ of predicted, absolute reduction of distance in the 6MWT by $\geq 50 \mathrm{~m}$, hospitalisations due to respiratory cause or death of any cause. It was demonstrated that pirfenidone significantly reduced the frequency of multiple progression events or death after any progression event within 12 months of treatment versus placebo [266]. The above study results suggest that continued antifibrotic treatment benefits IPF patients despite disease progression during the treatment.

\section{Recommendation 15.}

We suggest that disease progression NOT be an indication for discontinuation of antifibrotic treatment.

\section{Quality of evidence: poor}

Strength of recommendation: conditional

Votes: strongly for (recognising disease progression as an indication for discontinuing antifibrotic treatment) -0 ; conditionally for -2 ; strongly against -5 ; conditionally against -11 ; abstained -3

\section{Commentary}

Currently, there is no unambiguous, commonly accepted definition of disease progression and, consequently, of antifibrotic treatment failure. The assessment of antifibrotic treatment efficacy in clinical trials was based on a longterm analysis of FVC, although it is known that this parameter is characterised by a certain intrapersonal variability. In addition to pulmonary function parameters ( $\mathrm{FVC}, \mathrm{T}_{\mathrm{L}, \mathrm{CO}}$ ) a comprehensive assessment of the disease course should take into account other parameters, such as clinical symptoms (dyspnoea, cough, exercise capacity, etc.), possible complications (such as exacerbations, hospitalisations, pulmonary hypertension) or imaging examination results (HRCT). In a pooled analysis of the CAPACITY and ASCEND trials, Nathan et al. confirmed that FVC in longterm follow-up of IPF patients is characterised by a marked intrapersonal variability, which prevents a reliable assessment of therapeutic response using a series of FVC measurements 
[264]. In addition, it should be stressed that even though a decline in FVC by $\geq 10 \%$ is indisputably significant, it does not prove lack of treatment efficacy. This is because it cannot be ruled out that a much larger FVC decline would have been observed if no treatment had been provided. The presented results of a pooled analyses of the above clinical trials proved that disease progression in IPF patients undergoing antifibrotic treatment should not be interpreted as treatment failure leading to discontinuation as long as tolerability is satisfactory [265]. No data is currently available on whether it is more beneficial to continue the same treatment or switch agents in case of disease progression. In case of further deterioration of respiratory function, it is recommended to refer the patient to a transplant centre unless contraindications for lung transplant exist [264, 266].

\section{Question 16. In what situations should one consider switching from one antifibrotic agent to the other?}

\section{Introduction}

It was demonstrated that both pirfenidone and nintedanib slow down IPF progression expressed as a reduced FVC decline over time. However, no head-to-head trials comparing both agents have been conducted to date [82, 83]. The choice between the two drugs is, therefore, based on the experience of the treating pulmonologist, contraindications and adverse effect profile of a given antifibrotic, concomitant use of other drugs and possible interactions as well as the patient's preferences. A possible justification of switching one drug for the other is the development of unacceptable adverse effects or lack of efficacy. This, however, must be adjudicated with great caution. The problem of defining IPF progression during antifibrotic treatment is discussed in Question 8. Treatment-related adverse events for pirfenidone and nintedanib partially overlap, especially as regards the gastrointestinal system (nausea, vomiting, diarrhoea) or increased liver enzyme activity as well as bodyweight loss. On the other hand, pirfenidone is additionally associated with skin adverse effects such as rash or photosensitivity reaction. Adverse effects associated with antifibrotic treatment are usually mild to moderate and adequate management (dose reduction, short treatment interruption or symptomatic management) makes it possible to continue the treatment in most patients. Clinical studies suggest that treatment-related adverse events were the cause of discontinuation in 15\% of pirfenidone-treated [82] and 19\% of nintedanib-treated cases [83]. The availability of two antifibrotic agents makes it possible to switch between the treatments in certain cases. Data on the switching of antifibrotic agents is limited and it pertains to switching from pirfenidone to nintedanib due to adverse effects or disease progression [267-269]. The above studies indicate that in selected patients who do not tolerate pirfenidone treatment, switching to nintedanib can be associated with good tolerability of the treatment in spite of the similar adverse effect profiles of both agents. It was additionally observed that individual responses to treatment with any of the drugs can differ. It was demonstrated that patients who were stable during the treatment with one of the antifibrotic agents experienced progression when using the other [268].

\section{Recommendation 16.}

We suggest switching from one antifibrotic agent to the other in case of significant lack of tolerance or adverse effects.

\section{Quality of evidence: very poor}

Strength of recommendation: conditional

Votes: strongly for (changing an antifibrotic agent in case of intolerance or adverse effects) 4; conditionally for -15 ; strongly against -0 ; conditionally against -0 ; abstained -2

\section{Commentary}

The first drug to have been approved in the treatment of IPF in Europe was pirfenidone. This happened in 2011 [270], after the publication of the CAPACITY study results [82]. That is why most patients in many centres providing IPF treatment were at first qualified for this treatment. The second agent to have been approved for IPF treatment in Europe was nintedanib, in 2015. This posed several important questions to pulmonologists, for instance, which of the agents should be used first and when switching from one agent to the other should be considered. Long-term open-label studies, pooled analyses of earlier randomised clinical studies and real-world data confirmed the beneficial safety and tolerability profiles of both pirfenidone [237, 238, 271, 272] and nintedanib [242, 267]. However, in a certain percentage of patients - in spite of dose adjustments, interruptions or symptomatic management - the treatment is discontinued because of persistent adverse effects. Despite the partial overlapping of the adverse effects of pirfenidone and nintedanib, different pharmacodynamic and 
pharmacokinetic properties of the agents make it possible to switch the treatment safely in selected patients [242, 267]. No data on switching from nintedanib to pirfenidone has been published to date. Studies analysing nintedanib treatment in patients previously treated with pirfenidone additionally revealed there was an intrapersonal variability of responses to treatment, from stable to progressive disease, depending on the agent used [268]. In case of adverse effects preventing the use of one of the antifibrotic agents or disease progression, it seems worthwhile to consider switching from one antifibrotic to the other after assessing the anticipated risks and benefits and discussing it with the patient. In order to answer the question whether switching from one agent to the other in case of disease progression could be beneficial to IPF patients, prospective, randomised clinical trials are necessary.

\section{Question 17. Should all IPF patients be treated with anti-acid agents?}

\section{Introduction}

It is known that an increased frequency of gastroesophageal reflux disease (GERD) is observed in IPF patients. Studies have revealed that more than a half of patients with acid reflux experience symptoms of the disease. However, the severity of the gastroesophageal reflux (GER) is not correlated with severity of IPF. Moreover, in more than $60 \%$ of patients receiving standard anti-reflux treatment (AAT), episodes of low oesophageal $\mathrm{pH}$ are still observed [41]. Discussions about the causal relationship between GERD and IPF are ongoing [17]. The use of agents inhibiting hydrochloric acid secretion (proton pump inhibitor (PPIs), H2 blockers) in IPF patients has been an object of interest for years. PPIs are drugs of pleiotropic properties. In vitro studies demonstrated that they inhibit pro-inflammatory cytokines, adhesive molecules and metalloproteinases and induce cytoprotective enzymes, at the same time inhibiting fibroblast proliferation and decreasing collagen production stimulated by TGF- $\beta$ [273]. Thus, the effect of PPIs in IPF patients is not necessarily linked with suppression of acidic GER but with additional anti-inflammatory and antifibrotic effects of these agents. The results of several retrospective studies indicate a longer survival in IPF patients taking AAT [274, 275] as well as a lower rate of FVC decline and reduction in acute exacerbations [276]. A meta-analysis of 13 observational studies assessing the effects of pharmacological treatment of reflux disease on the course of IPF demonstrated that using agents reducing gastric acid secretion caused a significant reduction in IPF-associated mortality as well as prolonged survival without lung transplant. However, no influence on all-cause mortality or pulmonary function parameters was observed. On the other hand, in patients with FVC $<70 \%$ of predicted a significant increase in the incidence of respiratory infections was observed. No randomised, placebo-controlled study was found that would assess the effects of anti-reflux treatment on the course of IPF. Therefore, the results of this meta-analysis should be interpreted with caution [277]. In addition, in some observational studies the presence of so-called immortal time bias was demonstrated - in order to undergo assessment, the subjects had to survive until the endpoint, which created a false impression of the drug's protective properties [278]. Despite numerous controversies and lack of randomised trials assessing their efficacy, the international guidelines of 2015 conditionally recommend regular use of AAT in IPF treatment, regardless of GERD symptoms [75].

\section{Recommendation 17.}

We suggest that anti-acid agents in IPF patients NOT be used in absence of other indications for such treatment.

\section{Quality of evidence: very poor}

Strength of recommendation: conditional

Votes: strongly for (the use of anti-acid agents in IPF patients without indications for such treatment) -0 ; conditionally for -0 ; strongly against -1 ; conditionally against -17 ; abstained -3

\section{Commentary}

Post-hoc analyses of randomised clinical studies of using pirfenidone and nintedanib in IPF treatment were free of immortal time bias and yielded opposite results on the protective role of AAT. Among IPF patients who received pirfenidone as part of three clinical phase 3 trials, nearly $44 \%$ took also agents inhibiting hydrochloric acid secretion. No differences were observed in any of endpoints assessing IPF progression between groups treated with PPIs and those not receiving this treatment. On the other hand, PPI-treated patients presented with more serious gastrointestinal adverse effects [228]. Similarly, an analysis of the placebo-treated groups in these same randomised trials failed to demonstrate any difference in the number of deaths, hospitalisations or FVC decline rate. An insignificantly higher rate of 
infections, including respiratory infections, was observed in patients receiving PPIs [75]. Patients participating in the INPULSIS studies, irrespective of whether they were taking or not agents reducing hydrochloric acid secretion, were found to exhibit no changes in the natural history of the disease (placebo group) or the effect of these agents on nintedanib efficacy. Similarly to pirfenidone studies, an insignificantly higher rate of respiratory infections was observed in patients receiving PPIs [279]. The treatment of cough associated with IPF is a separate issue. Cough is known to be one of the most bothersome and most difficult-to-treat IPF symptoms. GERD can exacerbate cough. A single-centre, randomised, double-blind, placebo-controlled clinical trial was conducted to assess the efficacy of omeprazole in reducing cough episodes in IPF patients. A $39 \%$ decline in the rate of cough attacks was demonstrated in the omeprazole-treated group. No changes were observed in FVC, $\mathrm{T}_{\mathrm{L}, \mathrm{CO}}$ or quality of life assessments during three months of follow-up. The study results can support the efficacy of omeprazole in managing cough in IPF patients and indicate a need of additional, multicentre trials with larger patient populations [280].

\section{Question 18. Should N-acetylcysteine be used in IPF treatment?}

\section{Introduction}

$\mathrm{N}$-acetylcysteine (NAC) is a drug of antioxidant properties, a precursor of glutathione which is the basic endogenous antioxidant. In vitro and animal studies indicated that NAC inhibited the profibrotic effects of TGF- $\beta$ on tissues and transformation of epithelial cells into mesenchymal cells [281, 282]. For this reason, it was believed that NAC use in IPF patients in whom the TGF- $\beta$ action is an important disease mechanism would result in suppression of fibrosis and improvement in lung function parameters. The recommendations for NAC use in IPF patients were based on the results of the IFIGENIA study, which demonstrated that patients receiving NAC in combination with prednisone and azathioprine had a lower FVC decline during 12 months of treatment than placebo-treated patients. In addition, lower myelotoxicity of immunosuppressive treatment was seen in these patients, albeit with no differences in survival [283]. The results of the IFIGENIA study led to widespread use of triple instead of double therapy in IPF patients. In order to assess the efficacy of NAC monotherapy compared with triple therapy, the PANTHER-IPF study was desi- gned. In this study, patients received NAC alone, placebo or NAC, prednisone and azathioprine. The PANTHER-IPF study demonstrated that triple treatment is associated with higher mortality and hospitalisation rate than NAC or placebo, and for this reason the study was discontinued [67]. However, the comparison of the placebo group with NAC monotherapy group was continued and no significant differences in the course of IPF were seen in the two patient groups [284]. Subgroup analysis assessing the influence of polymorphisms of single TOLLIP genes demonstrated that patients with the TT genotype of the rs3750920 gene (TOLLIP) can benefit from NAC treatment, but NAC administration in patients with the CC genotype is associated with worsening of lung function. Therefore, the use of NAC in IPF patients should be preceded by a polymorphism analysis of the TOLLIP gene [285].

\section{Recommendation 18.}

We recommend that $\mathrm{N}$-acetylcysteine NOT be used in the treatment of IPF patients, either as monotherapy or in combination with other agents.

\section{Quality of evidence: poor}

Strength of recommendation: strong

Votes: strongly for (the use of $\mathrm{N}$-acetylcysteine in IPF patients) -0 ; conditionally for -0 ; strongly against -11 ; conditionally against -6 ; abstained -4

\section{Commentary}

There are contradicting reports on combination therapy with NAC and pirfenidone. One Japanese study that enrolled patients with advanced disease who had experienced FVC decline $\geq 10 \%$ within 6 months preceding the study demonstrated that the add-on of inhaled NAC caused deceleration of FVC decline rate compared with a group taking pirfenidone alone. However, it was a casecontrol study and the study population was very small [286]. In another study, among patients with an early IPF form, the efficacy of inhaled NAC was observed in individuals with FVC $<95 \%$ of predicted and $\mathrm{T}_{\mathrm{L}, \mathrm{CO}}<55 \%$ of predicted [287]. On the other hand, the PANORAMA study, a multicentre, double-blind, placebo-controlled study involving 123 IPF patients, failed to reveal any positive effect of administering oral NAC at a dose of $3 \times$ $600 \mathrm{mg}$ in combination with pirfenidone. NAC failed to improve pirfenidone tolerability, and in the group receiving both agents, FVC decline was even higher than in the pirfenidone monotherapy 
group [288]. The most recent recommendations for the treatment of IPF [75] sustained the earlier position on NAC treatment as contraindicated in most IPF patients. The use of NAC would be justified in patients with the TT genotype of the TOLLIP gene, although targeted therapy is not currently used.

\section{Question 19. Should IPF patients receive immunosuppressive treatment?}

\section{Introduction}

The initial concept of the disease process involved in IPF as having a largely inflammatory nature led to the use of immunosuppressive treatment. In the past, immunosuppressive treatment was considered an important element of IPF management and recommended in the first international diagnostic and therapeutic recommendations [9]. Despite the widespread past use of glucocorticosteroids (GCS) in IPF treatment, there are no randomised, placebo-controlled trials of adequate quality that would support their use in this indication [289]. In a similar vein, a systematic review of studies using other nonsteroidal immunosuppressive drugs, such as cyclophosphamide, azathioprine (AZA) or interferon- $\gamma$, failed to demonstrate their beneficial effects in the treatment of IPF patients [290]. Moreover, the once widely used triple treatment with prednisone, AZA and NAC proved to be associated with higher rates of hospitalisations and deaths compared with placebo [67]. Based on the current international IPF treatment guidelines, immunosuppressants received a strong recommendation against their use in the treatment of IPF patients [75].

\section{Recommendation 19.}

We recommend that NO type of immunosuppressive treatment be used in IPF patients.

\section{Quality of evidence: poor}

Strength of recommendation: strong

Votes: strongly for (the use of immunosuppressive treatment in IPF patients) - 0 ; conditionally for -0 ; strongly against -12 ; conditionally against -6 ; abstained -3

\section{Commentary}

Attempts at using immunosuppressant in the treatment of IPF patients have been made in the past usually in relation to the original theory which linked the pathobiology of IPF at least in part with inflammation. Few available studies, often of low quality, failed to demonstrate any benefit of such an approach. However, many adverse effects associated with this treatment were demonstrated and even, as in the case of triple treatment (GCS + AZA + NAC), an increased risk of death in actively treated patients [67]. Given lack of evidence confirming any benefits and observed toxicity, the use of immunosuppressive treatment in IPF should be considered harmful and inconsistent with evidence-based medicine [289, 290].

\section{Question 20. Should agents dedicated to treating pulmonary hypertension be used in IPF patients?}

\section{Introduction}

Pulmonary hypertension, defined as mean pulmonary artery pressure $\geq 25 \mathrm{~mm} \mathrm{Hg}$, is frequent in IPF patients, especially in an advanced stage of the disease or in case of concomitant emphysema [291, 292]. At diagnosis, approximately 8-15\% patients have concomitant pulmonary hypertension [46, 293], and this percentage reaches $30-50 \%$ during qualification for transplant [292, 294, 295]. The presence of pulmonary hypertension in IPF patients is associated with increased mortality, more severe dyspnoea, decreased exercise tolerance, $\mathrm{T}_{\mathrm{L}, \mathrm{CO}}$ impairment, more severe hypoxaemia and increased risk of an AE-IPF [294, 296]. Several randomised clinical trials assessed treating IPF patients with different drugs used in pulmonary hypertension but yielded negative results. As regards the treatment of IPF-associated pulmonary hypertension, lack of efficacy was demonstrated in the case of dual endothelin receptor antagonists (bosentan and macitentan) [76, 77, 297]. The selective antagonist ambrisentan, assessed in the ARTEMIS-IPF study and the terminated ARTEMIS-PH study, demonstrated lack of efficacy in the treatment of pulmonary hypertension and increased the frequency of hospitalisations due to respiratory causes [70]. A phase 2 study of riociguat, a soluble guanylate cyclase stimulator, in ILDs with symptomatic pulmonary hypertension was also preliminary terminated due to an increased risk of death and other serious adverse events in the riociguat-treated group vs placebo [298]. In a randomised controlled trial STEP-IPF of phosphodiesterase- 5 inhibitor, sildenafil, used in patients with advanced IPF, defined as $\mathrm{T}_{\mathrm{L}, \mathrm{CO}}$ $<35 \%$ of predicted, the primary endpoint, i.e. a significant increase of distance in the 6MWT, was not met [78]. On the other hand, in the sil- 
denafil-treated group a significant improvement vs placebo was demonstrated in terms of secondary endpoints, i.e. dyspnoea severity, quality of life, blood oxygen saturation and $\mathrm{T}_{\mathrm{L}, \mathrm{CO}}$. Based on this encouraging data, the INSTAGE study was conducted in patients with advanced IPF. The study analysed the efficacy and safety of nintedanib in combination with sildenafil compared with nintedanib and placebo [299]. However, no significant benefits of combination therapy with nintedanib and sildenafil were demonstrated compared with nintedanib monotherapy in this population of IPF patients. The only treatment currently recommended by the European Society of Cardiology/European Respiratory Society (ESC/ /ERS) for pulmonary hypertension in correlation with IPF involves long-term oxygen therapy, treatment of comorbidities and referring the patient to a transplant centre if no contraindications are present [300].

\section{Recommendation 20.}

We suggest that agents dedicated to treating pulmonary hypertension NOT be used in IPF patients.

Quality of evidence: very poor

Strength of recommendation: conditional

Votes: strongly for (the use of agents dedicated to treating pulmonary hypertension in IPF patients) -0 ; conditionally for -1 ; strongly against -3 ; conditionally against -13 ; abstained -4

\section{Commentary}

Coexistence of pulmonary hypertension in IPF patients is a well-defined prognosis-worsening factor in this serious disease. A retrospective analysis of IPF patients who underwent right heart catheterisation as part of pre-lung transplant assessments demonstrated higher annual mortality ( $28 \%$ vs $5,5 \%)$ in the group of patients with pulmonary hypertension compared with those without pulmonary hypertension [294]. Despite many clinical randomised trials assessing the efficacy of different drug classes used in the treatment of pulmonary hypertension, no beneficial effects have been yet demonstrated in the case of IPF patients with concomitant pulmonary hypertension. The most encouraging results came from the STEP-IPF study (improvement only in terms of secondary endpoints), which enrolled 180 patients with advanced IPF [78]. In addition, data from the international COMPERA registry confirmed short-term functional improvement in certain patients treated with agents dilating pul- monary vessels, mostly phosphodiesterase-5 inhibitors [301]. Unfortunately, these results have not been yet confirmed in large randomised clinical trials. Therefore, agents dilating pulmonary vessels are not recommended for routine use in IPF patients associated with pulmonary hypertension outside of randomised clinical trials. There is an ongoing study of sildenafil added to pirfenidone treatment (clinicaltrials.gov NCT02951429) in patients with probable pulmonary hypertension assessed non-invasively [302].

\section{NON-PHARMACOLOGICAL TREATMENT AND PALLIATIVE CARE}

\section{Question 21. Should pulmonary rehabilitation be used in IPF patients?}

\section{Introduction}

Pulmonary rehabilitation is a complex intervention based on thorough assessment of the patient's condition, adjusted to their individual capabilities and involving training, education and shaping of appropriate health-promoting behaviours. It is aimed at improving the patients' physical and mental fitness and long-term compliance with the aforementioned behaviours [303]. The beneficial effect of rehabilitation in IPF patients has been documented in many prospective, non-randomised observational studies [304-310] and numerous randomised trials [311-318]. A 2014 meta-analysis of 5 randomised studies (86 patients with ILDs, including IPF, undergoing rehabilitation and 82 non-rehabilitated patients comprising the control group) confirmed the beneficial effects of rehabilitation on distance in the 6MWT, peak oxygen uptake, dyspnoea severity and quality of life, with lack of adverse effects [319]. The most recent meta-analyses of 5 randomised trials involving more than 130 IPF patients divided into a group of subjects receiving rehabilitation and a control group demonstrated an improvement in exercise tolerance, reduction of symptoms and quality of life improvement [320]. Another meta-analysis of 4 randomised trials (a total of 142 subjects) confirmed beneficial short-term effects of rehabilitation on exercise capacity and quality of life but failed to confirm any distant effects [321]. The most recent meta-analysis of 7 studies involving 190 IPF patients demonstrated improved exercise capacity measured as distance in the 6MWT and improved quality of life [322]. Pulmonary rehabilitation involves the following: physical exercises (aerobic, endu- 
rance and flexibility exercises as well as arm and inspiratory muscle training), education (symptom management, oxygen therapy optimisation, selfcare), optimisation of nutrition and psychosocial support [323]. A rehabilitation programme should be started in a specialist pulmonary rehabilitation centre, in the inpatient or outpatient setting, and led and supervised by adequately prepared medical staff [324]. Attempts should be made to continue the programme at home. Supervised home rehabilitation, with optional use of telemedicine, can be an alternative to the traditional method [325].

\section{Recommendation 21.}

We recommend the use of pulmonary rehabilitation in IPF patients.

Quality of evidence: moderate

Strength of recommendation: strong

Votes: strongly for (the use of pulmonary rehabilitation in IPF patients) - 15; conditionally for -5 ; strongly against -0 ; conditionally against -0 ; abstained -1

\section{Commentary}

The authors of the international guidelines for IPF diagnosis and treatment of 2011 recommend pulmonary rehabilitation in IPF patients (weak recommendation, very poor evidence quality), concluding that rehabilitation should be used in most IPF patients, but it may be appropriate to forgo it in a minority of them [10]. The update of treatment guidelines of 2015 does not pertain to pulmonary rehabilitation of IPF patients [75]. However, a majority of randomised trials were published after 2011 [311-314, 317]. Currently, the amount and quality of evidence should be considered sufficient to recommend pulmonary rehabilitation in IPF patients as an important component of treatment. The question of precise identification of patients who can benefit most from it still needs to be elucidated. Many authors stress the validity of initiating rehabilitation in an early period of the disease [307, 308], although greater early effects are achieved in patients with more advanced disease [313]. Another issue is one associated with individualisation and standardisation of the rehabilitation programme, taking into account the patient's capabilities and preferences and resulting, among others, from the degree of functional impairment, need for oxygen therapy and comorbidities. Another controversial question is that of the duration of the effects of rehabilitation, since many authors claim that the effects last up to 6 [307, 313, 321], 11 [326] or even 12 months [325] after completing the programme, while others do not confirm its lasting beneficial effects in a longer term [315, 321]. Lack of unequivocal data confirming distant effect indicates it is necessary to use rehabilitation in a continuous and systematic way.

\section{Question 22. Should long-term oxygen therapy (LTOT) be used in patients with respiratory failure in the course of IPF?}

\section{Introduction}

Sings of chronic hypoxaemic respiratory failure occur in IPF patients at a late stage of the disease. This is when one should consider indications for long-term home oxygen therapy (LTOT). However, there is no unambiguous evidence confirming the efficacy of LTOT in IPF patients. The studies conducted to date have only demonstrated a shorter survival in oxygen-treated patients due to respiratory failure in the course of ILD compared with COPD [327]. The cited studies were not randomised and contained no comparative groups, so the impact of LTOT on survival cannot be directly assessed. Recently published qualitative studies point to the fact that some IPF patients using LTOT reported improvement [328, 329]. Others complained about the bothersomeness of this type of treatment and the limitations in everyday life it causes [329].

\section{Recommendation 22.}

We recommend using long-term oxygen therapy (LTOT) in patients with chronic respiratory failure in the course of IPF.

\section{Quality of evidence: very poor}

Strength of recommendation: strong

Votes: strongly for (the use of long-term oxygen therapy in IPF patients with chronic respiratory failure) -15 ; conditionally for -5 ; strongly against -0 ; conditionally against -0 ; abstained -1

\section{Commentary}

This recommendation is in line with the position presented in the international ATS/ ERS/JRS/ALAT recommendations of 2011 (strong recommendation, very poor quality of evidence) [10]. There is limited data supporting the beneficial effects of LTOT in patients with respiratory failure in the course of IPF, so this recommen- 
dation stems from medical knowledge of the pathophysiology of respiration and the established clinical management of respiratory failure. Above all, the authors took into account the results of studies confirming the efficacy of chronic oxygen therapy in patients with other chronic lung diseases, including COPD. The recommendation does not contradict recommendations in guidelines by working groups or pulmonology societies published after 2011 [87, 330, 331]. The authors of the ATS/ ERS/JRS/ALAT guidelines (2011) failed to specify unambiguously the qualification criteria for LTOT, leaving this to the treating doctor's discretion [10]. The authors of Swiss [87], Japanese [330] and Australian [331] guidelines recommend LTOT in IPF patients diagnosed with resting hypoxaemia $\left(\mathrm{PaO}_{2} \leq 55 \mathrm{~mm} \mathrm{Hg}\right.$ or $\mathrm{PaO}_{2}<60 \mathrm{~mm} \mathrm{Hg}$ if one of the following signs is present: signs of pulmonary hypertension, signs of right ventricular hypertophy, polyglobulia). The patient should use oxygen for at least 15 hours a day and for the entire night.

\section{Question 23. Should oxygen be used during exercise in IPF patients?}

\section{Introduction}

The course of IPF involves limitation of exercise tolerance with concomitant shortness of breath, caused by insufficient amounts of oxygen delivered in relation to the demand. Reduced everyday physical activity and dyspnoea affect the patient's quality of life and prognosis [332]. Exertional desaturation and increased oxygen demand during exercise are negative prognostic factors for mortality and disease progression [333-335]. The use of oxygen therapy during exercise can reduce dyspnoea and improve physical capacity. However, there is an insufficient number of studies confirming the beneficial effects of oxygen therapy during exercise in IPF patients with exertional hypoxaemia. In a meta-analysis of three cross-over studies comparing the effects of oxygen and air from a portable oxygen source, two studies failed to confirm any benefits of oxygen therapy [336]. The third study [337] demonstrated improved oxygen saturation but with no effect on perceived dyspnoea. Another study demonstrated reduced dyspnoea, improved capacity and decreased desaturation degree in patients receiving oxygen during exercise, with high oxygen concentrations in inspiratory air $\left(\mathrm{FiO}_{2}\right.$ $>0.50$ ) [338]. In another randomised, cross-over, two-week, prospective trial comparing the effects of two-week oxygen therapy using a portable oxygen source with a period without oxygen therapy in IPF patients with latent hypoxaemic respiratory failure, oxygen therapy was found to have a beneficial effect on the quality of life [339]. Oxygen therapy using a portable oxygen source does not reduce exercise-induced increase in pulmonary artery pressure [340].

\section{Recommendation 23}

We suggest using oxygen during exercise in IPF patients with dyspnoea and exertional desaturation.

\section{Quality of evidence: very poor}

Strength of recommendation: conditional

Votes: strongly for (the use of oxygen during exercise in IPF patients with dyspnoea and exertional desaturation) -5 ; conditionally for -13 ; strongly against -0 ; conditionally against -0 ; abstained -3

\section{Commentary}

According to the authors of the British Thoracic Society (BTS) guidelines, oxygen from a portable source should not be routinely used in patients who do not qualify for home oxygen therapy or those who already receive this treatment chronically [341]. It should, however, be recommended to LTOT patients who are still involved in outdoor activities as well as patients participating in pulmonary rehabilitation programmes if improved physical capacity has been demonstrated as a result of using a portable oxygen source [341]. The AmbOx trial results suggest that, compared with lack of oxygen therapy, the use of oxygen from portable sources during exercise decreases desaturation and dyspnoea during exercise and also improves the quality of life in patients with ILDs, without resting hypoxaemia [339]. When recommending the use of oxygen from portable sources, one should remember the costs and physical strain associated with carrying or pulling an oxygen-delivering device as well as the need for frequent refilling [342]. Therefore, it is necessary to perform further studies assessing the efficacy of oxygen therapy in patients with exertional hypoxaemia. It is recommended to perform an individual assessment of potential benefits based on objective examinations.

\section{Question 24. Should preventive vaccinations be used in IPF patients?}

\section{Introduction}

The elderly, especially patients with chronic lung diseases, contracting flu or pneumococcal pneumonia, are at a high risk of death. This 
can be avoided through preventive vaccinations [343-345]. The Polish recommendations suggest vaccinating individuals above the age of 50 against pneumococci, stressing the fact that pneumococcal pneumonia in persons additionally affected by chronic lung disease is much more frequent, i.e. five times more frequent in IPF patients [346]. At the same time, we should remember that IPF by definition refers to people after the age of 50 and its incidence increases with age [4, 5, 347]. In line with the WHO guidelines, Poland's National Flu Centre (Krajowy Ośrodek ds. Grypy) recommends flu vaccinations in all individuals aged 6 months and more, especially in populations at the highest risk of flu or its serious complications. This group, similarly to pneumococcal pneumonia, includes the elderly and patients with chronic lung diseases [348]. Given the marked antigen variability of the influenza virus, every year a new vaccine is produced. Its aim is to protect the patient from flu and the serious consequences of its possible complications in the upcoming epidemiological season.

\section{Recommendation 24.}

We recommend use of pneumococcal and flu vaccinations in IPF patients.

\section{Quality of evidence: very poor}

Strength of recommendation: strong

Votes: strongly for (the use of protective vaccinations in IPF patients) - 13; conditionally for - 6 ; strongly against -0 ; conditionally against -0 ; abstained -2

\section{Commentary}

Patients with IPF are at a higher risk of pneumococcal pneumonia and flu as well as serious complications of these diseases. It is important to note that IPF patients' breathing reserves are limited to varying degrees. In individuals with a markedly lowered FVC and/or significantly impaired carbon monoxide diffusion indicated by $\mathrm{T}_{\mathrm{L}, \mathrm{CO}}$, a sudden further worsening of these parameters caused by bacterial or viral pneumonia can lead to acute respiratory failure necessitating invasive mechanical ventilation or even a life-threatening condition. Additionally, respiratory infection can be a factor causing an AE-IPF [349-351], according to the current definition of this condition [38]. It is associated with high mortality and can occur at any stage of the disease, even in asymptomatic patients who only have radiographic changes [210, 352]. Infection prevention should all the more comprise an important element of managing IPF patients. According to the current guidelines by the Centers for Disease Control and Prevention (CDC) [353] and Polish expert recommendations by the Polish Nationwide Flu Prevention Programme (Ogólnopolski Program Zwalczania Grypy) on flu prophylaxis [354], flu vaccination should be performed once a year, while a conjugated PVC13 vaccine against pneumococci requires a single administration. It is recommended to perform an additional pneumococcal vaccination with a polysaccharide PPSV23 vaccine after one year [353].

\section{Question 25. Should patients with advanced IPF be referred to palliative care centres?}

\section{Introduction}

The main objective of palliative care is to achieve the best possible quality of life in patients whose disease is not effectively treated with causal treatment [355, 356]. One of such diseases is IPF. As demonstrated by studies assessing the use of pirfenidone or nintedanib in IPF treatment, a specific therapy can slow down the course of the disease, but it reduces clinical symptoms only to a small extent [81, 83]. These symptoms (dyspnoea, cough, anxiety, depression, chronic fatigue) can at the same time affect the quality of life irrespective of the degree of disease advancement [357]. In addition to alleviating the somatic complaints as well as mental and spiritual suffering, comprehensive palliative care activities include also good communication with the patient and their family, help in solving social problems, affirmation of life with accepting death as a natural process, constant care until death and caution taken not to prolong the passing persistently. The international ATS/ERS/JRS/ ALAT guidelines for the treatment of IPF patients explicitly recommend palliative care targeted at symptoms (palliation) as a mandatory component, complementary to specific (antifibrotic) treatment targeted at the underlying disease [10]. Such care should be offered to the patient at least from the moment the disease enters the advanced stage or the first life-threatening exacerbation occurs [331, 358, 359]. In advanced and terminal IPF stages patient care should be provided by trained multidisciplinary teams of home and inpatient care. It is believed that the best form of palliative care in this period is home care. 


\section{Recommendation 25.}

We suggest that patients with advanced IPF be referred to palliative care centres.

Quality of evidence: very poor

Strength of recommendation: conditional

Votes: strongly for (referring patients with advanced IPF to palliative care centres) -9 ; conditionally for -9 ; strongly against -0 ; conditionally against -0 ; abstained -3

\section{Commentary}

Idiopathic pulmonary fibrosis patients, especially with advanced disease, can suffer from difficult-to-treat symptoms, such as dyspnoea, cough, fatigue or anxiety [360]. These symptoms significantly reduce the quality of life, irrespective of objective physiological parameters of the disease advancement. At the same time, patients experience a lot of spiritual suffering, being aware of the progression of the incurable disease and inevitability of death. Improvement of patients' quality of life at this stage can be best provided in a comprehensive way by specialist palliative care centres. Although no direct medical evidence is present (EBM, evidence-based medicine) supporting the benefits of palliative treatment in IPF, it is indirectly provided by extrapolation of results from studies of other advanced chronic lung diseases [361, 362]. However, compared for instance with lung cancer patients, IPF patients have limited access to palliative care [363]. It needs to be emphasised that care offered by palliative care centres should be individualised - adjusted to the patient's as well as caregivers' needs [10]. At present, palliative care options in the context of IPF patient care in Poland are severely limited. This is caused, above all, by an insufficient number of centres and lack of nursing personnel dedicated to caring for patients with ILDs.

\section{Question 26. Should morphine be used in palliative treatment?}

\section{Introduction}

Dyspnoea is a defensive mechanism leading to increased ventilation and improved respiratory gas exchange. It is also the most important symptom contributing to a poor quality of life in IPF patients [364]. Opioids have been demonstrated to decrease shortness of breath significantly in patients with chronic respiratory diseases, including IPF. They improve breathing comfort, exert anxiolytic action by decreasing the level of dyspnoea-associated anxiety and have a positive effect on sleep quality. The opioid of choice in the treatment of dyspnoea in patients with respiratory diseases is oral morphine, initially administered in an immediate-release form and, after the optimum daily dose has been established, also in a controlled-release form [365-370]. However, there is no unequivocal evidence for the efficacy of morphine inhaled from a nebuliser, despite hypothetical benefits of morphine acting on the peripheral receptors and lack of systemic adverse effects with this mode of administration [371].

\section{Recommendation 26.}

We suggest using oral morphine in patients with severe IPF in palliative treatment of persisting dyspnoea.

Quality of evidence: very poor

Strength of recommendation: conditional

Votes: strongly for (the use of morphine in patients with severe IPF) -6 ; conditionally for -11 ; strongly against -0 ; conditionally against -0 ; abstained -4

\section{Commentary}

Morphine dosage should be decided on an individual basis, discussed with the patient and their family and strictly monitored. It is important to note that elderly, emaciated or benzodiazepine-treated patients or those with concomitant COPD are more susceptible to opioid action, and administration of morphine in patients with hypercapnia is associated with a risk of respiratory centre depression. The starting oral morphine dose of $2.5 \mathrm{mg}$, administered as frequently as every 4 hours, can be safely used in IPF patients and gradually increased every couple of days until optimum effects are achieved [372]. This approach to morphine dose titration until reaching the optimum daily dose, even one exceeding $30 \mathrm{mg}$, is not associated with sedative effects or respiratory depression [373]. There is, however, a possibility of a significant problem in the form of constipation during opioid treatment. Therefore, it is important to administer laxative or stool-loosening agents, such as senna or lactulose [374].

\section{Question 27. Should invasive ventilation be used in IPF patients with acute respiratory failure?}

\section{Introduction}

AE-IPF is defined as clinically relevant worsening of respiration characterised by the pre- 
sence of new extensive changes in the alveoli in a patient with an existing or new IPF diagnosis. This deterioration cannot be explained by circulatory failure or overhydration and is characterised by unexplained dyspnoea (exacerbation or $d e$ novo), typically lasting for $<1$ month [38]. There are no unequivocal recommendations for effective management both in the case of a known cause and an acute exacerbation in an IPF patients if the event is associated with life-threatening hypoxaemia. The choice of therapeutic methods is limited to invasive ventilation, non-invasive ventilation (NIV) support, extracorporeal membrane oxygenation (ECMO) or administration of oxygen through a high-flow nasal cannula (HFNC) [375]. Idiopatic pulmonary fibrosis patients admitted to intensive care units due to acute respiratory failure who require mechanical ventilation are burdened with a poor prognosis and high mortality [376]. In these patients no improvement has been demonstrated in terms of survival or distant prognosis. Therefore, it is generally recommended to avoid this type of treatment in IPF patients, except for a situation where it is possible to perform lung transplant in a short time (bridge therapy) [377].

\section{Recommendation 27}

We suggest that invasive ventilation NOT be used in IPF patients with acute respiratory failure.

\section{Quality of evidence: poor}

Strength of recommendation: conditional

Votes: strongly for (the use of invasive ventilation in IPF patients) - 0 ; conditionally for -0 ; strongly against -6 ; conditionally against -12 ; abstained -3

\section{Commentary}

An alternative to mechanical ventilation can be non-invasive ventilation (NIV). In a retrospective study by Vianello et al., NIV use was associated in selected IPF patients with clinical benefits, such as longer survival and decreased rate of complications, including death [378]. Similarly, Gungor et al. [379] demonstrated that the use of NIV in IPF and other ILDs is associated with a better overall prognosis, although a higher mortality rate was observed in patients requiring continuous NIV use. Retrospective studies indicate higher mortality in patients who have undergone invasive ventilation compared with those treated with NIV [380, 381].

\section{Question 28. Should IPF patients be referred to lung transplant centres and if so, when?}

\section{Introduction}

The use of antifibrotic agents can slow down lung function decline. However, irrespective of whether such a treatment is used, the natural history of this disease inevitably leads to the development of respiratory failure, secondary pulmonary hypertension and death. Furthermore, this prognosis is worsened by coexistence of other chronic diseases, especially cardiovascular, and the presence of AE-IPF. If all suggested methods of both non-pharmacological and pharmacological treatment have been attempted, the only possible form of therapeutic management that could potentially improve the quality of life and prolong survival is lung transplant. The consensus report of the International Society for Heart and Lung Transplantation (ISHLT) specifies potential candidates for lung transplant as adult patients with a chronic lung disease in its end stage who additionally have a high risk of death within two years if no transplant is performed and, at the same time, are characterised by a high probability of survival after the procedure [382]. An important and beneficial global trend is the observed continuous increase in the number of lung transplant procedures [383]. IPF holds an important place among indications for lung transplant. On the other hand, considering the unfavourable prognosis associated with IPF (median survival of 2-3 years since diagnosis and 20-30\% 5-year survival [10]) as well as lack of both causal treatments and therapies that would significantly modify survival, lung transplant will still hold an important place in the therapeutic strategy of this disease. It is also worth noting that since the Lung Allocation Score (LAS) was introduced in the US, pulmonary fibrosis has overtaken COPD as the main transplant category as regards the relative priority assigned for the distribution of lungs available for transplantation.

\section{Recommendation 28A}

We recommend referring to lung transplant centres all IPF patients without contraindications for the procedure.

Quality of evidence: poor

Strength of recommendation: strong

Votes: strongly for (referring all IPF patients without contraindications for lung transplant to transplant centres) -14 ; conditionally for -5 ; 
strongly against -0 ; conditionally against -1 ; abstained -1

\section{Commentary}

Given the fact that IPF is a progressive disease, irrespective of whether antifibrotic treatment is started, we can assume that referring all IPF patients to lung transplant centres is a valid approach unless they have contraindications for the procedure. The validity of performing lung transplants in patients with lung fibrosis is supported by literature data. However, the evidence is associated with significant limitations, mainly the retrospective design of studies or heterogeneity of groups caused by enrolment of patients with lung fibrosis forms other than IPF. In a single-centre study of 46 IPF patients, Thabut et al. reported a survival rate of $79.4 \%$ in the first, $63.5 \%$ in the second and $39 \%$ in the fifth year following lung transplant. A multivariate analysis revealed, after adjusting for potential confounding variables, that lung transplant reduced the risk of death by $75 \%$ (95\% CI: $8-86 \%$; $p=0,03$ ). Median organ wait time in this study was 51 days [384]. Other trials report a five-year survival of as much as $50-56 \%[385,386]$. These include a study by Keating et al., who demonstrated a more favourable long-term prognosis in IPF compared with other indications for lung transplant. Despite a clear tendency towards a higher number of bilateral transplants [383], the question of whether one or both lungs should be routinely transplanted in IPF remains open. The results of studies analysing the benefits and risks of both procedures are varied [387-398] and make it impossible to adopt an unambiguous position. Therefore, this decision needs to be taken on an individual basis for each patient. In addition, it should be noted that unilateral transplantation is associated with an undoubted benefit in terms of managing organs for transplantation and that bilateral transplant is associated with a longer wait time [391].

\section{Recommendation 28B}

We suggest referring IPF patients to lung transplant centres immediately after the disease is diagnosed.

\section{Quality of evidence: very poor}

Strength of recommendation: conditional

Votes: strongly for (referring IPF patients to transplant centres immediately after diagnosis) 7 ; conditionally for -12 ; strongly against -0 ; conditionally against -0 ; abstained -2

\section{Commentary}

The times of referral and inclusion in the waitlist are clearly specified in the ISHLT consensus [382]. Patients should be referred to a transplant centre when at least one of the following criteria is met:

1. A histopathological or radiographic pattern warranting the diagnosis of UIP or fibrotic NSIP, irrespective of lung function.

2. Lung function impairment: FVC $<80 \%$ of predicted or $\mathrm{T}_{\mathrm{L}, \mathrm{CO}}<40 \%$ of predicted.

3. Any dyspnoea or functional limitation associated with lung disease.

4. Any requirement of oxygen, including situations when oxygen is needed only during exercise.

5. For ILD, inability to improve dyspnoea, oxygen demand and/or lung function after causal treatment.

On the other hand, including a patient in the waitlist is recommended when at least one of the following criteria is met:

1. An FVC decline $\geq 10 \%$ during a 6 -month follow-up (a decline of $5 \%$ is also associated with a poorer prognosis and can be a basis to include in the list).

2. A decline in $\mathrm{T}_{\mathrm{L}, \mathrm{CO}}>15 \%$ within 6 months of follow-up.

3. Desaturation $<88 \%$ or distance $<250 \mathrm{~m}$ in the $6 \mathrm{MWT}$ or a decline in distance $>50 \mathrm{~m}$ in the 6MWT during 6 months of follow-up.

4. Pulmonary hypertension diagnosed based on heart catheterisation or 2D echocardiography.

5. Hospitalisation due to impairment of respiratory parameters, pneumothorax or disease exacerbation

It is clear from these recommendations that the mere diagnosis of the UIP pattern is an indication for referral to a lung transplant centre. In addition, the validity of early referrals of patients to such a centre is supported by literature data which indicate higher mortality in IPF patients waiting for transplantation [384, 391]. The position that patients should be referred to transplant centres is also in line with the current ATS/ERS/JRS/ALAT guidelines [29].

\section{Author disclosure}

WJP was supported by Roche and Boehringer Ingelheim with travel grants, received fees for participation in advisory boards, and fees for lectures, took part in clinical trials for Roche and Boehringer Ingelheim, and was supported by research grants sponsored by Roche and 
Boehringer Ingelheim; IB received fees for lectures from Roche and Boehringer Ingelheim; AJB was supported by Roche and Boehringer Ingelheim with travel grants; PWB was supported by Roche and Boehringer Ingelheim with travel grants and received fees for lectures; PG declares no conflict of interest; EJ was supported by Roche and Boehringer Ingelheim with travel grants, received fees for participation in advisory boards, and fees for lectures, took part in clinical trials for Roche, Boehringer Ingelheim, and Avalyn Pharma, and was supported by educational grants sponsored by Roche and Boehringer Ingelheim; DJ was supported by Roche and Boehringer Ingelheim with travel grants, and received fees for for lectures; DK declares no conflict of interest; RL was receiving fees for lectures from Roche; KL was supported by Roche and Boehringer Ingelheim with travel grants, received fees for participation in advisory boards, and fees for lectures, took part in clinical trials for Roche, Boehringer Ingelheim, and was supported by research grants sponsored by both companies; SM was supported by Roche and Boehringer Ingelheim with travel grants, received fees for participation in advisory boards, and fees for lectures, took part in clinical trials for Roche, Boehringer Ingelheim, Gilead and Avalyn Pharma, and was supported by research grants sponsored by Roche and Boehringer Ingelheim; MMMB was supported by Roche and Boehringer Ingelheim with travel grants, received fees for participation in advisory boards, and fees for lectures; KO declares no conflict of interest; EP received fees for lectures from Roche and Boehringer Ingelheim; AS was supported by Roche and Boehringer Ingelheim with travel grants, received fees for lectures, and was supported by research grants sponsored by both companies; MS was supported by Roche and Boehringer Ingelheim with travel grants, and received fees for lectures, took part in clinical trials sponsored by Roche and Boehringer Ingelheim; MSz received fees for lectures and workshops from Roche and Boehringer Ingelheim; EW was supported by Roche and Boehringer Ingelheim with travel grants, received fees for participation in advisory boards, and fees for lectures; $\mathbf{G W}$ declares no conflict of interest; DZ was supported by Roche and Boehringer Ingelheim with travel grants, and received fees for lectures; JK was supported by Roche and Boehringer Ingelheim with travel grants, received fees for participation in advisory boards, and fees for lectures, took part in clinical trials for Roche, Boehringer Ingelheim.

\section{References:}

1. Travis WD, Costabel U, Hansell DM, et al. An official American Thoracic Society/European Respiratory Society statement: Update of the international multidisciplinary classification of the idiopathic interstitial pneumonias. Am J Respir Crit Care Med. 2013; 188(6): 733-748, doi: 10.1164/rccm.201308-1483ST, indexed in Pubmed: 24032382.

2. Lederer DJ, Martinez FJ. Idiopathic pulmonary fibrosis. N Engl J Med. 2018; 378(19): 1811-1823, doi: 10.1056/NEJMra1705751, indexed in Pubmed: 29742380.

3. Coultas DB, Zumwalt RE, Black WC, et al. The epidemiology of interstitial lung diseases. Am J Respir Crit Care Med. 1994; 150(4): 967-972, doi: 10.1164/ajrccm.150.4.7921471, indexed in Pubmed: 7921471.

4. Gribbin J, Hubbard RB, Le Jeune I, et al. Incidence and mortality of idiopathic pulmonary fibrosis and sarcoidosis in the UK. Thorax. 2006; 61(11): 980-985, doi: 10.1136/thx.2006.062836, indexed in Pubmed: 16844727.

5. Raghu G, Weycker D, Edelsberg J, et al. Incidence and prevalence of idiopathic pulmonary fibrosis. Am J Respir Crit Care Med. 2006; 174(7): 810-816, doi: 10.1164/rccm.200602-163OC, indexed in Pubmed: 16809633.

6. Szafrański W. Interstitial lung diseases among patients hospitalized in the Department of Respiratory Medicine in Radom District Hospital during the years 2000--2009. Pneumonol Alergol Pol. 2012; 80(6): 523-532, indexed in Pubmed: 23109204.

7. Kuś J, Wiatr E. Samoistne włóknienie płuc - jak często występuje i dlaczego należy do chorób sierocych (orphan diseases). In: Samoistne włóknienie płuc - aspekty kliniczne, ekonomiczne i systemowe. Biała Księga. Warszawa, Instytut Zarządzania w Ochronie Zdrowia 2015.

8. Schoenheit G, Becattelli I, Cohen AH. Living with idiopathic pulmonary fibrosis: an in-depth qualitative survey of European patients. Chron Respir Dis. 2011; 8(4): 225-231, doi: 10.1177/1479972311416382, indexed in Pubmed: 21856780.

9. American Thoracic Society. Idiopathic pulmonary fibrosis: diagnosis and treatment. International consensus statement. American Thoracic Society (ATS), and the European Respiratory Society (ERS). Am J Respir Crit Care Med. 2000; 161(2 Pt 1): 646-664, doi: 10.1164/ajrccm.161.2.ats3-00, indexed in Pubmed: 10673212.

10. Raghu G, Collard HR, Egan JJ, et al. An official ATS/ERS/JRS/ ALAT statement: idiopathic pulmonary fibrosis: evidence-based guidelines for diagnosis and management. Am J Respir Crit Care Med. 2011; 183(6): 788-824, doi: 10.1164/rccm.2009040GL, indexed in Pubmed: 21471066.

11. Ueda T, Ohta K, Suzuki N, et al. Idiopathic pulmonary fibrosis and high prevalence of serum antibodies to hepatitis $C$ virus. Am Rev Respir Dis. 1992; 146(1): 266-268, doi: 10.1164/ajrccm/146.1.266, indexed in Pubmed: 1320820.

12. Egan JJ, Stewart JP, Hasleton PS, et al. Epstein-Barr virus replication within pulmonary epithelial cells in cryptogenic fibrosing alveolitis. Thorax. 1995; 50(12): 1234-1239, doi: 10.1136/ thx.50.12.1234, indexed in Pubmed: 8553293.

13. Wangoo A, Shaw RJ, Diss TC, et al. Cryptogenic fibrosing alveolitis: lack of association with Epstein-Barr virus infection. Thorax. 1997; 52(10): 888-891, doi: 10.1136/thx.52.10.888, indexed in Pubmed: 9404376.

14. Tang YW, Johnson JE, Browning PJ, et al. Herpesvirus DNA is consistently detected in lungs of patients with idiopathic pulmonary fibrosis. J Clin Microbiol. 2003; 41(6): 2633-2640, doi: 10.1128/ jcm.41.6.2633-2640.2003, indexed in Pubmed: 12791891.

15. Lasithiotaki I, Antoniou KM, Vlahava VM, et al. Detection of herpes simplex virus type-1 in patients with fibrotic lung diseases. PLoS One. 2011; 6(12): e27800, doi: 10.1371/journal. pone.0027800, indexed in Pubmed: 22205929.

16. Downing L, Sawarynski KE, Li J, et al. A simple quantitative method for assessing pulmonary damage after $\mathrm{x}$ irradiation. Radiat Res. 2010; 173(4): 536-544, doi: 10.1667/RR1712.1, indexed in Pubmed: 20334526.

17. Lee JS, Collard HR, Raghu G, et al. Does chronic microaspiration cause idiopathic pulmonary fibrosis? Am J Med. 2010; 
123(4): 304-311, doi: 10.1016/j.amjmed.2009.07.033, indexed in Pubmed: 20362747.

18. Barros A, Oldham J, Noth I. Genetics of idiopathic pulmonary fibrosis. Am J Med Sci. 2019; 357(5): 379-383, doi: 10.1016/j. amjms.2019.02.009, indexed in Pubmed: 31010464.

19. Talbert JL, Schwartz DA, Steele MP. Familial interstitial pneumonia (FIP). Clin Pulm Med. 2014; 21(3): 120-127, doi: 10.1097/cpm.0000000000000034, indexed in Pubmed: 25506193.

20. Seibold MA, Wise AL, Speer MC, et al. A common MUC5B promoter polymorphism and pulmonary fibrosis. N Engl J Med. 2011; 364(16): 1503-1512, doi: 10.1056/NEJMoa1013660, indexed in Pubmed: 21506741.

21. Kaur A, Mathai SK, Schwartz DA. Genetics in idiopathic pulmonary fibrosis pathogenesis, prognosis, and treatment. Front Med (Lausanne). 2017; 4: 154, doi: 10.3389/fmed.2017.00154, indexed in Pubmed: 28993806.

22. Wuyts WA, Cavazza A, Rossi G, et al. Differential diagnosis of usual interstitial pneumonia: when is it truly idiopathic? Eur Respir Rev. 2014; 23(133): 308-319, doi: 10.1183/09059180.00004914, indexed in Pubmed: 25176967.

23. Wolters PJ, Blackwell TS, Eickelberg O, et al. Time for a change: is idiopathic pulmonary fibrosis still idiopathic and only fibrotic? Lancet Respir Med. 2018; 6(2): 154-160, doi: 10.1016/ S2213-2600(18)30007-9, indexed in Pubmed: 29413083.

24. Alder JK, Chen JJL, Lancaster L, et al. Short telomeres are a risk factor for idiopathic pulmonary fibrosis. Proc Natl Acad Sci U S A. 2008; 105(35): 13051-13056, doi: 10.1073/ pnas.0804280105, indexed in Pubmed: 18753630.

25. Snetselaar R, van Batenburg AA, van Oosterhout MFM, et al. Short telomere length in IPF lung associates with fibrotic lesions and predicts survival. PLoS One. 2017; 12(12): e0189467, doi: 10.1371/journal.pone.0189467, indexed in Pubmed: 29281671

26. McDonough JE, Martens DS, Tanabe N, et al. A role for telomere length and chromosomal damage in idiopathic pulmonary fibrosis. Respir Res. 2018; 19(1): 132, doi: 10.1186/s12931-0180838-4, indexed in Pubmed: 29986708.

27. Dai J, Cai H, Zhuang Yi, et al. Telomerase gene mutations and telomere length shortening in patients with idiopathic pulmonary fibrosis in a Chinese population. Respirology. 2015 20(1): 122-128, doi: 10.1111/resp.12422, indexed in Pubmed: 25346280 .

28. Ghavami S, Yeganeh B, Zeki AA, et al. Autophagy and the unfolded protein response promote profibrotic effects of TGF- $\beta$ in human lung fibroblasts. Am J Physiol Lung Cell Mol Physiol. 2018; 314(3): L493-L504, doi: 10.1152/ajplung.00372.2017, indexed in Pubmed: 29074489.

29. Raghu G, Remy-Jardin M, Myers JL, et al. Diagnosis of idiopathic pulmonary fibrosis. An official ATS/ERS/JRS/ALAT clinical practice guideline. Am J Respir Crit Care Med. 2018; 198(5): e44-e68, doi: 10.1164/rccm.201807-1255ST, indexed in Pubmed: 30168753.

30. Gruden JF, Panse PM, Leslie KO, et al. UIP diagnosed at surgical lung biopsy, 2000-2009: HRCT patterns and proposed classification system. AJR Am J Roentgenol. 2013; 200(5) W458-W467, doi: 10.2214/AJR.12.9437, indexed in Pubmed: 23617514.

31. Lynch DA, Sverzellati N, Travis WD, et al. Diagnostic criteria for idiopathic pulmonary fibrosis: a Fleischner Society White Paper. Lancet Respir Med. 2018; 6(2): 138-153, doi: 10.1016/ S2213-2600(17)30433-2, indexed in Pubmed: 29154106.

32. Behr J, Kreuter M, Hoeper MM, et al. Management of patients with idiopathic pulmonary fibrosis in clinical practice: the INSIGHTS-IPF registry. Eur Respir J. 2015; 46(1): 186-196, doi 10.1183/09031936.00217614, indexed in Pubmed: 25837040.

33. Kim DS, Park JH, Park BK, et al. Acute exacerbation of idiopathic pulmonary fibrosis: frequency and clinical features. Eur Respir J. 2006; 27(1): 143-150, doi: 10.1183/09031936.06.00114004, indexed in Pubmed: 16387947.

34. Zurkova M, Kriegova E, Kolek V, et al. ILD section, IPF registry. Effect of pirfenidone on lung function decline and survival: 5 -yr experience from a real-life IPF cohort from the Czech EMPIRE registry. Respir Res. 2019; 20(1): 16, doi: 10.1186/ s12931-019-0977-2, indexed in Pubmed: 30665416.
35. Krauss E, Gehrken G, Drakopanagiotakis F, et al. Clinical characteristics of patients with familial idiopathic pulmonary fibrosis (f-IPF). BMC Pulm Med. 2019; 19(1): 130, doi: 10.1186/ s12890-019-0895-6, indexed in Pubmed: 31319833.

36. Borie R, Kannengiesser C, Nathan N, et al. Familial pulmonary fibrosis. Rev Mal Respir. 2015; 32(4): 413-434, doi: 10.1016/j. rmr.2014.07.017, indexed in Pubmed: 25596800.

37. Sellarés J, Hernández-González F, Lucena CM, et al. Auscultation of velcro crackles is associated with usual interstitial pneumonia. Medicine (Baltimore). 2016; 95(5): e2573, doi: 10.1097/MD.0000000000002573, indexed in Pubmed: 26844464 .

38. Collard HR, Ryerson CJ, Corte TJ, et al. Acute exacerbation of idiopathic pulmonary fibrosis. An international working group report. Am J Respir Crit Care Med. 2016; 194(3): 265-275, doi: 10.1164/rccm.201604-0801CI, indexed in Pubmed: 27299520.

39. Jo HE, Corte TJ, Glaspole I, et al. Gastroesophageal reflux and antacid therapy in IPF: analysis from the Australia IPF Registry. BMC Pulm Med. 2019; 19(1): 84, doi: 10.1186/s12890-0190846-2, indexed in Pubmed: 31053121.

40. Savarino E, Carbone R, Marabotto E, et al. Gastro-oesophageal reflux and gastric aspiration in idiopathic pulmonary fibrosis patients. Eur Respir J. 2013; 42(5): 1322-1331, doi: 10.1183/09031936.00101212, indexed in Pubmed: 23471347.

41. Raghu G, Freudenberger TD, Yang S, et al. High prevalence of abnormal acid gastro-oesophageal reflux in idiopathic pulmonary fibrosis. Eur Respir J. 2006; 27(1): 136-142, doi: 10.1183/09031936.06.00037005, indexed in Pubmed: 16387946.

42. Portillo K, Perez-Rodas N, García-Olivé I, et al. Lung cancer in patients with combined pulmonary fibrosis and emphysema and idiopathic pulmonary fibrosis. A descriptive study in a spanish series. Arch Bronconeumol. 2017; 53(6): 304-310, doi 10.1016/j.arbres.2016.10.004, indexed in Pubmed: 27986408.

43. Liu Y, Zhu M, Geng J, et al. Incidence and radiologic-pathological features of lung cancer in idiopathic pulmonary fibrosis. Clin Respir J. 2018; 12(4): 1700-1705, doi: 10.1111/crj.12732, indexed in Pubmed: 29094803.

44. Cottin V. The impact of emphysema in pulmonary fibrosis. Eur Respir Rev. 2013; 22(128): 153-157, doi: 10.1183/09059180.00000813, indexed in Pubmed: 23728869.

45. Seeger W, Adir Y, Barberà J, et al. Pulmonary hypertension in chronic lung diseases. Journal of the American College of Cardiology. 2013; 62(25): D109-D116, doi: 10.1016/j. jacc.2013.10.036.

46. Raghu G, Nathan SD, Behr J, et al. Pulmonary hypertension in idiopathic pulmonary fibrosis with mild-to-moderate restriction. Eur Respir J. 2015; 46(5): 1370-1377, doi: 10.1183/13993003.01537-2014, indexed in Pubmed: 26250495.

47. Gille T, Didier M, Boubaya M, et al. collaborators. Obstructive sleep apnoea and related comorbidities in incident idiopathic pulmonary fibrosis. Eur Respir J. 2017; 49(6), doi: 10.1183/13993003.01934-2016, indexed in Pubmed: 28596432.

48. Kreuter M, Ehlers-Tenenbaum S, Palmowski K, et al. Impact of comorbidities on mortality in patients with idiopathic pulmonary fibrosis. PLoS One. 2016; 11(3): e0151425, doi: 10.1371/ journal.pone.0151425, indexed in Pubmed: 27023440.

49. Torrisi SE, Vancheri A, Pavone M, et al. Comorbidities of IPF: How do they impact on prognosis. Pulm Pharmacol Ther. 2018; 53: 6-11, doi: 10.1016/j.pupt.2018.09.003, indexed in Pubmed: 30193867

50. Kreuter M, Swigris J, Pittrow D, et al. The clinical course of idiopathic pulmonary fibrosis and its association to quality of life over time: longitudinal data from the INSIGHTS-IPF registry. Respir Res. 2019; 20(1): 59, doi: 10.1186/s12931-019 1020-3, indexed in Pubmed: 30876420.

51. King TE, Pardo A, Selman M. Idiopathic pulmonary fibrosis. Lancet. 2011; 378(9807): 1949-1961, doi: 10.1016/S01406736(11)60052-4, indexed in Pubmed: 21719092.

52. Vancheri C, Failla M, Crimi N, et al. Idiopathic pulmonary fibrosis: a disease with similarities and links to cancer biology. Eur Respir J. 2010; 35(3): 496-504, doi 10.1183/09031936.00077309, indexed in Pubmed: 20190329.

53. Fisher M, Nathan SD, Hill C, et al. Predicting life expectancy for pirfenidone in idiopathic pulmonary fibrosis. J Manag Care 
Spec Pharm. 2017; 23(3-b Suppl): S17-S24, doi: 10.18553/ jmcp.2017.23.3-b.s17, indexed in Pubmed: 28287347.

54. Costabel U, Albera C, Glassberg MK, et al. Safety of pirfenidone in patients with idiopathic pulmonary fibrosis: integrated analysis of cumulative data from 5 clinical trials. BMJ Open Respir Res. 2016; 3(1): e000105-415, doi: 10.1136/bmjresp-2015-000105, indexed in Pubmed: 26835133.

55. Lancaster L, Crestani B, Hernandez P, et al. Safety and survival data in patients with idiopathic pulmonary fibrosis treated with nintedanib: pooled data from six clinical trials. BMJ Open Respir Res. 2019; 6(1): e000397, doi: 10.1136/bmjresp-2018-000397, indexed in Pubmed: 31179001.

56. Ley B, Ryerson CJ, Vittinghoff E, et al. A multidimensional index and staging system for idiopathic pulmonary fibrosis. Ann Intern Med. 2012; 156(10): 684-691, doi: 10.7326/0003-4819156-10-201205150-00004, indexed in Pubmed: 22586007.

57. Ley B, Bradford WZ, Weycker D, et al. Unified baseline and longitudinal mortality prediction in idiopathic pulmonary fibrosis. Eur Respir J. 2015; 45(5): 1374-1381, doi: 10.1183/09031936.00146314, indexed in Pubmed: 25614172.

58. Piotrowski W, Martusewicz-Boros M, Białas A, et al. Idiopathic pulmonary fibrosis (IPF) common practice in Poland before the "antifibrotic drugs era". Advances in Respiratory Medicine. 2017; 85(3), doi: 10.5603/arm.2017.0023.

59. Ryerson CJ, Corte TJ, Lee JS, et al. A standardized diagnostic ontology for fibrotic interstitial lung disease. An international working group perspective. Am J Respir Crit Care Med. 2017; 196(10): 1249-1254, doi: 10.1164/rccm.201702-0400PP, indexed in Pubmed: 28414524.

60. Bouros D, Tzilas V, Tzouvelekis A. Diagnostic guidelines for IPF: when art meets science. Lancet Respir Med. 2018; 6(11): 812-814, doi: 10.1016/S2213-2600(18)30430-2, indexed in Pubmed: 30484427.

61. Akashi T, Takemura T, Ando N, et al. Histopathologic analysis of sixteen autopsy cases of chronic hypersensitivity pneumonitis and comparison with idiopathic pulmonary fibrosis/usual interstitial pneumonia. Am J Clin Pathol. 2009; 131(3): 405415, doi: 10.1309/AJCPNWX4SLZRP9SW, indexed in Pubmed: 19228646.

62. Yunt ZX, Chung JH, Hobbs S, et al. High resolution computed tomography pattern of usual interstitial pneumonia in rheumatoid arthritis-associated interstitial lung disease: Relationship to survival. Respir Med. 2017; 126: 100-104, doi: 10.1016/j. rmed.2017.03.027, indexed in Pubmed: 28427540.

63. Attanoos RL, Alchami FS, Pooley FD, et al. Usual interstitial pneumonia in asbestos-exposed cohorts - concurrent idiopathic pulmonary fibrosis or atypical asbestosis? Histopathology. 2016; 69(3): 492-498, doi: 10.1111/his.12951, indexed in Pubmed: 26864248 .

64. Collins BF, McClelland RL, Ho LA, et al. Sarcoidosis and IPF in the same patient - a coincidence, an association or a phenotype? Respir Med. 2018; 144S: S20-S27, doi: 10.1016/j. rmed.2018.08.008, indexed in Pubmed: 30166087.

65. Chatterjee K, Kamimoto JJo, Dunn A, et al. A case of DIPNECH presenting as usual interstitial pneumonia. Pneumonol Alergol Pol. 2016; 84(3): 174-177, doi: 10.5603/PiAP.2016.0020, indexed in Pubmed: 27238180.

66. Fang X, Luo B, Yi X, et al. Usual interstitial pneumonia coexisted with nonspecific interstitial pneumonia, What's the diagnosis? Diagn Pathol. 2012; 7: 167, doi: 10.1186/1746-15967-167, indexed in Pubmed: 23206520.

67. Raghu G, Anstrom KJ, King TE, et al. Prednisone, azathioprine, and $\mathrm{N}$-acetylcysteine for pulmonary fibrosis. N Engl J Med. 2012; 366(21): 1968-1977

68. Noth I, Anstrom KJ, Calvert SB, et al. A placebo-controlled randomized trial of warfarin in idiopathic pulmonary fibrosis. Am J Respir Crit Care Med. 2012; 186(1): 88-95, doi: 10.1164/ rccm.201202-0314OC, indexed in Pubmed: 22561965.

69. Kubo H, Nakayama K, Yanai M, et al. Anticoagulant therapy for idiopathic pulmonary fibrosis. Chest. 2005; 128(3): 1475-1482, doi: 10.1378/chest.128.3.1475, indexed in Pubmed: 16162746.

70. Raghu G, Behr J, Brown KK, et al. Treatment of idiopathic pulmonary fibrosis with ambrisentan: a parallel, randomized trial. Ann Intern Med. 2013; 158(9): 641-649, doi: 10.7326/00034819-158-9-201305070-00003, indexed in Pubmed: 23648946.
71. King TE, Albera C, Bradford WZ, et al. Effect of interferon gamma-1b on survival in patients with idiopathic pulmonary fibrosis (INSPIRE): a multicentre, randomised, placebo-controlled trial. Lancet. 2009; 374(9685): 222-228, doi: 10.1016/ S0140-6736(09)60551-1, indexed in Pubmed: 19570573.

72. Antoniou KM, Nicholson AG, Dimadi M, et al. Long-term clinical effects of interferon gamma- $1 \mathrm{~b}$ and colchicine in idiopathic pulmonary fibrosis. Eur Respir J. 2006; 28(3): 496-504, doi: 10.1183/09031936.06.00032605, indexed in Pubmed: 16611657.

73. Miyazaki Y, Azuma A, Inase N, et al. Cyclosporine A combined with low-dose corticosteroid treatment in patients with idiopathic pulmonary fibrosis. Respir Investig. 2015; 53(6): 288-295, doi: 10.1016/j.resinv.2015.05.002, indexed in Pubmed: 26521106

74. Raghu G, Brown KK, Costabel U, et al. Treatment of idiopathic pulmonary fibrosis with etanercept: an exploratory, placebocontrolled trial. Am J Respir Crit Care Med. 2008; 178(9): 948-955, doi: 10.1164/rccm.200709-1446OC, indexed in Pubmed: 18669816.

75. Raghu G, Rochwerg B, Zhang Y, et al. An Official ATS/ERS/ JRS/ALAT Clinical Practice Guideline: Treatment of Idiopathic Pulmonary Fibrosis. An Update of the 2011 Clinical Practice Guideline. Am J Respir Crit Care Med. 2015; 192(2): e3-e19.

76. Raghu G, Million-Rousseau R, Morganti A, et al. Macitentan for the treatment of idiopathic pulmonary fibrosis: the randomised controlled MUSIC trial. Eur Respir J. 2013; 42(6): 1622-1632, doi: 10.1183/09031936.00104612, indexed in Pubmed: 23682110 .

77. King TE, Brown KK, Raghu G, et al. BUILD-3: a randomized, controlled trial of bosentan in idiopathic pulmonary fibrosis. Am J Respir Crit Care Med. 2011; 184(1): 92-99, doi: 10.1164/ rccm.201011-18740C, indexed in Pubmed: 21474646.

78. Zisman DA, Schwarz M, Anstrom KJ, et al. A controlled trial of sildenafil in advanced idiopathic pulmonary fibrosis. N Engl J Med. 2010; 363(7): 620-628, doi: 10.1056/NEJMoa1002110, indexed in Pubmed: 20484178.

79. Daniels CE, Lasky JA, Limper AH, et al. Imatinib treatment for idiopathic pulmonary fibrosis: Randomized placebo-controlled trial results. Am J Respir Crit Care Med. 2010; 181(6): 604-610, doi: 10.1164/rccm.200906-0964OC, indexed in Pubmed: 20007927.

80. Raghu G, Brown KK, Collard HR, et al. Efficacy of simtuzumab versus placebo in patients with idiopathic pulmonary fibrosis: a randomised, double-blind, controlled, phase 2 trial. Lancet Respir Med. 2017; 5(1): 22-32, doi: 10.1016/S22132600(16)30421-0, indexed in Pubmed: 27939076.

81. King TE, Bradford WZ, Castro-Bernardini S, et al. A phase 3 trial of pirfenidone in patients with idiopathic pulmonary fibrosis. N Engl J Med. 2014; 370(22): 2083-2092, doi: 10.1056/ NEJMoa1402582, indexed in Pubmed: 24836312.

82. Noble PW, Albera C, Bradford WZ, et al. Pirfenidone in patients with idiopathic pulmonary fibrosis (CAPACITY): two randomised trials. Lancet. 2011; 377(9779): 1760-1769, doi: 10.1016/ S0140-6736(11)60405-4, indexed in Pubmed: 21571362.

83. Richeldi L, du Bois RM, Raghu G, et al. Efficacy and safety of nintedanib in idiopathic pulmonary fibrosis. N Engl J Med. 2014; 370(22): 2071-2082, doi: 10.1056/NEJMoa1402584, indexed in Pubmed: 24836310.

84. Agencja Oceny Technologii Medycznych i Taryfikacji. Ramy metodyczne opracowywania zaleceń postępowania diagnostyczno-terapeutycznego. Agencja Oceny Technologii Medycznych i Taryfikacji 2017.

85. Schünemann HJ, Jaeschke R, Cook DJ, et al. An official ATS statement: grading the quality of evidence and strength of recommendations in ATS guidelines and recommendations. Am J Respir Crit Care Med. 2006; 174(5): 605-614, doi: 10.1164/ rccm.200602-197ST, indexed in Pubmed: 16931644.

86. Narzędzie oceny wytycznych AGGREE II.

87. Funke-Chambour M, Azzola A, Adler D, et al. Idiopathic pulmonary fibrosis in Switzerland: diagnosis and treatment. Respiration. 2017; 93(5): 363-378, doi: 10.1159/000464332, indexed in Pubmed: 28343230.

88. Raghu G, Lynch D, Godwin JD, et al. Diagnosis of idiopathic pulmonary fibrosis with high-resolution CT in patients with 
little or no radiological evidence of honeycombing: secondary analysis of a randomised, controlled trial. Lancet Respir Med. 2014; 2(4): 277-284, doi: 10.1016/S2213-2600(14)70011-6, indexed in Pubmed: 24717624.

89. Chung JH, Chawla A, Peljto AL, et al. CT scan findings of probable usual interstitial pneumonitis have a high predictive value for histologic usual interstitial pneumonitis. Chest. 2015; 147(2): 450-459, doi: 10.1378/chest.14-0976, indexed in Pubmed: 25317858.

90. Chung JH, Oldham JM, Montner SM, et al. CT-pathologic correlation of major types of pulmonary fibrosis: insights for revisions to current guidelines. AJR Am J Roentgenol. 2018; 210(5): 1034-1041, doi: 10.2214/AJR.17.18947, indexed in Pubmed: 29547052.

91. Tomassetti S, Cavazza A, Colby TV, et al. Transbronchial biopsy is useful in predicting UIP pattern. Respir Res. 2012; 13: 96, doi: 10.1186/1465-9921-13-96, indexed in Pubmed: 23107232

92. Casoni GL, Tomassetti S, Cavazza A, et al. Transbronchial lung cryobiopsy in the diagnosis of fibrotic interstitial lung diseases. PLoS One. 2014; 9(2): e86716, doi: 10.1371/journal. pone.0086716, indexed in Pubmed: 24586252.

93. Sumikawa H, Johkoh T, Fujimoto K, et al. Pathologically proved nonspecific interstitial pneumonia: CT pattern analysis as compared with usual interstitial pneumonia CT pattern. Radiology. 2014; 272(2): 549-556, doi: 10.1148/radiol.14130853, indexed in Pubmed: 24661246.

94. Kaunisto J, Kelloniemi K, Sutinen E, et al. Re-evaluation of diagnostic parameters is crucial for obtaining accurate data on idiopathic pulmonary fibrosis. BMC Pulm Med. 2015; 15 92, doi: 10.1186/s12890-015-0074-3, indexed in Pubmed: 26285574.

95. Pezzuto G, Claroni G, Puxeddu E, et al. Structured multidisciplinary discussion of HRCT scans for IPF/UIP diagnosis may result in indefinite outcomes. Sarcoidosis Vasc Diffuse Lung Dis. 2015; 32(1): 32-36, indexed in Pubmed: 26237353.

96. Yagihashi K, Huckleberry J, Colby TV, et al. Radiologic-pathologic discordance in biopsy-proven usual interstitial pneumonia. Eur Respir J. 2016; 47(4): 1189-1197, doi 10.1183/13993003.01680-2015, indexed in Pubmed: 26917616.

97. Brownell R, Moua T, Henry TS, et al. The use of pretest probability increases the value of high-resolution CT in diagnosing usual interstitial pneumonia. Thorax. 2017; 72(5): 424-429, doi: 10.1136/thoraxjnl-2016-209671, indexed in Pubmed: 28082530

98. Gruden JF, Panse PM, Gotway MB, et al. Diagnosis of usual interstitial pneumonitis in the absence of honeycombing: evaluation of specific CT criteria with clinical follow-up in 38 patients. AJR Am J Roentgenol. 2016; 206(3): 472-480, doi: 10.2214/AJR.15.14525, indexed in Pubmed: 26587800.

99. Salisbury ML, Xia M, Murray S, et al. Predictors of idiopathic pulmonary fibrosis in absence of radiologic honeycombing: A cross sectional analysis in ILD patients undergoing lung tissue sampling. Respir Med. 2016; 118: 88-95, doi: 10.1016/j. rmed.2016.07.016, indexed in Pubmed: 27578476.

100. Kim H, Yoon SHo, Hong H, et al. Diagnosis of idiopathic pulmonary fibrosis in a possible usual interstitial pneumonia pattern: a meta-analysis. Sci Rep. 2018; 8(1): 15886, doi: 10.1038/ s41598-018-34230-z, indexed in Pubmed: 30367143.

101. Fell CD, Martinez FJ, Liu LX, et al. Clinical predictors of a diagnosis of idiopathic pulmonary fibrosis. Am J Respir Crit Care Med. 2010; 181(8): 832-837, doi: 10.1164/rccm. 200906-0959OC, indexed in Pubmed: 20056903.

102.Patterson KC, Shah RJ, Porteous MK, et al. Interstitial lung disease in the elderly. Chest. 2017; 151(4): 838-844, doi: 10.1016/j.chest.2016.11.003, indexed in Pubmed: 27865876.

103.Raghu G, Wells AU, Nicholson AG, et al. Effect of nintedanib in subgroups of idiopathic pulmonary fibrosis by diagnostic criteria. Am J Respir Crit Care Med. 2017; 195(1): 78-85, doi: 10.1164/rccm.201602-0402OC, indexed in Pubmed: 27331880

104.Richeldi L, Wilson KC, Raghu G. Diagnosing idiopathic pulmonary fibrosis in 2018: bridging recommendations made by experts serving different societies. Eur Respir J. 2018; 52(3), doi: 10.1183/13993003.01485-2018, indexed in Pubmed: 30190265 .
105. Lettieri CJ, Veerappan GR, Helman DL, et al. Outcomes and safety of surgical lung biopsy for interstitial lung disease. Chest. 2005; 127(5): 1600-1605, doi: 10.1378/ chest.127.5.1600, indexed in Pubmed: 15888834.

106. Ryerson CJ, Urbania TH, Richeldi L, et al. Prevalence and prognosis of unclassifiable interstitial lung disease. Eur Respir J. 2013; 42(3): 750-757, doi: 10.1183/09031936.00131912, indexed in Pubmed: 23222877.

107. Troy L, Glaspole I, Goh N, et al. Prevalence and prognosis of unclassifiable interstitial lung disease. Eur Respir J. 2014; 43(5): 1529-1530, doi: 10.1183/09031936.00003414, indexed in Pubmed: 24789954.

108. Ooi A, Iyenger S, Ferguson J, et al. VATS lung biopsy in suspected, diffuse interstitial lung disease provides diagnosis, and alters management strategies. Heart Lung Circ. 2005; 14(2): 90-92, doi: 10.1016/j.hlc.2005.01.002, indexed in Pubmed: 16352261.

109. Zhang D, Liu Y. Surgical lung biopsies in 418 patients with suspected interstitial lung disease in China. Intern Med. 2010 49(12): 1097-1102, doi: 10.2169/internalmedicine.49.3225, indexed in Pubmed: 20558924.

110. Kadokura M, Colby TV, Myers JL, et al. Pathologic comparison of video-assisted thoracic surgical lung biopsy with traditional open lung biopsy. J Thorac Cardiovasc Surg. 1995; 109(3): 494-498, doi: 10.1016/S0022-5223(95)70280-6, indexed in Pubmed: 7877310.

111. Raghu G, Remy-Jardin M, Myers J, et al. Diagnosis of Idiopathic Pulmonary Fibrosis. An Official ATS/ERS/JRS/ALAT Clinical Practice Guideline. Am J Respir Crit Care Med. 2018; 198(5): e44-e68, doi: 10.1164/rccm.201807-1255st.

112. Monaghan H, Wells AU, Colby TV, et al. Prognostic implications of histologic patterns in multiple surgical lung biopsies from patients with idiopathic interstitial pneumonias. Chest. 2004; 125(2): 522-526, doi: 10.1378/chest.125.2.522, indexed in Pubmed: 14769733.

113. Flaherty KR, Travis WD, Colby TV, et al. Histopathologic variability in usual and nonspecific interstitial pneumonias. Am J Respir Crit Care Med. 2001; 164(9): 1722-1727, doi: 10.1164/ ajrccm.164.9.2103074, indexed in Pubmed: 11719316.

114. Qureshi RA, Ahmed TA, Grayson AD, et al. Does lung biopsy help patients with interstitial lung disease? Eur J Cardiothorac Surg. 2002; 21(4): 621-6; discussion 626, doi: 10.1016/s10107940(02)00021-0, indexed in Pubmed: 11932157.

115. Luo Q, Han Q, Chen X, et al. The diagnosis efficacy and safety of video-assisted thoracoscopy surgery (VATS) in undefined interstitial lung diseases: a retrospective study. J Thorac Dis. 2013; 5(3): 283-288, doi: 10.3978/j.issn.20721439.2013.04.12, indexed in Pubmed: 23825760.

116. Plönes T, Osei-Agyemang T, Elze M, et al. Morbidity and mortality in patients with usual interstitial pneumonia (UIP) pattern undergoing surgery for lung biopsy. Respir Med. 2013; 107(4): 629-632, doi: 10.1016/j.rmed.2012.11.020, indexed in Pubmed: 23337301.

117. Fibla JJ, Molins L, Blanco A, et al. Video-assisted thoracoscopic lung biopsy in the diagnosis of interstitial lung disease: a prospective, multi-center study in 224 patients. Arch Bronconeumol. 2012; 48(3): 81-85, doi: 10.1016/j. arbres.2011.11.002, indexed in Pubmed: 22244947.

118. Warner DO, Warner MA, Divertie MB. Open lung biopsy in patients with diffuse pulmonary infiltrates and acute respiratory failure. Am Rev Respir Dis. 1988; 137(1): 90-94, doi: 10.1164/ ajrccm/137.1.90, indexed in Pubmed: 3337474.

119. Raj R, Brown KK. Mortality related to surgical lung biopsy in patients with interstitial lung disease. The devil is in the denominator. Am J Respir Crit Care Med. 2016; 193(10): 1082-1084, doi: 10.1164/rccm.201512-2488ED, indexed in Pubmed: 27174478.

120. Hutchinson JP, McKeever TM, Fogarty AW, et al. Surgical lung biopsy for the diagnosis of interstitial lung disease in England: 1997-2008. Eur Respir J. 2016; 48(5): 1453-1461, doi: 10.1183/13993003.00378-2016, indexed in Pubmed: 27660509.

121. Hutchinson JP, Fogarty AW, McKeever TM, et al. In-Hospital Mortality after Surgical Lung Biopsy for Interstitial Lung Disease in the United States. 2000 to 2011. Am J Respir 
Crit Care Med. 2016; 193(10): 1161-1167, doi: 10.1164/rccm. 201508-1632OC, indexed in Pubmed: 26646481.

122. Johannson KA, Marcoux VS, Ronksley PE, et al. Diagnostic yield and complications of transbronchial lung cryobiopsy for interstitial lung disease. A systematic review and metaanalysis. Ann Am Thorac Soc. 2016; 13(10): 1828-1838, doi: 10.1513/AnnalsATS.201606-461SR, indexed in Pubmed: 27466899.

123. Ravaglia C, Bonifazi M, Wells AU, et al. Safety and diagnostic yield of transbronchial lung cryobiopsy in diffuse parenchymal lung diseases: a comparative study versus video-assisted thoracoscopic lung biopsy and a systematic review of the literature. Respiration. 2016; 91(3): 215-227, doi: 10.1159/000444089, indexed in Pubmed: 26926876.

124. Colby TV, Tomassetti S, Cavazza A, et al. Transbronchial cryobiopsy in diffuse lung disease: update for the pathologist. Arch Pathol Lab Med. 2017; 141(7): 891-900, doi: 10.5858/ arpa.2016-0233-RA, indexed in Pubmed: 27588334.

125. Tomassetti S, Wells AU, Costabel U, et al. Bronchoscopic lung cryobiopsy increases diagnostic confidence in the multidisciplinary diagnosis of idiopathic pulmonary fibrosis. Am J Respir Crit Care Med. 2016; 193(7): 745-752, doi: 10.1164/ rccm.201504-0711OC, indexed in Pubmed: 26562389.

126. Ravaglia C, Bosi M, Wells AU, et al. Idiopathic pulmonary fibrosis: prognostic impact of histologic honeycombing in transbronchial lung cryobiopsy. Multidiscip Respir Med. 2019; 14: 3, doi: 10.1186/s40248-019-0170-y, indexed in Pubmed: 30774952

127. Sheth JS, Belperio JA, Fishbein MC, et al. Utility of transbronchial vs surgical lung biopsy in the diagnosis of suspected fibrotic interstitial lung disease. Chest. 2017; 151(2): 389399, doi: 10.1016/j.chest.2016.09.028, indexed in Pubmed: 27729263

128. Ramaswamy A, Homer R, Killam J, et al. Comparison of transbronchial and cryobiopsies in evaluation of diffuse parenchymal lung disease. J Bronchology Interv Pulmonol. 2016; 23(1): 14-21, doi: 10.1097/LBR.0000000000000246, indexed in Pubmed: 26705007.

129. Kim SuY, Diggans J, Pankratz D, et al. Classification of usual interstitial pneumonia in patients with interstitial lung disease: assessment of a machine learning approach using highdimensional transcriptional data. Lancet Respir Med. 2015; 3(6): 473-482, doi: 10.1016/S2213-2600(15)00140-X, indexed in Pubmed: 26003389.

130. Pankratz DG, Choi Y, Imtiaz U, et al. Usual interstitial pneumonia can be detected in transbronchial biopsies using machine learning. Ann Am Thorac Soc. 2017; 14(11): 16461654, doi: 10.1513/AnnalsATS.201612-947OC, indexed in Pubmed: 28640655 .

131. Cascante JA, Cebollero P, Herrero S, et al. Transbronchial cryobiopsy in interstitial lung disease: are we on the right path? J Bronchology Interv Pulmonol. 2016; 23(3): 204-209, doi: 10.1097/LBR.0000000000000292, indexed in Pubmed: 27261937.

132. Fruchter O, Fridel L, El Raouf BA, et al. Histological diagnosis of interstitial lung diseases by cryo-transbronchial biopsy. Respirology. 2014; 19(5): 683-688, doi: 10.1111/resp.12296, indexed in Pubmed: 24750376.

133. Griff S, Schönfeld N, Ammenwerth W, et al. Diagnostic yield of transbronchial cryobiopsy in non-neoplastic lung disease: a retrospective case series. BMC Pulm Med. 2014; 14: 171, doi: 10.1186/1471-2466-14-171, indexed in Pubmed: 25366106.

134. Hagmeyer L, Theegarten D, Treml M, et al. Validation of transbronchial cryobiopsy in interstitial lung disease - interim analysis of a prospective trial and critical review of the literature. Sarcoidosis Vasc Diffuse Lung Dis. 2016; 33(1): 2-9, indexed in Pubmed: 27055830.

135. Hernández-González F, Lucena CM, Ramírez J, et al. Cryobiopsy in the diagnosis of diffuse interstitial lung disease: yield and cost-effectiveness analysis. Arch Bronconeumol. 2015; 51(6): 261-267, doi: 10.1016/j.arbres.2014.09.009, indexed in Pubmed: 25454902.

136. Kronborg-White S, Folkersen B, Rasmussen TR, et al. Introduction of cryobiopsies in the diagnostics of interstitial lung diseases - experiences in a referral center. Eur Clin Respir J.
2017; 4(1): 1274099, doi: 10.1080/20018525.2016.1274099, indexed in Pubmed: 28326178.

137. Kropski JA, Pritchett JM, Mason WR, et al. Bronchoscopic cryobiopsy for the diagnosis of diffuse parenchymal lung disease. PLoS One. 2013; 8(11): e78674, doi: 10.1371/journal. pone.0078674, indexed in Pubmed: 24265706.

138. Pourabdollah M, Shamaei M, Karimi S, et al. Transbronchial lung biopsy: the pathologist's point of view. Clin Respir J. 2016; 10(2): 211-216, doi: 10.1111/crj.12207, indexed in Pubmed: 25185518.

139. Ussavarungsi K, Kern RM, Roden AC, et al. Transbronchial cryobiopsy in diffuse parenchymal lung disease: retrospective analysis of 74 cases. Chest. 2017; 151(2): 400-408, doi: 10.1016/j.chest.2016.09.002, indexed in Pubmed: 27660154.

140. Pajares V, Puzo C, Castillo D, et al. Diagnostic yield of transbronchial cryobiopsy in interstitial lung disease: a randomized trial. Respirology. 2014; 19(6): 900-906, doi: 10.1111/ resp.12322, indexed in Pubmed: 24890124.

141. Hagmeyer L, Theegarten D, Wohlschläger J, et al. The role of transbronchial cryobiopsy and surgical lung biopsy in the diagnostic algorithm of interstitial lung disease. Clin Respir J. 2016; 10(5): 589-595, doi: 10.1111/crj.12261, indexed in Pubmed: 25620578.

142. Gershman E, Fruchter O, Benjamin F, et al. Safety of cryo -transbronchial biopsy in diffuse lung diseases: analysis of three hundred cases. Respiration. 2015; 90(1): 40-46, doi: 10.1159/000381921, indexed in Pubmed: 25998966.

143. DiBardino DM, Haas AR, Lanfranco AR, et al. High complication rate after introduction of transbronchial cryobiopsy into clinical practice at an academic medical center. Ann Am Thorac Soc. 2017; 14(6): 851-857, doi: 10.1513/AnnalsATS. 201610-8290C, indexed in Pubmed: 28231021.

144. Bango-Álvarez A, Ariza-Prota M, Torres-Rivas H, et al. Transbronchial cryobiopsy in interstitial lung disease: experience in 106 cases - how to do it. ERJ Open Res. 2017; 3(1), doi: 10.1183/23120541.00148-2016, indexed in Pubmed: 28344982.

145. Sriprasart T, Aragaki A, Baughman R, et al. A single US center experience of transbronchial lung cryobiopsy for diagnosing interstitial lung disease with a 2-scope technique. J Bronchology Interv Pulmonol. 2017; 24(2): 131-135, doi: 10.1097/ LBR.0000000000000366, indexed in Pubmed: 28323726.

146. Guenther A, Krauss E, Tello S, et al. The European IPF registry (eurIPFreg): baseline characteristics and survival of patients with idiopathic pulmonary fibrosis. Respir Res. 2018; 19(1): 141, doi: 10.1186/s12931-018-0845-5, indexed in Pubmed: 30055613 .

147. Hetzel J, Maldonado F, Ravaglia C, et al. Transbronchial cryobiopsies for the diagnosis of diffuse parenchymal lung diseases: expert statement from the cryobiopsy working group on safety and utility and a call for standardization of the procedure. Respiration. 2018; 95(3): 188-200, doi: 10.1159/000484055, indexed in Pubmed: 29316560.

148. Agarwal R, Dhooria S, Sehgal I, et al. Bronchoscopic lung cryobiopsy: An Indian association for bronchology position statement. Lung India. 2019; 36(1): 48, doi: 10.4103/lungindia.lungindia 7518 .

149. Lodhi T, Hughes G, Stanel S, et al. Transbronchial lung cryobiopsy in idiopathic pulmonary fibrosis: a state of the art review. Adv Ther. 2019; 36(9): 2193-2204, doi: 10.1007/s12325019-01036-y, indexed in Pubmed: 31363997.

150. Berbescu EA, Katzenstein ALA, Snow JL, et al. Transbronchial biopsy in usual interstitial pneumonia. Chest. 2006; 129(5): 1126-1131, doi: 10.1378/chest.129.5.1126, indexed in Pubmed: 16685001

151. Casoni GL, Gurioli C, Chhajed PN, et al. The value of transbronchial lung biopsy using jumbo forceps via rigid bronchoscope in diffuse lung disease. Monaldi Arch Chest Dis. 2008; 69(2): 59-64, doi: 10.4081/monaldi.2008.397, indexed in Pubmed: 18837418.

152. Han Q, Luo Q, Xie JX, et al. Diagnostic yield and postoperative mortality associated with surgical lung biopsy for evaluation of interstitial lung diseases: A systematic review and meta-analysis. J Thorac Cardiovasc Surg. 2015; 149(5): 1394-401.e1, doi: 10.1016/j.jtcvs.2014.12.057, indexed in Pubmed: 25648484 
153. Park JH, Kim DK, Kim DS, et al. Mortality and risk factors for surgical lung biopsy in patients with idiopathic interstitial pneumonia. Eur J Cardiothorac Surg. 2007; 31(6): 11151119, doi: 10.1016/j.ejcts.2007.02.035, indexed in Pubmed: 17418586.

154. Ravaglia C, Wells AU, Tomassetti S, et al. Diagnostic yield and risk/benefit analysis of trans-bronchial lung cryobiopsy in diffuse parenchymal lung diseases: a large cohort of 699 patients. BMC Pulm Med. 2019; 19(1): 16, doi: 10.1186/s12890019-0780-3, indexed in Pubmed: 30651103.

155. Juarez MM, Chan AL, Norris AG, et al. Acute exacerbation of idiopathic pulmonary fibrosis-a review of current and novel pharmacotherapies. J Thorac Dis. 2015; 7(3): 499-519, doi: 10.3978/j.issn.2072-1439.2015.01.17, indexed in Pubmed: 25922733.

156. Ghatol A, Ruhl AP, Danoff SK. Exacerbations in idiopathic pulmonary fibrosis triggered by pulmonary and nonpulmonary surgery: a case series and comprehensive review of the literature. Lung. 2012; 190(4): 373-380, doi: 10.1007/s00408012-9389-5, indexed in Pubmed: 22543997.

157. Lee JS, Kim EJ, Lynch KL, et al. Prevalence and clinical significance of circulating autoantibodies in idiopathic pulmonary fibrosis. Respir Med. 2013; 107(2): 249-255, doi: 10.1016/j. rmed.2012.10.018, indexed in Pubmed: 23186614.

158. Collins BF, Spiekerman CF, Shaw MA, et al. Idiopathic interstitial pneumonia associated with autoantibodies: a large case series followed over 1 year. Chest. 2017; 152(1): 103-112, doi: 10.1016/j.chest.2017.03.004, indexed in Pubmed: 28300570.

159. Vij R, Noth I, Strek ME. Autoimmune-featured interstitial lung disease: a distinct entity. Chest. 2011; 140(5): 1292-1299, doi: 10.1378/chest.10-2662, indexed in Pubmed: 21565966.

160. Haslam PL, Thompson B, Mohammed I, et al. Circulating immune complexes in patients with cryptogenic fibrosing alveolitis. Clin Exp Immunol. 1979; 37(3): 381-390, indexed in Pubmed: 315841.

161. Fischer A, Pfalzgraf FJ, Feghali-Bostwick CA, et al. Anti-th/ to-positivity in a cohort of patients with idiopathic pulmonary fibrosis. J Rheumatol. 2006; 33(8): 1600-1605, indexed in Pubmed: 16783860.

162. Song JW, Do KH, Kim MY, et al. Pathologic and radiologic differences between idiopathic and collagen vascular disease-related usual interstitial pneumonia. Chest. 2009; 136(1): 23-30, doi: 10.1378/chest.08-2572, indexed in Pubmed: 19255290.

163. Kamiya H, Panlaqui OM. Prognostic significance of autoantibodies for idiopathic pulmonary fibrosis: protocol for a systematic review. BMJ Open. 2018; 8(3): e020862, doi: 10.1136/ bmjopen-2017-020862, indexed in Pubmed: 29523572.

164. Kamiya H, Panlaqui OM. Systematic review and meta-analysis of clinical significance of autoantibodies for idiopathic pulmonary fibrosis. BMJ Open. 2019; 9(5): e027849, doi: 10.1136/ bmjopen-2018-027849, indexed in Pubmed: 31147365.

165. Hu Y, Wang LS, Wei YR, et al. Clinical characteristics of connective tissue disease-associated interstitial lung disease in 1,044 Chinese patients. Chest. 2016; 149(1): 201-208, doi: 10.1378/chest.15-1145, indexed in Pubmed: 26447566.

166. Bongartz T, Nannini C, Medina-Velasquez YF, et al. Incidence and mortality of interstitial lung disease in rheumatoid arthritis: a population-based study. Arthritis Rheum. 2010; 62(6): 1583-1591, doi: 10.1002/art.27405, indexed in Pubmed: 20155830.

167. Kim DS, Yoo B, Lee JS, et al. The major histopathologic pattern of pulmonary fibrosis in scleroderma is nonspecific in terstitial pneumonia. Sarcoidosis Vasc Diffuse Lung Dis Off J WASOG. 2002; 19(2): 121-7.

168. Fischer A, Swigris JJ, Groshong SD, et al. Clinically significant interstitial lung disease in limited scleroderma: histopathology, clinical features, and survival. Chest. 2008; 134(3): 601-605, doi: 10.1378/chest.08-0053, indexed in Pubmed: 18403656.

169. Parambil JG, Myers JL, Lindell RM, et al. Interstitial lung disease in primary Sjögren syndrome. Chest. 2006; 130(5): 1489-1495, doi: 10.1378/chest.130.5.1489, indexed in Pubmed: 17099028.

170. Assayag D, Elicker BM, Urbania TH, et al. Rheumatoid arthritis-associated interstitial lung disease: radiologic identifica- tion of usual interstitial pneumonia pattern. Radiology. 2014; 270(2): 583-588, doi: 10.1148/radiol.13130187, indexed in Pubmed: 24126367.

171. Kim EJ, Collard HR, King TE. Rheumatoid arthritis-associated interstitial lung disease: the relevance of histopathologic and radiographic pattern. Chest. 2009; 136(5): 1397-1405, doi: 10.1378/chest.09-0444, indexed in Pubmed: 19892679.

172. Kim EJ, Elicker BM, Maldonado F, et al. Usual interstitial pneumonia in rheumatoid arthritis-associated interstitial lung disease. Eur Respir J. 2010; 35(6): 1322-1328, doi: 10.1183/09031936.00092309, indexed in Pubmed: 19996193.

173. Wang JX, Du CG. A retrospective study of clinical characteristics of interstitial lung disease associated with rheumatoid arthritis in Chinese patients. Med Sci Monit. 2015; 21 708-715, doi: 10.12659/MSM.890880, indexed in Pubmed: 25746669.

174. Johnson C, Giles JT, Bathon J, et al. Smoking and subclinical ILD in RA versus the multi-ethnic study of atherosclerosis. PLoS One. 2016; 11(4): e0153024, doi: 10.1371/journal. pone.0153024, indexed in Pubmed: 27050433.

175. Morell F, Villar A, Montero MÁ, et al. Chronic hypersensitivity pneumonitis in patients diagnosed with idiopathic pulmonary fibrosis: a prospective case-cohort study. Lancet Respir Med. 2013; 1(9): 685-694, doi: 10.1016/S22132600(13)70191-7, indexed in Pubmed: 24429272.

176. Fernández Pérez ER, Swigris JJ, Forssén AV, et al. Identifying an inciting antigen is associated with improved survival in patients with chronic hypersensitivity pneumonitis. Chest. 2013; 144(5): 1644-1651, doi: 10.1378/chest.12-2685, indexed in Pubmed: 23828161.

177. Salisbury ML, Myers JL, Belloli EA, et al. Diagnosis and treatment of fibrotic hypersensitivity pneumonia. Where we stand and where we need to go. Am J Respir Crit Care Med. 2017; 196(6): 690-699, doi: 10.1164/rccm.201608-1675PP, indexed in Pubmed: 28002680.

178. Vasakova M, Morell F, Walsh S, et al. Hypersensitivity pneumonitis: perspectives in diagnosis and management. Am J Respir Crit Care Med. 2017; 196(6): 680-689, doi: 10.1164/ rccm.201611-2201PP, indexed in Pubmed: 28598197.

179. Flaherty KR, Mumford JA, Murray S, et al. Prognostic implications of physiologic and radiographic changes in idiopathic interstitial pneumonia. Am J Respir Crit Care Med. 2003; 168(5): 543-548, doi: 10.1164/rccm.200209-1112OC, indexed in Pubmed: 12773329.

180. Hanak V, Golbin JM, Ryu JH. Causes and presenting features in 85 consecutive patients with hypersensitivity pneumonitis. Mayo Clin Proc. 2007; 82(7): 812-816, doi: 10.4065/82.7.812, indexed in Pubmed: 17605960.

181. Cano-Jiménez E, Rubal D, Pérez de Llano LA, et al. Farmer's lung disease: Analysis of 75 cases. Med Clin (Barc). 2017 149(10): 429-435, doi: 10.1016/j.medcli.2017.03.052, indexed in Pubmed: 28587854.

182. Masuo M, Miyazaki Y, Suhara K, et al. Factors associated with positive inhalation provocation test results in subjects suspected of having chronic bird-related hypersensitivity pneumonitis. Respir Investig. 2016; 54(6): 454-461, doi: 10.1016/j. resinv.2016.05.002, indexed in Pubmed: 27886857.

183. Morell F, Roger A, Reyes L, et al. Bird fancier's lung: a series of 86 patients. Medicine (Baltimore). 2008; 87(2): 110-130 doi: 10.1097/MD.0b013e31816d1dda, indexed in Pubmed: 18344808.

184. Millerick-May ML, Mulks MH, Gerlach J, et al. Hypersensitivity pneumonitis and antigen identification. An alternate approach. Respir Med. 2016; 112: 97-105, doi: 10.1016/j. rmed.2015.09.001, indexed in Pubmed: 26831202.

185. Giacomi FD, Andreano A, Faverio P, et al. Utility of precipitating antibody testing in the diagnostic evaluation of chronic hypersensitivity pneumonia. Sarcoidosis Vasc Diffuse Lung Dis. 2017; 34(2): 149-155.

186. Koschel D, Stark W, Karmann F, et al. Extrinsic allergic alveolitis caused by misting fountains. Respir Med. 2005; 99(8): 943-947, doi: 10.1016/j.rmed.2005.01.004, indexed in Pubmed: 15950134.

187. Salisbury ML, Gu T, Murray S, et al. Hypersensitivity pneumonitis: radiologic phenotypes are associated with di- 
stinct survival time and pulmonary function trajectory. Chest. 2019; 155(4): 699-711, doi: 10.1016/j.chest.2018.08.1076, indexed in Pubmed: 30243979.

188. Efared B, Ebang-Atsame G, Rabiou S, et al. The diagnostic value of the bronchoalveolar lavage in interstitial lung diseases. J Negat Results Biomed. 2017; 16(1): 4, doi: 10.1186/s12952017-0069-0, indexed in Pubmed: 28245857.

189. Domagała-Kulawik J, Skirecki T, Maskey-Warzechowska M, et al. Bronchoalveolar lavage total cell count in interstitial lung diseases — does it matter? Inflammation. 2012; 35(3): 803-809, doi: 10.1007/s10753-011-9378-5, indexed in Pubmed: 21882075 .

190. Espoladore LM, Gregório BB, Lima MS, et al. Cytological analysis of bronchoalveolar lavage in patients with interstitial lung diseases and the relation of cytological analysis to fibrosis in high-resolution computed tomography. Anal Quant Cytopathol Histpathol. 2014; 36(4): 206-212, indexed in Pubmed: 25291858.

191. Ohshimo S, Bonella F, Cui Ai, et al. Significance of bronchoalveolar lavage for the diagnosis of idiopathic pulmonary fibrosis. Am J Respir Crit Care Med. 2009; 179(11): 1043-1047, doi: 10.1164/rccm.200808-13130C, indexed in Pubmed: 19246718.

192. Vasakova M, Sterclova M, Kolesar L, et al. Bronchoalveolar lavage fluid cellular characteristics, functional parameters and cytokine and chemokine levels in interstitial lung diseases. Scand J Immunol. 2009; 69(3): 268-274, doi: 10.1111/j. 1365-3083.2008.02222.x, indexed in Pubmed: 19281539.

193. Meyer KC, Raghu G, Baughman RP, et al. An official American Thoracic Society clinical practice guideline: the clinical utility of bronchoalveolar lavage cellular analysis in interstitial lung disease. Am J Respir Crit Care Med. 2012; 185(9): 1004-1014, doi: 10.1164/rccm.201202-0320ST, indexed in Pubmed: 22550210.

194. Singh S, Collins BF, Sharma BB, et al. Interstitial lung disease in India. Results of a prospective registry. Am J Respir Crit Care Med. 2017; 195(6): 801-813, doi: 10.1164/rccm. 201607-1484OC, indexed in Pubmed: 27684041.

195. Chaudhuri N, Spencer L, Greaves M, et al. A review of the multidisciplinary diagnosis of interstitial lung diseases: a retrospective analysis in a single UK specialist centre. J Clin Med. 2016; 5(8), doi: 10.3390/jcm5080066, indexed in Pubmed: 27472372 .

196. Thomeer M, Demedts M, Behr J, et al. Multidisciplinary interobserver agreement in the diagnosis of idiopathic pulmonary fibrosis. Eur Respir J. 2008; 31(3): 585-591, doi: 10.1183/09031936.00063706, indexed in Pubmed: 18057059.

197. Jo HE, Glaspole IN, Levin KC, et al. Clinical impact of the interstitial lung disease multidisciplinary service. Respirology. 2016; 21(8): 1438-1444, doi: 10.1111/resp.12850, indexed in Pubmed: 27427515.

198. Theegarten D, Müller HM, Bonella F, et al. Diagnostic approach to interstitial pneumonias in a single centre: report on 88 cases. Diagn Pathol. 2012; 7: 160, doi: 10.1186/1746-1596-7160, indexed in Pubmed: 23181688.

199. Flaherty KR, King TE, Raghu G, et al. Idiopathic interstitial pneumonia: what is the effect of a multidisciplinary approach to diagnosis? Am J Respir Crit Care Med. 2004; 170(8): 904-910, doi: 10.1164/rccm.200402-147OC, indexed in Pubmed: 15256390

200. Flaherty KR, Andrei AC, King TE, et al. Idiopathic interstitial pneumonia: do community and academic physicians agree on diagnosis? Am J Respir Crit Care Med. 2007; 175(10): 1054-1060, doi: 10.1164/rccm.200606-833OC, indexed in Pubmed: 17255566.

201. Behr J, Günther A, Ammenwerth W, et al. German guideline for diagnosis and management of idiopathic pulmonary fibrosis. Pneumologie. 2013; 67(2): 81-111, doi: 10.1055/s-00321326009, indexed in Pubmed: 23325398.

202. Cottin V, Crestani B, Valeyre D, et al. French practical guidelines for the diagnosis and management of idiopathic pulmonary fibrosis. From the National Reference and the Competence centers for rare diseases and the Société de Pneumologie de Langue Française. Rev Mal Respir. 2013; 30(10): 879-902, doi: 10.1016/j.rmr.2013.09.007, indexed in Pubmed: 24314711.
203. Behr J, Günther A, Bonella F, et al. German Guideline for Idiopathic Pulmonary Fibrosis - Update on Pharmacological Therapies 2017. Pneumologie. 2018; 72(2): 155-168, doi: 10.1055/s-0043-123035, indexed in Pubmed: 29341047.

204. Chung JH, Lynch DA. The value of a multidisciplinary approach to the diagnosis of usual interstitial pneumonitis and idiopathic pulmonary fibrosis: radiology, pathology, and clinical correlation. AJR Am J Roentgenol. 2016; 206(3): 463-471, doi: 10.2214/AJR.15.15627, indexed in Pubmed: 26901003.

205. Walsh SLF, Wells AU, Desai SR, et al. Multicentre evaluation of multidisciplinary team meeting agreement on diagnosis in diffuse parenchymal lung disease: a case-cohort study. Lancet Respir Med. 2016; 4(7): 557-565, doi: 10.1016/S22132600(16)30033-9, indexed in Pubmed: 27180021.

206. Walsh SLF, Calandriello L, Sverzellati N, et al. Interobserver agreement for the ATS/ERS/JRS/ALAT criteria for a UIP pattern on CT. Thorax. 2016; 71(1): 45-51, doi: 10.1136/thoraxjnl-2015-207252, indexed in Pubmed: 26585524.

207. Sumikawa H, Johkoh T, Colby TV, et al. Computed tomography findings in pathological usual interstitial pneumonia relationship to survival. Am J Respir Crit Care Med. 2008; 177(4): 433-439, doi: 10.1164/rccm.200611-16960C, indexed in Pubmed: 17975197.

208. Kazerooni EA, Martinez FJ, Flint A, et al. Thin-section CT obtained at $10-\mathrm{mm}$ increments versus limited three-level thin-section CT for idiopathic pulmonary fibrosis: correlation with pathologic scoring. AJR Am J Roentgenol. 1997; 169(4): 977-983, doi: 10.2214/ajr.169.4.9308447, indexed in Pubmed: 9308447.

209. Ley B, Bradford WZ, Vittinghoff E, et al. Predictors of mortality poorly predict common measures of disease progression in idiopathic pulmonary fibrosis. Am J Respir Crit Care Med. 2016; 194(6): 711-718, doi: 10.1164/rccm.201508-1546OC, indexed in Pubmed: 26938706.

210. Ley B, Collard HR, King TE. Clinical course and prediction of survival in idiopathic pulmonary fibrosis. Am J Respir Crit Care Med. 2011; 183(4): 431-440, doi: 10.1164/rccm. 201006-0894CI, indexed in Pubmed: 20935110.

211. Schmidt SL, Tayob N, Han MK, et al. Predicting pulmonary fibrosis disease course from past trends in pulmonary function. Chest. 2014; 145(3): 579-585, doi: 10.1378/chest.13-0844, indexed in Pubmed: 24231810.

212. Battista G, Zompatori M, Fasano L, et al. Progressive worsening of idiopathic pulmonary fibrosis. High resolution computed tomography (HRCT) study with functional correlations. Radiol Med. 2003; 105(1/2): 2-11, indexed in Pubmed: 12700539.

213. Iwasawa T, Ogura T, Sakai F, et al. CT analysis of the effect of pirfenidone in patients with idiopathic pulmonary fibrosis. Eur J Radiol. 2014; 83(1): 32-38, doi: 10.1016/j.ejrad.2012.02.014, indexed in Pubmed: 22465123.

214. Paterniti MO, Bi Y, Rekić D, et al. Acute exacerbation and decline in forced vital capacity are associated with increased mortality in idiopathic pulmonary fibrosis. Ann Am Thorac Soc. 2017; 14(9): 1395-1402, doi: 10.1513/AnnalsATS. 201606-458OC, indexed in Pubmed: 28388260.

215. Reichmann WM, Yu YF, Macaulay D, et al. Change in forced vital capacity and associated subsequent outcomes in patients with newly diagnosed idiopathic pulmonary fibrosis. BMC Pulm Med. 2015; 15: 167, doi: 10.1186/s12890-015-0161-5, indexed in Pubmed: 26714746.

216. Collard HR, King TE, Bartelson BB, et al. Changes in clinical and physiologic variables predict survival in idiopathic pulmonary fibrosis. Am J Respir Crit Care Med. 2003; 168(5) 538-542, doi: 10.1164/rccm.200211-13110C, indexed in Pubmed: 12773325

217. Bois Rdu, Nathan S, Richeldi L, et al. Idiopathic Pulmonary Fibrosis. American Journal of Respiratory and Critical Care Medicine. 2012; 186(8): 712-715, doi: 10.1164/rccm. 201206-1010pp.

218. Karimi-Shah BA, Chowdhury BA. Forced vital capacity in idiopathic pulmonary fibrosis--FDA review of pirfenidone and nintedanib. N Engl J Med. 2015; 372(13): 1189-1191, doi: 10.1056/NEJMp1500526, indexed in Pubmed: 25806913.

219. Latsi P, Bois Rdu, Nicholson A, et al. Fibrotic Idiopathic Interstitial Pneumonia. American Journal of Respiratory and 
Critical Care Medicine. 2003; 168(5): 531-537, doi: 10.1164/ rccm.200210-1245oc.

220. Richeldi L, Cottin V, Flaherty KR, et al. Design of the INPULSIS $^{\mathrm{TM}}$ trials: two phase 3 trials of nintedanib in patients with idiopathic pulmonary fibrosis. Respir Med. 2014; 108(7): 1023-1030, doi: 10.1016/j.rmed.2014.04.011, indexed in Pubmed: 24834811.

221. Richeldi L, Cottin V, du Bois RM, et al. Nintedanib in patients with idiopathic pulmonary fibrosis: Combined evidence from the TOMORROW and INPULSIS(®) trials. Respir Med. 2016; 113: 74-79, doi: 10.1016/j.rmed.2016.02.001, indexed in Pubmed: 26915984.

222. Nathan SD, Albera C, Bradford WZ, et al. Effect of continued treatment with pirfenidone following clinically meaningful declines in forced vital capacity: analysis of data from three phase 3 trials in patients with idiopathic pulmonary fibrosis. Thorax. 2016; 71(5): 429-435, doi: 10.1136/thoraxjnl-2015-207011, indexed in Pubmed: 26968970.

223. Noble PW, Albera C, Bradford WZ, et al. Pirfenidone for idiopathic pulmonary fibrosis: analysis of pooled data from three multinational phase 3 trials. Eur Respir J. 2016; 47(1): 243-253, doi: 10.1183/13993003.00026-2015, indexed in Pubmed: 26647432.

224. Brown KK, Flaherty KR, Cottin V, et al. Lung function outcomes in the INPULSIS trials of nintedanib in idiopathic pulmonary fibrosis. Respir Med. 2019; 146: 42-48, doi: 10.1016/j. rmed.2018.11.012, indexed in Pubmed: 30665517.

225. Richeldi L, Ryerson CJ, Lee JS, et al. Relative versus absolute change in forced vital capacity in idiopathic pulmonary fibrosis. Thorax. 2012; 67(5): 407-411, doi: 10.1136/thoraxjnl-2011-201184, indexed in Pubmed: 22426899.

226. Taniguchi H, Kondoh Y, Ebina M, et al. The clinical significance of $5 \%$ change in vital capacity in patients with idiopathic pulmonary fibrosis: extended analysis of the pirfenidone trial. Respir Res. 2011; 12: 93, doi: 10.1186/1465-9921-12-93, indexed in Pubmed: 21756364

227. Zappala CJ, Latsi PI, Nicholson AG, et al. Marginal decline in forced vital capacity is associated with a poor outcome in idiopathic pulmonary fibrosis. Eur Respir J. 2010; 35(4): 830-836, doi: 10.1183/09031936.00155108, indexed in Pubmed: 19840957.

228. Kreuter M, Spagnolo P, Wuyts W, et al. Antacid therapy and disease progression in patients with idiopathic pulmonary fibrosis who received pirfenidone. Respiration. 2017; 93(6): 415-423, doi: 10.1159/000468546, indexed in Pubmed: 28399537.

229. Wells AU, Desai SR, Rubens MB, et al. Idiopathic pulmonary fibrosis: a composite physiologic index derived from disease extent observed by computed tomography. Am J Respir Crit Care Med. 2003; 167(7): 962-969, doi: 10.1164/rccm.2111053, indexed in Pubmed: 12663338.

230. Wells AU. Forced vital capacity as a primary end point in idiopathic pulmonary fibrosis treatment trials: making a silk purse from a sow's ear. Thorax. 2013; 68(4): 309-310, doi: 10.1136/ thoraxjnl-2012-202640, indexed in Pubmed: 23019257.

231. Stanojevic S, Graham BL, Cooper BG, et al. Official ERS technical standards: Global Lung Function Initiative reference values for the carbon monoxide transfer factor for Caucasians. Eur Respir J. 2017; 50(3), doi: 10.1183/13993003.00010-2017, indexed in Pubmed: 28893868.

232. Quanjer PH, Stanojevic S, Cole TJ, et al. Multi-ethnic reference values for spirometry for the 3-95-yr age range: the global lung function 2012 equations. Eur Respir J. 2012; 40(6): 1324-1343, doi: 10.1183/09031936.00080312, indexed in Pubmed: 22743675.

233. Raghu G, Johnson WC, Lockhart D, et al. Treatment of idiopathic pulmonary fibrosis with a new antifibrotic agent, pirfenidone: results of a prospective, open-label Phase II study. Am J Respir Crit Care Med. 1999; 159(4 Pt 1): 1061-1069, doi: 10.1164/ajrccm.159.4.9805017, indexed in Pubmed: 10194146.

234. Azuma A, Nukiwa T, Tsuboi E, et al. Double-blind, placebocontrolled trial of pirfenidone in patients with idiopathic pulmonary fibrosis. Am J Respir Crit Care Med. 2005; 171(9): 1040-1047, doi: 10.1164/rccm.200404-571OC, indexed in Pubmed: 15665326.
235. Taniguchi H, Ebina M, Kondoh Y, et al. Pirfenidone in idiopathic pulmonary fibrosis. Eur Respir J. 2010; 35(4): 821829, doi: 10.1183/09031936.00005209, indexed in Pubmed: 19996196.

236. Ley B, Swigris J, Day BM, et al. Pirfenidone reduces respiratory-related hospitalizations in idiopathic pulmonary fibrosis. Am J Respir Crit Care Med. 2017; 196(6): 756-761, doi: 10.1164/rccm.201701-0091OC, indexed in Pubmed: 28471697.

237. Lancaster L, Albera C, Bradford WZ, et al. Safety of pirfenidone in patients with idiopathic pulmonary fibrosis: integrated analysis of cumulative data from 5 clinical trials. BMJ Open Respir Res. 2016; 3(1): e000105, doi: 10.1136/ bmjresp-2015-000105, indexed in Pubmed: 26835133.

238. Cottin V, Koschel D, Günther A, et al. Long-term safety of pirfenidone: results of the prospective, observational PASSPORT study. ERJ Open Res. 2018; 4(4), doi: 10.1183/23120541.000842018, indexed in Pubmed: 30364407.

239. Inomata M, Nishioka Y, Azuma A. Nintedanib: evidence for its therapeutic potential in idiopathic pulmonary fibrosis. Core Evid. 2015; 10: 89-98, doi: 10.2147/CE.S82905, indexed in Pubmed: 26346347.

240. Richeldi L, Costabel U, Selman M, et al. Efficacy of a tyrosine kinase inhibitor in idiopathic pulmonary fibrosis. $\mathrm{N}$ Engl J Med. 2011; 365(12): 1079-1087, doi: 10.1056/NEJMoa1103690, indexed in Pubmed: 21992121.

241. Costabel U, Inoue Y, Richeldi L, et al. Efficacy of nintedanib in idiopathic pulmonary fibrosis across prespecified subgroups in INPULSIS. Am J Respir Crit Care Med. 2016; 193(2): 178-185, doi: 10.1164/rccm.201503-0562OC, indexed in Pubmed: 26393389.

242. Crestani B, Huggins JT, Kaye M, et al. Long-term safety and tolerability of nintedanib in patients with idiopathic pulmonary fibrosis: results from the open-label extension study, INPULSIS-ON. Lancet Respir Med. 2019; 7(1): 60-68, doi: 10.1016 S2213-2600(18)30339-4, indexed in Pubmed: 30224318.

243. King CS, Nathan SD. Practical considerations in the pharmacologic treatment of idiopathic pulmonary fibrosis. Curr Opin Pulm Med. 2015; 21(5): 479-489, doi: 10.1097/ MCP.0000000000000190, indexed in Pubmed: 26164298.

244. Ogura T, Taniguchi H, Azuma A, et al. Safety and pharmacokinetics of nintedanib and pirfenidone in idiopathic pulmonary fibrosis. Eur Respir J. 2015; 45(5): 1382-1392, doi: 10.1183/09031936.00198013, indexed in Pubmed: 25504994.

245. Vancheri C, Kreuter M, Richeldi L, et al. Nintedanib with Add-on pirfenidone in idiopathic pulmonary fibrosis. Results of the INJOURNEY trial. Am J Respir Crit Care Med. 2018; 197(3): 356-363, doi: 10.1164/rccm.201706-1301OC, indexed in Pubmed: 28889759.

246. Flaherty KR, Fell CD, Huggins JT, et al. Safety of nintedanib added to pirfenidone treatment for idiopathic pulmonary fibrosis. Eur Respir J. 2018; 52(2), doi: 10.1183/13993003.002302018, indexed in Pubmed: 29946005.

247. Richeldi L, Fletcher S, Adamali H, et al. No relevant pharmacokinetic drug-drug interaction between nintedanib and pirfenidone. Eur Respir J. 2019; 53(1), doi: 10.1183/13993003.010602018, indexed in Pubmed: 30442716.

248. Raghu G, Wells AU, Nicholson AG, et al. Effect of nintedanib in subgroups of idiopathic pulmonary fibrosis by diagnostic criteria. Am J Respir Crit Care Med. 2017; 195(1): 78-85, doi: 10.1164/rccm.201602-0402OC, indexed in Pubmed: 27331880.

249. Vancheri C, Sebastiani A, Rottoli P, et al. Late breaking abstract - effectiveness and tolerability of pirfenidone (PFD) in patients with idiopathic pulmonary fibrosis (IPF) from a large italian practice cohort. Idiopathic interstitial pneumonias. 2018, doi: 10.1183/13993003.congress-2018.oa5358.

250. Albera C, Costabel U, Fagan EA, et al. Efficacy of pirfenidone in patients with idiopathic pulmonary fibrosis with more preserved lung function. Eur Respir J. 2016; 48(3): 843-851, doi: 10.1183/13993003.01966-2015, indexed in Pubmed: 27471208.

251. Azuma A, Taguchi Y, Ogura T, et al. Exploratory analysis of a phase III trial of pirfenidone identifies a subpopulation of 
patients with idiopathic pulmonary fibrosis as benefiting from treatment. Respir Res. 2011; 12: 143, doi: 10.1186/1465-992112-143, indexed in Pubmed: 22035508.

252. Arai T, Inoue Y, Sasaki Y, et al. Predictors of the clinical effects of pirfenidone on idiopathic pulmonary fibrosis. Respir Investig. 2014; 52(2): 136-143, doi: 10.1016/j.resinv.2013.09.002, indexed in Pubmed: 24636270.

253. Taguchi Y, Ebina M, Hashimoto S, et al. Efficacy of pirfenidone and disease severity of idiopathic pulmonary fibrosis: Extended analysis of phase III trial in Japan. Respir Investig. 2015; 53(6): 279-287, doi: 10.1016/j.resinv.2015.06.002, indexed in Pubmed: 26521105.

254. Kolb M, Richeldi L, Behr J, et al. Nintedanib in patients with idiopathic pulmonary fibrosis and preserved lung volume. Thorax. 2017; 72(4): 340-346, doi: 10.1136/thoraxjnl-2016-208710, indexed in Pubmed: 27672117.

255. du Bois RM, Weycker D, Albera C, et al. Forced vital capacity in patients with idiopathic pulmonary fibrosis: test properties and minimal clinically important difference. Am J Respir Crit Care Med. 2011; 184(12): 1382-1389, doi: 10.1164/rccm. 201105-0840OC, indexed in Pubmed: 21940789.

256. Xaubet A, Molina-Molina M, Acosta O, et al. Guidelines for the medical treatment of idiopathic pulmonary fibrosis. Arch Bronconeumol. 2017; 53(5): 263-269, doi: 10.1016/j. arbres.2016.12.011, indexed in Pubmed: 28292522.

257. Cottin V, Crestani B, Cadranel J, et al. French practical guidelines for the diagnosis and management of idiopathic pulmonary fibrosis - 2017 update. Full-length version. Rev Mal Respir. 2017; 34(8): 900-968, doi: 10.1016/j.rmr.2017.07.017, indexed in Pubmed: 28939155.

258. Yoon H-Y, Kim DS, Song JW. Efficacy and safety of pirfenidone in advanced idiopathic pulmonary fibrosis. Respir Int Rev Thorac Dis. 2018; 17: 1-10.

259. Tzouvelekis A, Ntolios P, Karampitsakos T, et al. Safety and efficacy of pirfenidone in severe idiopathic pulmonary fibrosis: a real-world observational study. Pulm Pharmacol Ther. 2017; 46: 48-53, doi: 10.1016/j.pupt.2017.08.011, indexed in Pubmed: 28843616.

260. Yoon HY, Park S, Kim DS, et al. Efficacy and safety of nintedanib in advanced idiopathic pulmonary fibrosis. Respir Res. 2018; 19(1): 203, doi: 10.1186/s12931-018-0907-8, indexed in Pubmed: 30340638.

261. Harari S, Caminati A, Poletti V, et al. A Real-Life Multicenter National Study on Nintedanib in Severe Idiopathic Pulmonary Fibrosis. Respir Int Rev Thorac Dis. 2018; 95(6): 433-440, doi: 10.1159/000487711.

262. Harari S, Caminati A, Albera C, et al. Efficacy of pirfenidone for idiopathic pulmonary fibrosis: An Italian real life study. Respir Med. 2015; 109(7): 904-913, doi: 10.1016/j. rmed.2015.04.010, indexed in Pubmed: 25962649.

263. Wuyts WA, Kolb M, Stowasser S, et al. First data on efficacy and safety of nintedanib in patients with idiopathic pulmonary fibrosis and forced vital capacity of $\leq 50 \%$ of predicted value. Lung. 2016; 194(5): 739-743, doi: 10.1007/s00408-0169912-1, indexed in Pubmed: 27377558.

264. Nathan SD, Albera C, Bradford WZ, et al. Effect of continued treatment with pirfenidone following clinically meaningful declines in forced vital capacity: analysis of data from three phase 3 trials in patients with idiopathic pulmonary fibrosis. Thorax. 2016; 71(5): 429-435, doi: 10.1136/thoraxjnl-2015-207011, indexed in Pubmed: 26968970.

265. Richeldi L, Azuma A, Selman M, et al. Twenty-four week decline in forced vital capacity predicts mortality at week 52 in the INPULSIS $\AA^{\circledR}$ trials. 1.5 Diffuse Parenchymal Lung Disease. 2016, doi: 10.1183/13993003.congress-2016.oa1814.

266. Nathan SD, Costabel U, Glaspole I, et al. Efficacy of pirfenidone in the context of multiple disease progression events in patients with idiopathic pulmonary fibrosis. Chest. 2019; 155(4): 712-719, doi: 10.1016/j.chest.2018.11.008, indexed in Pubmed: 30472023.

267. Bonella F, Kreuter M, Hagmeyer L, et al. Insights from the German Compassionate Use Program of Nintedanib for the Treatment of Idiopathic Pulmonary Fibrosis. Respiration. 2016; 92(2): 98-106, doi: 10.1159/000448288, indexed in Pubmed: 27544537.
268. Milger K, Kneidinger N, Neurohr C, et al. Switching to nintedanib after discontinuation of pirfenidone due to adverse events in IPF. Eur Respir J. 2015; 46(4): 1217-1221, doi: 10.1183/13993003.00584-2015, indexed in Pubmed: 26341986

269. Brunnemer E, Wälscher J, Tenenbaum S, et al. Real-World experience with nintedanib in patients with idiopathic pulmonary fibrosis. Respiration. 2018; 95(5): 301-309, doi: 10.1159/000485933, indexed in Pubmed: 29490307.

270. European Medicines Agency. EU/3/04/241. Available at: https:/www.ema.europa.eu/en/medicines/human/orphan-designations/eu304241 [Access: 20.02.2020]

271. Oltmanns U, Kahn N, Palmowski K, et al. Pirfenidone in idiopathic pulmonary fibrosis: real-life experience from a German tertiary referral center for interstitial lung diseases. Respiration. 2014; 88(3): 199-207, doi: 10.1159/000363064, indexed in Pubmed: 25115833.

272. Okuda R, Hagiwara E, Baba T, et al. Safety and efficacy of pirfenidone in idiopathic pulmonary fibrosis in clinical practice. Respir Med. 2013; 107(9): 1431-1437, doi: 10.1016/j. rmed.2013.06.011, indexed in Pubmed: 23849626.

273. Ghebremariam YT, Cooke JP, Gerhart W, et al. Pleiotropic effect of the proton pump inhibitor esomeprazole leading to suppression of lung inflammation and fibrosis. J Transl Med. 2015; 13: 249, doi: 10.1186/s12967-015-0614-x, indexed in Pubmed: 26231702.

274. Lee JS, Ryu JH, Elicker BM, et al. Gastroesophageal reflux therapy is associated with longer survival in patients with idiopathic pulmonary fibrosis. Am J Respir Crit Care Med. 2011; 184(12): 1390-1394, doi: 10.1164/rccm.201101-0138OC, indexed in Pubmed: 21700909.

275. Lee CM, Lee DHo, Ahn BK, et al. Protective effect of proton pump inhibitor for survival in patients with gastroesophageal reflux disease and idiopathic pulmonary fibrosis. J Neurogastroenterol Motil. 2016; 22(3): 444-451, doi: 10.5056/ jnm15192, indexed in Pubmed: 26932897.

276. Lee JS, Collard HR, Anstrom KJ, et al. Anti-acid treatment and disease progression in idiopathic pulmonary fibrosis: an analysis of data from three randomised controlled trials. Lancet Respir Med. 2013; 1(5): 369-376, doi: 10.1016/ S2213-2600(13)70105-X, indexed in Pubmed: 24429201.

277. Fidler L, Sitzer N, Shapera S, et al. Treatment of gastroesophageal reflux in patients with idiopathic pulmonary fibrosis: a systematic review and meta-analysis. Chest. 2018; 153(6): 1405-1415, doi: 10.1016/j.chest.2018.03.008, indexed in Pubmed: 29559309

278. Tran T, Suissa S. The effect of anti-acid therapy on survival in idiopathic pulmonary fibrosis: a methodological review of observational studies. Eur Respir J. 2018; 51(6), doi: 10.1183/13993003.00376-2018, indexed in Pubmed: 29724921

279. Costabel U, Behr J, Crestani B, et al. Anti-acid therapy in idiopathic pulmonary fibrosis: insights from the INPULSIS ${ }^{\circledR}$ trials. Respir Res. 2018; 19(1): 167, doi: 10.1186/s12931-0180866-0, indexed in Pubmed: 30176872.

280. Dutta P, Funston W, Mossop H, et al. Randomised, double -blind, placebo-controlled pilot trial of omeprazole in idiopathic pulmonary fibrosis. Thorax. 2019; 74(4): 346-353, doi: 10.1136/thoraxjnl-2018-212102, indexed in Pubmed: 30610155

281. Sugiura H, Ichikawa T, Liu X, et al. N-acetyl-L-cysteine inhibits TGF-beta1-induced profibrotic responses in fibroblasts. Pulm Pharmacol Ther. 2009; 22(6): 487-491, doi: 10.1016/j. pupt.2009.04.002, indexed in Pubmed: 19393328.

282. Felton VM, Borok Z, Willis BC. N-acetylcysteine inhibits alveolar epithelial-mesenchymal transition. Am J Physiol Lung Cell Mol Physiol. 2009; 297(5): L805-L812, doi: 10.1152/ ajplung.00009.2009, indexed in Pubmed: 19648289.

283. Demedts M, Behr J, Buhl R, et al. High-dose acetylcysteine in idiopathic pulmonary fibrosis. N Engl J Med. 2005; 353(21): 22292242, doi: 10.1056/NEJMoa042976, indexed in Pubmed: 16306520.

284. Martinez FJ, de Andrade JA, Anstrom KJ, et al. Randomized trial of acetylcysteine in idiopathic pulmonary fibrosis. N Engl J Med. 2014; 370(22): 2093-2101, doi: 10.1056/NEJMoa1401739, indexed in Pubmed: 24836309. 
285. Oldham JM, Ma SF, Martinez FJ, et al. TOLLIP, MUC5B, and the response to $\mathrm{N}$-acetylcysteine among individuals with idiopathic pulmonary fibrosis. Am J Respir Crit Care Med. 2015; 192(12): 1475-1482, doi: 10.1164/rccm.201505-1010OC, indexed in Pubmed: 26331942

286. Sakamoto S, Muramatsu Y, Satoh K, et al. Effectiveness of combined therapy with pirfenidone and inhaled N-acetylcysteine for advanced idiopathic pulmonary fibrosis: a casecontrol study. Respirology. 2015; 20(3): 445-452, doi: 10.1111/ resp.12477, indexed in Pubmed: 25639750.

287. Homma S, Azuma A, Taniguchi H, et al. Efficacy of inhaled $\mathrm{N}$-acetylcysteine monotherapy in patients with early stage idiopathic pulmonary fibrosis. Respirology. 2012; 17(3): 467-477, doi: 10.1111/j.1440-1843.2012.02132.x, indexed in Pubmed: 22257422.

288. Behr J, Bendstrup E, Crestani B, et al. Safety and tolerability of acetylcysteine and pirfenidone combination therapy in idiopathic pulmonary fibrosis: a randomised, double-blind, placebo-controlled, phase 2 trial. Lancet Respir Med. 2016; 4(6): 445-453, doi: 10.1016/S2213-2600(16)30044-3, indexed in Pubmed: 27161257.

289. Richeldi L, Davies HR, Ferrara G, et al. Corticosteroids for idiopathic pulmonary fibrosis. Cochrane Database Syst Rev. 2003(3): CD002880, doi: 10.1002/14651858.CD002880, indexed in Pubmed: 12917934

290. Spagnolo P, Del Giovane C, Luppi F, et al. Non-steroid agents for idiopathic pulmonary fibrosis. Cochrane Database Syst Rev. 2010(9): CD003134, doi: 10.1002/14651858.CD003134. pub2, indexed in Pubmed: 20824834.

291. Cottin V, Le Pavec J, Prévot G, et al. Pulmonary hypertension in patients with combined pulmonary fibrosis and emphysema syndrome. Eur Respir J. 2010; 35(1): 105-111, doi: 10.1183/09031936.00038709, indexed in Pubmed: 19643948.

292. Shorr AF, Wainright JL, Cors CS, et al. Pulmonary hypertension in patients with pulmonary fibrosis awaiting lung transplant. Eur Respir J. 2007; 30(4): 715-721, doi: 10.1183/09031936.00107206, indexed in Pubmed: 17626111.

293. Kimura M, Taniguchi H, Kondoh Y, et al. Pulmonary hypertension as a prognostic indicator at the initial evaluation in idiopathic pulmonary fibrosis. Respiration. 2013; 85(6): 456-463, doi: 10.1159/000345221, indexed in Pubmed: 23257350.

294. Lettieri CJ, Nathan SD, Barnett SD, et al. Prevalence and outcomes of pulmonary arterial hypertension in advanced idiopathic pulmonary fibrosis. Chest. 2006; 129(3): 746-752, doi: 10.1378/chest.129.3.746, indexed in Pubmed: 16537877.

295. Nathan SD, Shlobin OA, Barnett SD, et al. Right ventricular systolic pressure by echocardiography as a predictor of pulmonary hypertension in idiopathic pulmonary fibrosis. Respir Med. 2008; 102(9): 1305-1310, doi: 10.1016/j. rmed.2008.03.022, indexed in Pubmed: 18619825.

296. Judge EP, Fabre A, Adamali HI, et al. Acute exacerbations and pulmonary hypertension in advanced idiopathic pulmonary fibrosis. Eur Respir J. 2012; 40(1): 93-100, doi: 10.1183/09031936.00115511, indexed in Pubmed: 22135282.

297. King TE, Behr J, Brown KK, et al. BUILD-1: a randomized placebo-controlled trial of bosentan in idiopathic pulmonary fibrosis. Am J Respir Crit Care Med. 2008; 177(1): 75-81, doi: 10.1164/rccm.200705-732OC, indexed in Pubmed: 17901413.

298. Efficacy and safety of riociguat in patients with symptomatic pulmonary hypertension $(\mathrm{PH})$ associated with idiopathic interstitial pneumonias (IIP) - full text view - clinicaltrials.gov. Available at: https://clinicaltrials.gov/ct2/show/ NCT02138825.

299. Kolb M, Raghu G, Wells AU, et al. Nintedanib plus sildenafil in patients with idiopathic pulmonary fibrosis. N Engl J Med. 2018; 379(18): 1722-1731, doi: 10.1056/NEJMoa1811737, indexed in Pubmed: 30220235.

300. Galiè N, Humbert M, Vachiery JL, et al. 2015 ESC/ERS Guidelines for the diagnosis and treatment of pulmonary hypertension: The Joint Task Force for the Diagnosis and Treatment of Pulmonary Hypertension of the European Society of Cardiology (ESC) and the European Respiratory Society (ERS): Endorsed by: Association for European Paediatric and Congenital Cardiology (AEPC), International Society for Heart and Lung Transplantation (ISHLT). Eur Respir J. 2015; 46(4):
903-975, doi: 10.1183/13993003.01032-2015, indexed in Pubmed: 26318161.

301. Hoeper MM, Behr J, Held M, et al. Pulmonary hypertension in patients with chronic fibrosing idiopathic interstitial pneumonias. PLoS One. 2015; 10(12): e0141911, doi: 10.1371/ journal.pone.0141911, indexed in Pubmed: 26630396.

302. Efficacy, safety, and tolerability study of pirfenidone in combination with sildenafil in participants with advanced idiopathic pulmonary fibrosis (IPF) and risk of group 3 pulmonary hypertension - full text view - clinicaltrials.gov. Available at: https://clinicaltrials.gov/ct2/show/NCT02951429 [Access: 20.02.2020].

303. Spruit MA, Singh SJ, Garvey C, et al. An official American Thoracic Society/European Respiratory Society statement: key concepts and advances in pulmonary rehabilitation. Am J Respir Crit Care Med. 2013; 188(8): e13-e64, doi: 10.1164/ rccm.201309-1634ST, indexed in Pubmed: 24127811.

304. Kozu R, Senjyu H, Jenkins SC, et al. Differences in response to pulmonary rehabilitation in idiopathic pulmonary fibrosis and chronic obstructive pulmonary disease. Respiration. 2011; 81(3): 196-205, doi: 10.1159/000315475, indexed in Pubmed: 20516666.

305. Swigris JJ, Fairclough DL, Morrison M, et al. Benefits of pulmonary rehabilitation in idiopathic pulmonary fibrosis. Respir Care. 2011; 56(6): 783-789, doi: 10.4187/respcare.00939, indexed in Pubmed: 21333082.

306. Huppmann P, Sczepanski B, Boensch M, et al. Effects of inpatient pulmonary rehabilitation in patients with interstitial lung disease. Eur Respir J. 2013; 42(2): 444-453, doi: 10.1183/09031936.00081512, indexed in Pubmed: 23100507.

307. Ryerson CJ, Cayou C, Topp F, et al. Pulmonary rehabilitation improves long-term outcomes in interstitial lung disease: a prospective cohort study. Respir Med. 2014; 108(1): 203210, doi: 10.1016/j.rmed.2013.11.016, indexed in Pubmed: 24332409.

308. Holland AE, Hill CJ, Glaspole I, et al. Predictors of benefit following pulmonary rehabilitation for interstitial lung disease. Respir Med. 2012; 106(3): 429-435, doi: 10.1016/j. rmed.2011.11.014, indexed in Pubmed: 22182340.

309. Arizono S, Taniguchi H, Sakamoto K, et al. Endurance time is the most responsive exercise measurement in idiopathic pulmonary fibrosis. Respir Care. 2014; 59(7): 1108-1115, doi: 10.4187/respcare.02674, indexed in Pubmed: 24327743.

310. Florian J, Rubin A, Mattiello R, et al. Impact of pulmonary rehabilitation on quality of life and functional capacity in patients on waiting lists for lung transplantation. J Bras Pneumol. 2013; 39(3): 349-356, doi: 10.1590/S180637132013000300012, indexed in Pubmed: 23857680.

311. Jackson RM, Gómez-Marín OW, Ramos CF, et al. Exercise limitation in IPF patients: a randomized trial of pulmonary rehabilitation. Lung. 2014; 192(3): 367-376, doi: 10.1007/ s00408-014-9566-9, indexed in Pubmed: 24705678.

312. Vainshelboim B, Oliveira J, Yehoshua L, et al. Exercise training-based pulmonary rehabilitation program is clinically beneficial for idiopathic pulmonary fibrosis. Respiration. 2014; 88(5): 378-388, doi: 10.1159/000367899, indexed in Pubmed: 25341682.

313. Dowman LM, McDonald CF, Hill CJ, et al. The evidence of benefits of exercise training in interstitial lung disease: a randomised controlled trial. Thorax. 2017; 72(7): 610-619, doi: 10.1136/thoraxjnl-2016-208638, indexed in Pubmed: 28213592.

314. Gaunaurd IA, Gómez-Marín OW, Ramos CF, et al. Physical activity and quality of life improvements of patients with idiopathic pulmonary fibrosis completing a pulmonary rehabilitation program. Respir Care. 2014; 59(12): 1872-1879, doi: 10.4187/respcare.03180, indexed in Pubmed: 25185149.

315. Holland AE, Hill CJ, Conron M, et al. Short term improvement in exercise capacity and symptoms following exercise training in interstitial lung disease. Thorax. 2008; 63(6): 549-554, doi: 10.1136/thx.2007.088070, indexed in Pubmed: 18245143.

316. Nishiyama O, Kondoh Y, Kimura T, et al. Effects of pulmonary rehabilitation in patients with idiopathic pulmonary fibrosis. Respirology. 2008; 13(3): 394-399, doi: 10.1111/j. 1440-1843.2007.01205.x, indexed in Pubmed: 18399862. 
317. Vainshelboim B, Fox BD, Kramer MR, et al. Short-Term improvement in physical activity and body composition after supervised exercise training program in idiopathic pulmonary fibrosis. Arch Phys Med Rehabil. 2016; 97(5): 788-797, doi: 10.1016/j.apmr.2016.01.018, indexed in Pubmed: 26869288.

318. Jastrzebski D, Kozielski J, Zebrowska A. Pulmonary rehabilitation in patients with idiopathic pulmonary fibrosis with inspiratory muscle training. Pneumonol Alergol Pol. 2008; 76(3): 131-141, indexed in Pubmed: 18843927.

319. Dowman L, Hill CJ, Holland AE. Pulmonary rehabilitation for interstitial lung disease. Cochrane Database Syst Rev. 2014(10): CD006322, doi: 10.1002/14651858.CD006322.pub3, indexed in Pubmed: 25284270.

320. Gomes-Neto M, Silva CM, Ezequiel D, et al. Impact of pulmonary rehabilitation on exercise tolerance and quality of life in patients with idiopathic pulmonary fibrosis: a systematic review an meta-analysis. J Cardiopulm Rehabil Prev. 2018; 38(5): 273-278, doi: 10.1097/HCR.0000000000000273, indexed in Pubmed: 29351129.

321. Cheng Li, Tan B, Yin Y, et al. Short- and long-term effects of pulmonary rehabilitation for idiopathic pulmonary fibrosis: a systematic review and meta-analysis. Clin Rehabil. 2018; 32(10): 1299-1307, doi: 10.1177/0269215518779122, indexed in Pubmed: 29843523.

322. Yu X, Li X, Wang L, et al. Pulmonary rehabilitation for exercise tolerance and quality of life in IPF patients: a systematic review and meta-analysis. Biomed Res Int. 2019; 2019: 8498603, doi: 10.1155/2019/8498603, indexed in Pubmed: 31016200.

323. Nici L, Donner C, Wouters E, et al. American Thoracic Society/European Respiratory Society statement on pulmonary rehabilitation. Am J Respir Crit Care Med. 2006; 173(12): 1390-1413, doi: 10.1164/rccm.200508-1211ST, indexed in Pubmed: 16760357.

324. Rochester CL, Vogiatzis I, Holland AE, et al. An Official American Thoracic Society/European Respiratory Society Policy Statement: Enhancing Implementation, Use, and Delivery of Pulmonary Rehabilitation. Am J Respir Crit Care Med. 2015; 192(11): 1373-1386, doi: 10.1164/rccm.201510-1966ST, indexed in Pubmed: 26623686

325. Wallaert B, Duthoit L, Drumez E, et al. Long-term evaluation of home-based pulmonary rehabilitation in patients with fibrotic idiopathic interstitial pneumonias. ERJ Open Res. 2019 5(2), doi: 10.1183/23120541.00045-2019, indexed in Pubmed: 30972352

326. Vainshelboim B, Oliveira J, Fox BD, et al. Long-term effects of a 12-week exercise training program on clinical outcomes in idiopathic pulmonary fibrosis. Lung. 2015; 193(3): 345354, doi: 10.1007/s00408-015-9703-0, indexed in Pubmed: 25731736.

327. Crockett AJ, Alpers JH, Moss JR. Home oxygen therapy: an audit of survival. Aust N Z J Med. 1991; 21(2): 217-221, doi: 10.1111/j.1445-5994.1991.tb00445.x, indexed in Pubmed: 1872748.

328. Duck A, Spencer LG, Bailey S, et al. Perceptions, experiences and needs of patients with idiopathic pulmonary fibrosis. J Adv Nurs. 2015; 71(5): 1055-1065, doi: 10.1111/jan.12587, indexed in Pubmed: 25533573.

329. Belkin A, Albright K, Swigris JJ. A qualitative study of informal caregivers' perspectives on the effects of idiopathic pulmonary fibrosis. BMJ Open Respir Res. 2014; 1(1): e000007, doi: 10.1136/bmjresp-2013-000007, indexed in Pubmed: 25478168.

330. Homma S, Bando M, Azuma A, et al. Japanese guideline for the treatment of idiopathic pulmonary fibrosis. Respir Investig. 2018; 56(4): 268-291, doi: 10.1016/j.resinv.2018.03.003, indexed in Pubmed: 29980444.

331. Jo HE, Troy LK, Keir G, et al. Treatment of idiopathic pulmonary fibrosis in Australia and New Zealand: A position statement from the Thoracic Society of Australia and New Zealand and the Lung Foundation Australia. Respirology. 2017; 22(7): 1436-1458, doi: 10.1111/resp.13146, indexed in Pubmed: 28845557.

332. Matsuda T, Taniguchi H, Ando M, et al. Depression is significantly associated with the health status in patients with idiopathic pulmonary fibrosis. Intern Med. 2017; 56(13): 1637-1644, doi: 10.2169/internalmedicine.56.7019, indexed in Pubmed: 28674350.

333. Lama VN, Flaherty KR, Toews GB, et al. Prognostic value of desaturation during a 6 -minute walk test in idiopathic interstitial pneumonia. Am J Respir Crit Care Med. 2003; 168(9): 1084-1090, doi: 10.1164/rccm.200302-219OC, indexed in Pubmed: 12917227.

334. Lettieri CJ, Nathan SD, Browning RF, et al. The distance-saturation product predicts mortality in idiopathic pulmonary fibrosis. Respir Med. 2006; 100(10): 1734-1741, doi: 10.1016/j. rmed.2006.02.004, indexed in Pubmed: 16545950.

335. Hook JL, Arcasoy SM, Zemmel D. Titrated oxygen requirement and prognostication in idiopathic pulmonary fibrosis. Eur Respir J. 2012; 39(2): 359-365, doi: 10.1183/09031936.00108111.

336. Sharp C, Adamali H, Millar A. Ambulatory and short-burst oxygen for interstitial lung disease. Cochrane Database Syst Rev. 2016, doi: 10.1002/14651858.cd011716.pub2.

337. Nishiyama O, Miyajima H, Fukai Y, et al. Effect of ambulatory oxygen on exertional dyspnea in IPF patients without resting hypoxemia. Respir Med. 2013; 107(8): 1241-1246, doi 10.1016/j.rmed.2013.05.015, indexed in Pubmed: 23806287.

338. Dowman LM, McDonald CF, Bozinovski S, et al. Greater endurance capacity and improved dyspnoea with acute oxygen supplementation in idiopathic pulmonary fibrosis patients without resting hypoxaemia. Respirology. 2017; 22(5): 957964, doi: 10.1111/resp.13002, indexed in Pubmed: 28225205.

339. Visca D, Mori L, Tsipouri V, et al. Effect of ambulatory oxygen on quality of life for patients with fibrotic lung disease (AmbOx): a prospective, open-label, mixed-method, crossover randomised controlled trial. Lancet Respir Med. 2018; 6(10): 759-770, doi: 10.1016/S2213-2600(18)30289-3, indexed in Pubmed: 30170904

340. Pouwels-Fry S, Pouwels S, Fournier C, et al. Effects of oxygen on exercise-induced increase of pulmonary arterial pressure in idiopathic pulmonary fibrosis. Sarcoidosis Vasc Diffuse Lung Dis. 2008; 25(2): 133-139, indexed in Pubmed: 19382532

341. Hardinge M, Suntharalingam J, Wilkinson T, et al. British Thoracic Society guidelines for home oxygen use in adults. Thorax. 2015; 70 Suppl 1(6): i1-43, doi: 10.1136/thoraxjnl-2015-206865, indexed in Pubmed: 25870317.

342. Ramadurai D, Riordan M, Graney B, et al. The impact of carrying supplemental oxygen on exercise capacity and dyspnea in patients with interstitial lung disease. Respiratory Medicine. 2018; 138: 32-37, doi: 10.1016/j.rmed.2018.03.025.

343. Nichol KL, Margolis KL, Wuorenma J, et al. The efficacy and cost effectiveness of vaccination against influenza among elderly persons living in the community. N Engl J Med. 1994; 331(12): 778-784, doi: 10.1056/NEJM199409223311206, indexed in Pubmed: 8065407.

344. Falkenhorst G, Remschmidt C, Harder T, et al. Effectiveness of the 23-valent pneumococcal polysaccharide vaccine (PPV23) against pneumococcal disease in the elderly: systematic review and meta-analysis. PLoS One. 2017; 12(1): e0169368, doi: 10.1371/journal.pone.0169368, indexed in Pubmed: 28061505.

345. Kopsaftis Z, Wood-Baker R, Poole P. Influenza vaccine for chronic obstructive pulmonary disease (COPD). Cochrane Database Syst Rev. 2018; 6: CD002733, doi: 10.1002/14651858. CD002733.pub3, indexed in Pubmed: 29943802.

346. Albrecht P, Antczak A, Hryniewicz W, et al. Recommendations for prevention of community-acquired pneumonia with bacteremia as the leading form of invasive pneumococcal infections in the population of people over 50 years of age and risk groups above 19 years of age. Pol Merkur Lekarski. 2014; 36(212): 79-87, indexed in Pubmed: 24720101.

347. Nadrous HF, Myers JL, Decker PA, et al. Idiopathic pulmonary fibrosis in patients younger than 50 years. Mayo Clin Proc. 2005; 80(1): 37-40, doi: 10.1016/S0025-6196(11)62955-8, indexed in Pubmed: 15667027

348. Byrdak LB, Romanowska M, Radzikowski A, et al. Polskie standardy profilaktyki i leczenia grypy. Wydanie III. Warszawak 2007. Available at: http://pis lodz pl/data/other/brydaklb standardy_leczenia_i_profilakty_1.pdf [Access: 20.02.2020]. 
349. Azadeh N, Limper AH, Carmona EM, et al. The role of infection in interstitial lung diseases: a review. Chest. 2017; 152(4): 842-852, doi: 10.1016/j.chest.2017.03.033, indexed in Pubmed: 28400116.

350. Wootton SC, Kim DS, Kondoh Y, et al. Viral infection in acute exacerbation of idiopathic pulmonary fibrosis. Am J Respir Crit Care Med. 2011; 183(12): 1698-1702, doi: 10.1164/rccm. 201010-1752OC, indexed in Pubmed: 21471095.

351. Song JW, Hong SB, Lim CM, et al. Acute exacerbation of idiopathic pulmonary fibrosis: incidence, risk factors and outcome. Eur Respir J. 2011; 37(2): 356-363, doi: 10.1183/09031936.00159709, indexed in Pubmed: 20595144.

352. Kishaba T, Tamaki H, Shimaoka Y, et al. Staging of acute exacerbation in patients with idiopathic pulmonary fibrosis. Lung. 2014; 192(1): 141-149, doi: 10.1007/s00408-013-95300, indexed in Pubmed: 24221341.

353. Table 1. Recommended Adult Immunization Schedule for ages 19 years or older. United States 2020. Available at: www. cdc.gov/vaccines/schedules/hcp/imz/adult.html?CDC_AA_re$\mathrm{fVal}=\mathrm{https} \% 3 \mathrm{~A} \% 2 \mathrm{~F} \% 2 \mathrm{Fw} w w . c d c . g o v \% 2 \mathrm{Fvaccines} \% 2 \mathrm{Fschedu}-$ les\%2Feasy-to-read\%2Fadult.html [Access: 20.02.2020].

354. Antczak A, Jahn-Różyk K, Krzywański J, et al. Rekomendacje ekspertów Ogólnopolskiego Programu Zwalczania Grypy dotyczące profilaktyki grypy w sezonie epidemicznym 2017/2018. FLU FORUM, Warszawa 2017. Available at: www. ump.edu.pl/media/uid/60a792_-6b0-_4_be_f6/b3fa50.pdf [Access: 20.02.2020].

355. World Health Organization. WHO Definition of Palliative Care. Available at: /www.who.int/cancer/palliative/definition/ en/ [Access: 20.02.2020].

356. Sepúlveda C, Marlin A, Yoshida T, et al. Palliative care: the world health organization's global perspective. J Pain Symptom Manage. 2002; 24(2): 91-96, doi: 10.1016/s08853924(02)00440-2, indexed in Pubmed: 12231124.

357. Swigris JJ, Stewart AL, Gould MK, et al. Patients' perspectives on how idiopathic pulmonary fibrosis affects the quality of their lives. Health Qual Life Outcomes. 2005; 3: 61, doi: 10.1186/1477-7525-3-61, indexed in Pubmed: 16212668.

358. Lee JS, McLaughlin S, Collard HR. Comprehensive care of the patient with idiopathic pulmonary fibrosis. Curr Opin Pulm Med. 2011; 17(5): 348-354, doi: 10.1097/ MCP.0b013e328349721b, indexed in Pubmed: 21760508.

359. Koegelenberg CFN, Ainslie GM, Dheda K, et al. Recommendations for the management of idiopathic pulmonary fibrosis in South Africa: a position statement of the South African Thoracic Society. J Thorac Dis. 2016; 8(12): 3711-3719, doi: 10.21037/jtd.2016.12.05, indexed in Pubmed: 28149568.

360. Bajwah S, Higginson IJ, Ross JR, et al. The palliative care needs for fibrotic interstitial lung disease: a qualitative study of patients, informal caregivers and health professionals. Palliat Med. 2013; 27(9): 869-876, doi: 10.1177/0269216313497226, indexed in Pubmed: 23885010.

361. Bajwah S, Ross JR, Wells AU, et al. Palliative care for patients with advanced fibrotic lung disease: a randomised controlled phase II and feasibility trial of a community case conference intervention. Thorax. 2015; 70(9): 830-839, doi: 10.1136/thoraxjnl-2014-206583, indexed in Pubmed: 26103995.

362. Temel JS, Greer JA, Muzikansky A, et al. Early palliative care for patients with metastatic non-small-cell lung cancer. N Engl J Med. 2010; 363(8): 733-742, doi: 10.1056/NEJMoa1000678, indexed in Pubmed: 20818875.

363. Ahmadi Z, Wysham NG, Lundström S, et al. End-of-life care in oxygen-dependent ILD compared with lung cancer: a national population-based study. Thorax. 2016; 71(6): 510-516, doi: 10.1136/thoraxinl-2015-207439, indexed in Pubmed: 26865603.

364. Rajala K, Lehto JT, Sutinen E, et al. mMRC dyspnoea scale indicates impaired quality of life and increased pain in patients with idiopathic pulmonary fibrosis. ERJ Open Res. 2017; 3(4), doi: 10.1183/23120541.00084-2017, indexed in Pubmed: 29255720.

365. Jennings AL, Davies AN, Higgins JPT, et al. A systematic review of the use of opioids in the management of dyspnoea. Thorax. 2002; 57(11): 939-944, doi: 10.1136/thorax.57.11.939, indexed in Pubmed: 12403875.
366. Allen S, Raut S, Woollard J, et al. Low dose diamorphine reduces breathlessness without causing a fall in oxygen saturation in elderly patients with end-stage idiopathic pulmonary fibrosis. Palliat Med. 2005; 19(2): 128-130, doi: 10.1191/0269216305pm998oa, indexed in Pubmed: 15810751.

367. Kohberg C, Andersen CU, Bendstrup E. Opioids: an unexplored option for treatment of dyspnea in IPF. Eur Clin Respir J. 2016; 3: 30629, doi: 10.3402/ecrj.v3.30629, indexed in Pubmed: 26969472.

368. Ekström MP, Abernethy AP, Currow DC. The management of chronic breathlessness in patients with advanced and terminal illness. BMJ. 2015; 350: g7617, doi: 10.1136/bmj.g7617, indexed in Pubmed: 25556037.

369. Dorman S, Jolley C, Abernethy A, et al. Researching breathlessness in palliative care: consensus statement of the National Cancer Research Institute Palliative Care Breathlessness Subgroup. Palliat Med. 2009; 23(3): 213-227, doi: 10.1177/0269216309102520, indexed in Pubmed: 19251835.

370. Mahler DA. Opioids for refractory dyspnea. Expert Rev Respir Med. 2013; 7(2): 123-34; quiz 135, doi: 10.1586/ers.13.5, indexed in Pubmed: 23547989.

371. Bausewein C, Simon ST. Inhaled nebulized and intranasal opioids for the relief of breathlessness. Curr Opin Support Palliat Care. 2014; 8(3): 208-212, doi: 10.1097/ SPC.0000000000000071, indexed in Pubmed: 25004175.

372. Bourke SJ, Peel ET. Palliative care of chronic progressive lung disease. Clin Med (Lond). 2014; 14(1): 79-82, doi: 10.7861/ clinmedicine.14-1-79, indexed in Pubmed: 24532753.

373. Bajwah S, Davies JM, Tanash H, et al. Safety of benzodiazepines and opioids in interstitial lung disease: a national prospective study. Eur Respir J. 2018; 52(6), doi: 10.1183/13993003.012782018, indexed in Pubmed: 30309973.

374. Larkin PJ, Sykes NP, Centeno C, et al. The management of constipation in palliative care: clinical practice recommendations. Palliat Med. 2008; 22(7): 796-807, doi 10.1177/0269216308096908, indexed in Pubmed: 18838491.

375. Millan-Billi P, Serra C, Alonso Leon A, et al. Comorbidities, complications and non-pharmacologic treatment in idiopathic pulmonary fibrosis. Med Sci (Basel). 2018; 6(3), doi: 10.3390/medsci6030059, indexed in Pubmed: 30042369.

376. Egan JJ. Follow-up and nonpharmacological management of the idiopathic pulmonary fibrosis patient. Eur Respir Rev. 2011; 20(120): 114-117, doi: 10.1183/09059180.00001811, indexed in Pubmed: 21632799.

377. Gaudry S, Vincent F, Rabbat A, et al. Invasive mechanical ventilation in patients with fibrosing interstitial pneumonia. J Thorac Cardiovasc Surg. 2014; 147(1): 47-53, doi: 10.1016/j. jtcvs.2013.06.039, indexed in Pubmed: 23968871.

378. Vianello A, Arcaro G, Battistella L, et al. Noninvasive ventilation in the event of acute respiratory failure in patients with idiopathic pulmonary fibrosis. J Crit Care. 2014; 29(4): 562-567, doi: 10.1016/j.jcrc.2014.03.019, indexed in Pubmed: 24768565.

379. Güngör G, Tatar D, Saltürk C, et al. Why do patients with interstitial lung diseases fail in the ICU? a 2-center cohort study. Respir Care. 2013; 58(3): 525-531, doi: 10.4187/respcare.01734, indexed in Pubmed: 23443285.

380. Rush B, Wiskar K, Berger L, et al. The use of mechanical ventilation in patients with idiopathic pulmonary fibrosis in the United States: A nationwide retrospective cohort analysis. Respir Med. 2016; 111: 72-76, doi: 10.1016/j.rmed.2015.12.005, indexed in Pubmed: 26733227.

381. Mooney JJ, Raimundo K, Chang E, et al. Mechanical ventilation in idiopathic pulmonary fibrosis: a nationwide analysis of ventilator use, outcomes, and resource burden. BMC Pulm Med. 2017; 17(1): 84, doi: 10.1186/s12890-017-0426-2, indexed in Pubmed: 28532459.

382. Weill D, Benden C, Corris PA, et al. A consensus document for the selection of lung transplant candidates: 2014 - an update from the Pulmonary Transplantation Council of the International Society for Heart and Lung Transplantation. J Heart Lung Transplant. 2015; 34(1): 1-15, doi: 10.1016/j. healun.2014.06.014, indexed in Pubmed: 25085497.

383. Chambers DC, Cherikh WS, Goldfarb SB, et al. The International Thoracic Organ Transplant Registry of the International 
Society for Heart and Lung Transplantation: Thirty-fifth adult lung and heart-lung transplant report-2018; Focus theme: Multiorgan Transplantation. J Heart Lung Transplant. 2018; 37(10): 1169-1183, doi: 10.1016/j.healun.2018.07.020, indexed in Pubmed: 30293613.

384. Thabut G, Mal H, Castier Y, et al. Survival benefit of lung transplantation for patients with idiopathic pulmonary fibrosis. J Thorac Cardiovasc Surg. 2003; 126(2): 469-475, doi: 10.1016/s0022-5223(03)00600-7, indexed in Pubmed: 12928646.

385. Mason DP, Brizzio ME, Alster JM, et al. Lung transplantation for idiopathic pulmonary fibrosis. Ann Thorac Surg. 2007; 84(4): 1121-1128, doi: 10.1016/j.athoracsur.2007.04.096, indexed in Pubmed: 17888957.

386. Keating D, Levvey B, Kotsimbos T, et al. Lung transplantation in pulmonary fibrosis: challenging early outcomes counterbalanced by surprisingly good outcomes beyond 15 years. Transplant Proc. 2009; 41(1): 289-291, doi: 10.1016/j. transproceed.2008.10.042, indexed in Pubmed: 19249537.

387. Wei D, Gao F, Wu Bo, et al. Single versus bilateral lung transplantation for idiopathic pulmonary fibrosis. Clin Respir J. 2019; 13(6): 376-383, doi: 10.1111/crj.13020, indexed in Pubmed: 30916868.

388. Chauhan D, Karanam AB, Merlo A, et al. Post-transplant survival in idiopathic pulmonary fibrosis patients concurrently listed for single and double lung transplantation. J Heart Lung Transplant. 2016; 35(5): 657-660, doi: 10.1016/j.healun.2015.12.030, indexed in Pubmed: 26856664.

389. Schaffer JM, Singh SK, Reitz BA, et al. Single- vs double-lung transplantation in patients with chronic obstructive pulmonary disease and idiopathic pulmonary fibrosis since the implementation of lung allocation based on medical need. JAMA. 2015; 313(9): 936-948, doi: 10.1001/jama.2015.1175, indexed in Pubmed: 25734735.

390. De Oliveira NC, Osaki S, Maloney J, et al. Lung transplant for interstitial lung disease: outcomes for single versus bilateral lung transplantation. Interact Cardiovasc Thorac Surg. 2012; 14(3): 263-267, doi: 10.1093/icvts/ivr085, indexed in Pubmed: 22180607.
391. Nathan SD, Shlobin OA, Ahmad S, et al. Comparison of wait times and mortality for idiopathic pulmonary fibrosis patients listed for single or bilateral lung transplantation. J Heart Lung Transplant. 2010; 29(10): 1165-1171, doi: 10.1016/j. healun.2010.05.014, indexed in Pubmed: 20598580.

392. Thabut G, Christie JD, Ravaud P, et al. Survival after bilateral versus single-lung transplantation for idiopathic pulmonary fibrosis. Ann Intern Med. 2009; 151(11): 767-774, doi: 10.7326/0003-4819-151-11-200912010-00004, indexed in Pubmed: 19949142.

393. Weiss ES, Allen JG, Merlo CA, et al. Survival after single versus bilateral lung transplantation for high-risk patients with pulmonary fibrosis. Ann Thorac Surg. 2009; 88(5): 1616-25; discussion 1625, doi: 10.1016/j.athoracsur.2009.06.044, indexed in Pubmed: 19853121.

394. Miñambres E, Llorca J, Suberviola B, et al. Early outcome after single vs bilateral lung transplantation in older recipients. Transplant Proc. 2008; 40(9): 3088-3089, doi: 10.1016/j. transproceed.2008.08.119, indexed in Pubmed: 19010203.

395. Nwakanma LU, Simpkins CE, Williams JA, et al. Impact of bilateral versus single lung transplantation on survival in recipients 60 years of age and older: analysis of United Network for Organ Sharing database. J Thorac Cardiovasc Surg. 2007; 133(2): 541-547, doi: 10.1016/j.jtcvs.2006.09.062, indexed in Pubmed: 17258596 .

396. Whelan TPM, Dunitz JM, Kelly RF, et al. Effect of preoperative pulmonary artery pressure on early survival after lung transplantation for idiopathic pulmonary fibrosis. J Heart Lung Transplant. 2005; 24(9): 1269-1274, doi: 10.1016/j.healun.2004.10.014, indexed in Pubmed: 16143244.

397. Gerbase MW, Spiliopoulos A, Rochat T, et al. Health-related quality of life following single or bilateral lung transplantation: a 7-year comparison to functional outcome. Chest. 2005; 128(3): 1371-1378, doi: 10.1378/chest.128.3.1371, indexed in Pubmed: 16162731.

398. Meyers BF, Lynch JP, Trulock EP, et al. Single versus bilateral lung transplantation for idiopathic pulmonary fibrosis: a ten-year institutional experience. J Thorac Cardiovasc Surg. 2000; 120(1): 99-107, doi: 10.1067/mtc.2000.106322, indexed in Pubmed: 10884661. 